\title{
The Respiratory Tract
}

\section{Introduction}

People were describing the potential use of pulmonary cytology in the diagnosis of ailments as long ago as 1845 , but by the late 1800 s it was becoming more widespread. Since its first description for intrathoracic lesions, needle aspiration has become a mainstay in the diagnosis of respiratory tract disease. In the early 1900s, Papanicolaou developed cytological techniques for diagnostic purposes. Originally it was a means of identifying the causative agents in a range of infective and inflammatory conditions including tuberculosis but by the 1930s establishing itself as a method for diagnosing lung cancer. Sputum was the main source of material early on, but methods have now moved with progress in sampling techniques from rigid bronchoscopy through to fiber-optic bronchoscopy to the recently introduced method of endoscopic (bronchoscopic) ultrasound-guided sampling - mainly by fine needle aspiration. That said, more traditional methods, such as examination of sputum, are still employed (see Table 3.1).

One of the main uses of respiratory tract cytology is in the diagnosis of tumors of the lung. It also plays a role in a range of infective and inflammatory processes. Although many respiratory samples show nonspecific appearances, respiratory cytology comes into its own in three main areas:

1. Identification a specific organism responsible for the symptoms

2. Cytological support or confirmation of a clinically suspected nonneoplastic condition

3. Confirmation or exclusion of malignancy and, if positive, determination or prediction of the type of tumor

\section{General Preparation Techniques}

The general principles of sample handling and preparation have been outlined in the opening chapter (no s). With regard to respiratory tract samples, there are only a few instances where deviation from these procedures should be considered.
The first is when the sample is bloody or mucoid as these alterations might interfere with the interpretation (mainly by obscuring the lesional cells). For bloody samples, acetic acid pretreatment can lyse the red blood cells. Some liquid-based media contain red cell lysing agents. The Lymphoprep gradient technique is also useful. Mucolytic agents such as acetylcysteine or Mucolex can be used to remove or liquefy unwanted mucus, and again some liquid-based media already contain their own mucolytic agents, just as some staining techniques include a liquefying step in their preparation, e.g., Saccomanno technique (see below).

All of the routine preparation techniques are applicable to respiratory samples, but the method of choice will tend to be dictated by the type of specimen received. Direct smears, cytospin preparations, cell blocks, agar histogel, clot preparations, membrane filter, and other liquid-based techniques such as thin prep all have their place in handling and managing respiratory samples. Often the specimen will arrive in the laboratory as a liquid, either due to the nature of the material, or because the material has been introduced into transport medium. As usual, air-dried samples are better assessed using Romanowsky-based stains such as MGG. Fixed samples are preferentially stained with Papanicolaou (or sometimes $\mathrm{H} \& \mathrm{E})$.

Occasionally other fixation materials are preferred, such as glutaraldehyde for samples which will require electron microscopy. It is best for this to be discussed with the laboratory before the sample is taken and the appropriate advice provided.

Table 3.1 Respiratory cytology specimen types

\section{Sputum}

FNA percutaneous

FNA transbronchial

Bronchial wash

Bronchial brush

Bronchoalveolar lavage (BAL)

Endoscopic ultrasound (EUS)

Endobronchial ultrasound (EBUS) 
Sample adequacy may be an issue, and in most cases it is obvious whether a particular sample is suitable for its need. For example, it is clearly sufficient if the material provides a specific diagnosis whether or not it strictly has the appropriate background content. In general, sputum should contain alveolar macrophages to ensure lower respiratory tract sampling, often with columnar cells (which may be from the upper or lower tract). However, saliva may contain tumor cells, and these should of course be reported as such. The main problem with unsuitable samples is that the lesional cells may be absent or obscured by food or other oral material. Blood may be a problem or problematic if it hides the other cellular material, and clearly the cellularity and state of fixation should be satisfactory without the confusion of degenerative changes. BAL samples should optimally be free from upper tract contamination.

All material sent to the laboratory is potentially infective and therefore needs to be handled appropriately. Tuberculosis is of course one of the main concerns here.

\section{Collection Methods}

\section{Nasal Secretions}

Secretions from the nose and upper air passages can be collected on a cotton gauze or swab or "rhinobrush." Direct smears are made either for air-drying or immediate fixation in alcohol. The former are routinely stained with MGG, the latter with Papanicolaou or H\&E. Material from this site is generally more frequently used for microbiological assessment, but occasionally the cell component is of some interest such as the number of eosinophils in allergic conditions. It is possible to challenge patients with allergens and count the eosinophilic response. Very occasionally malignancy may be suspected, and in the past, some have advocated this technique as a screening tool for those predisposed to nasopharyngeal carcinoma.

\section{Sputum}

This mucoid product of the respiratory tract is produced as a component of the protective mucociliary clearance mechanism to filter foreign particles and protect the underlying mucosa. It can be collected very easily, and with it are entrapped cells that are either shed from the surface of the underlying tissue or expelled to perform an immune function. Examination of sputum has the advantages of being cheap, quick, noninvasive, and easily repeatable. Sputum cytology has been used for both screening and diagnostic purposes to reasonable effect but is being superseded by fiber-optic bronchoscopy specimens because these are more sensitive with the advantages of being able to localize the abnormality and allow sampling under direct vision for cytology and histology. Nevertheless there is still a role for sputum cytology in the diagnosis of lung cancer with reported sensitivities of around $42 \%$ for one specimen, $82 \%$ for three consecutive specimens, and $91 \%$ for five daily specimens. It has also been suggested that post-bronchoscopy sputum samples may be useful when the bronchoscopy samples are nondiagnostic. The false positive rate lies somewhere between 2.7 and $4.8 \%$.

It is recommended that samples be obtained in the early morning although the material remains diagnostically useful if kept overnight in the fridge. If the sample is likely to be examined some time later, then it will need to be fixed in equal volume of $70 \%$ alcohol. It is wise to rinse the individual's mouth prior to sampling to prevent contamination with food. Sputum can be induced if required by a nebulizer, with heated hypertonic saline or methacholine 20 min before sampling. It may be necessary to undertake physiotherapy prior to sampling especially if the patient has a dry cough. This technique is also useful for diagnosing opportunistic infections in nonsmokers and prevents the need for a biopsy. Such samples should be submitted immediately fresh and unfixed although they are of course potentially infective.

A macroscopic examination of the sputum should be performed for blood, saliva, a purulent component, or other noticeable features. One can pull out the threads to make smears by mashing or pressing the material picked from the fluid and then smearing these onto the glass slides. Between two and four slides are prepared for staining. Papanicolaou is the preferred stain, but H\&E or alternatively the Saccomanno method is used especially in the USA. For this, the material is prefixed and concentrated in $50 \%$ alcohol. This is followed by centrifuging or filtering to form a pellet. The diagnostic accuracy is said to be better than the traditional method, and obviously a cell block can be made very easily if required. The material can also be liquefied and concentrated to increase cell yield, but cell preservation suffers and the cell presentation is therefore poorer. If the sputum is very watery, it is sensible to centrifuge and make smears from the sediment.

\section{Lower Respiratory Tract Samples}

Infrequently, the cytology laboratory may receive samples from the nasopharynx and nearby structures of the upper tract such as the epiglottis and larynx. This is usually from directly visualized lesions. If they are superficial and erosive, then targeted scrapes can be made. If the mucosa is intact with the lesion beneath, then needle aspiration is more likely to retrieve lesional cells. Tracheitis will often be fungal or viral and the organism may be identified cytologically although providing a suitable sample for virology or microbiology may be sensible as well. Similarly, local 
amyloid deposition or tumors can be diagnosed on cytology. These will have identical appearances to the equivalent tumors of the lower tract and descriptions will be given later in this chapter.

\section{Bronchoscopy}

In the mid-1900s, rigid bronchoscopy was used to visualize and sample central lesions, but since its introduction in the 1960s, the fiber-optic scope has now taken over from sputum as the mainstay of diagnosis in this area. There are complications however, and so, as with any interventional technique, the benefits must be weighed up against the risks before bronchoscopy is performed. Complications include bleeding, pneumothorax, bronchospasm, and hemoptysis, so the procedure should be avoided if the patient has a significant coagulation disorder or will not tolerate a pneumothorax. Overall the morbidity is reported to be around $0.15 \%$ and the mortality $<0.05 \%$.

\section{Bronchial Brushings}

A brush can be inserted into the bronchoscope and abnormal areas scraped. The brush is then retrieved, and the material spread directly onto a glass slide either along the length of the slide or in small circular area centrally. Alternatively the brush can be rinsed in fluid to produce a liquid sample for LBC. Thirdly, the slides can be made and the brush stored in case required later for agitation and centrifugation and cytospin. The slide can be fixed, and Papanicolaou stained or air-dried for MGG preparations. This procedure is reported to have a specificity and sensitivity of around $90 \%$.

\section{Bronchial Washings}

This differs from the brush procedure and involves introducing saline into the airway(s) under investigation and then collecting or trapping the fluid drawn off subsequently. As with other fluid samples, the material can either be handled further in the routine LBC manner or by centrifugation or cytospinning and slide preparation or production of a cell block as described previously.

\section{Bronchoalveolar Lavage}

This procedure, originally introduced for the treatment of asthma and alveolar proteinosis, is the method of choice for investigating diffuse nonneoplastic disorders, including a range of opportunistic and other infections, and also for peripherally situated tumors, especially bronchioloalveolar carcinoma and metastases. It has become established as a tool for managing lung transplants and has a potential role in the diagnosis and monitoring a range of interstitial lung diseases including idiopathic pulmonary fibrosis and sarcoidosis, primarily relating differential cell counts to certain diseases and absolute counts to response to treatment.
During this procedure, a wedge is placed into a lobar or segmental/subsegmental bronchus to seal prior to instilling normal saline and suction. The cell preservation is said to be better than routine washings and sputum samples, though it is recommended that a sample with an epithelial cell count above $5 \%$ should be considered potentially inadequate. The samples are processed in the same way as bronchial washings. The cellular composition and relative numbers of various cells are used a means to predict the underlying condition in a range of ailments, especially those causing interstitial lung disease (discussed later).

\section{Transbronchial Fine Needle Aspiration (TBNA)}

This technique is relatively new and is particularly useful for nodal assessment in the paratracheal and mediastinal regions where lymphadenopathy is frequently due to granulomatous inflammation, lymphoma, and metastases, among other causes. Complications are rare but include pneumothorax and hemorrhage. As a rule, a 19-22-gauge needle is safe and well tolerated. Direct smears are usually made with air-dried material being stained with MGG, while fixed material is usually stained with Papanicolaou. One can use any spare material by washing or rinsing the needle into a transport medium. This can be cytospin or used for the production of cell blocks and/or EM if required. Cell blocks can be remarkably cellular after EBUS or EUS FNA (see below).

\section{Endoscopic Ultrasound-Guided FNAs}

The introduction of the endoscopic ultrasound has meant that peribronchial lesions can be visualized ultrasonographically during the bronchoscopy and needle inserted to allow more accurate sampling. Small lymph nodes and masses that could not be accurately punctured previously can now be sampled without too much difficulty. The material is spread on to slides directly or introduced into liquid medium. The solid clotted blood (the "worm") can be embedded in paraffin and processed for histology. This frequently has significant fragments of diagnostic tissue and which can be used for further studies such as immunohistochemistry or molecular pathology, such as EGFR mutational status.

\section{Percutaneous FNA}

There are advantages and disadvantages when FNA and percutaneous core biopsy are considered together, and these have been discussed previously at various sites around the body. FNA is quick, with fewer complications (including pneumothorax), and it is relatively easily repeatable. While biopsy introduces the added benefit of architectural assessment and more material for ancillary studies, there is an increased pneumothorax rate and other complications. On the other hand, tissue is becoming more important with molecular phenotyping of non-small cell carcinomas especially adenocarcinomas. As a rule, both techniques should be avoided if the patient has known bleeding problems, is 
unconscious, or has an intractable cough. The rate of pneumothorax requiring drainage is reported to be $4-10 \%$ for this procedure which has a reported sensitivity of $90 \%$.

For completeness and interest mention will be made of pulmonary microvascular cytology. Certain conditions produce a significant quantity of pathological material within the small vessels of the lungs, and this can be recovered and examined microscopically. In essence, a blood sample is examined after it has been obtained from a pulmonary artery catheter. This technique has been promoted as a means to diagnose cancer (lymphangitis carcinomatosa), amniotic fluid embolism, and fat embolism, especially when the patient is too unwell for a transbronchial or surgical lung biopsy.

\section{Normal Anatomy of the Respiratory Tract}

A complete review of the anatomy and physiology of the respiratory tract is inappropriate here, but reasonable knowledge of the structure and composition of the tissue encountered anywhere from the nasal passages, through sinuses, nasopharynx, oropharynx, larynx, trachea, bronchi, and bronchioles to the terminal respiratory units including air ducts and sacs (alveoli) will stand the investigator in good stead for appreciating the normal material provided and recognition of pathological features and their significance.

Certain conditions affect different parts of the lungs, and so it is also sensible to remember the five conventional lobes plus lingula on the left when faced with a sample trying to establish cytological support for the diagnosis of middle lobe syndrome, idiopathic pulmonary fibrosis, or a Pancoast tumor. Of course, the pulmonary arterial tree travels beside the airways, but most of the functional arena is within the terminal parenchyma. Cytology is rarely important in the diagnosis of pulmonary vascular disease but has been advocated in lymphangitis carcinomatosa and embolic disease.

The crucial functions of the lungs in terms of air warming, gas exchange, removal of particulates, and a range of immunological roles lay the respiratory open to direct external assault, and the lungs have an important responsibility for protecting the body from many potentially harmful events.

It is also worth knowing the nomenclature for the intrathoracic lymph node stations as they may be important when assessing operability and other management issues in patients with lung cancer. Briefly, the nodes are number 1-14 beginning with the upper mediastinal lymph nodes progressing through the upper to lower paratracheal nodes on either side of the trachea and ending with peripheral subpleural, intraparenchymal nodes (14; Fig. 3.1). In summary, involvement of nodes 1-9 (mediastinal) nodes indicates $\mathrm{N} 2$ disease if ipsilateral. Lymph nodes in groups 10-14 (hilar or intrapleural) indicate N1 disease if ipsilateral. Contralateral nodal spread indicates N3 disease wherever it is situated, as does supraclavicular lymph node

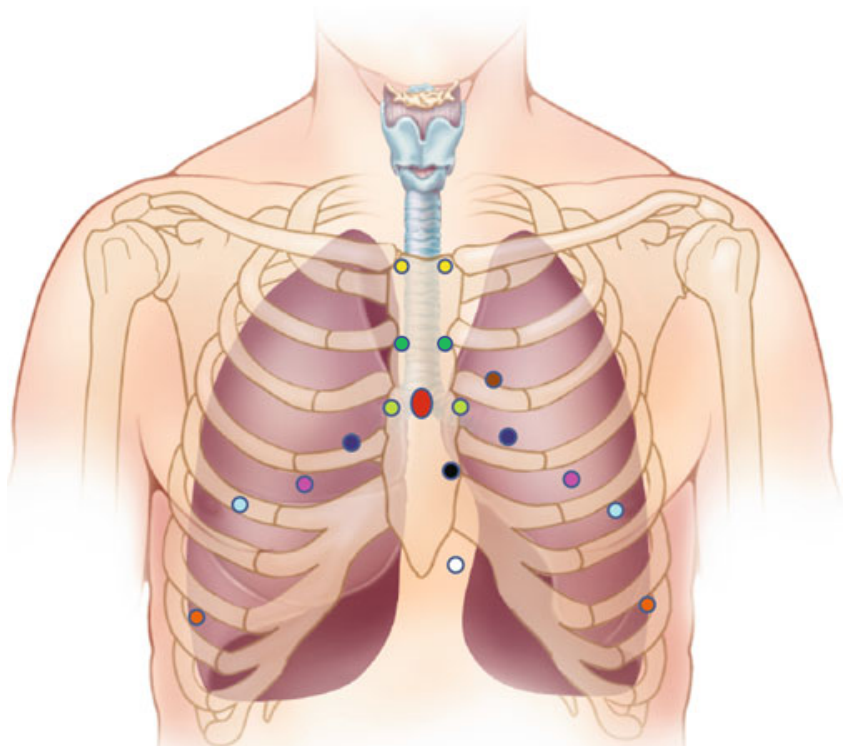

\begin{tabular}{|c|c|}
\hline Station (L=left; R=right) & Location \\
\hline 1 (not shown) & Highest mediastinal \\
\hline $2 \mathrm{~L}$ and $\mathrm{R} \bigcirc$ & Upper paratracheal \\
\hline 3 (not shown) & Prevascular and retrotracheal \\
\hline $4 \mathrm{~L}$ and $\mathrm{R} \odot$ & Lower paratracheal \\
\hline 5 & Aorto-pulmonary window \\
\hline 6 (not shown) & Anterior mediastinum \\
\hline 70 & Subcarinal \\
\hline 8 & Paraesophageal \\
\hline $9 \bigcirc$ & Pulmonary ligament \\
\hline $10 \mathrm{~L}$ and $\mathrm{R} \bigcirc$ & Tracheobronchial angle \\
\hline $11 \mathrm{~L}$ and $\mathrm{R} \bullet$ & Interlobar \\
\hline $12 \mathrm{~L}$ and $\mathrm{R} \odot$ & Lobar \\
\hline $13 \mathrm{~L}$ and $\mathrm{R} \bigcirc$ & Segmental \\
\hline $14 \mathrm{~L}$ and $\mathrm{R} \bigcirc$ & Subsegmental \\
\hline
\end{tabular}

Fig. 3.1 Lymph node stations within the thorax

disease. More distant nodal involvement is considered M1b (TNM 7th edition).

\section{Histology}

Squamous epithelium has a reputation for being one of the more robust and protective types of human epithelium, and so it is no surprise that the external parts of the respiratory system are covered by this, although most of the inner air passages are covered by respiratory epithelium. Squamous epithelium here is identical to that found elsewhere although it is rarely keratinizing. It is composed of stratified layers of cells including a proliferating basal layer through a parabasal zone to the more superior intermediate and superficial layers. Respiratory 
Fig. 3.2 Normal bronchial brushings with regular ciliated respiratory epithelial cells

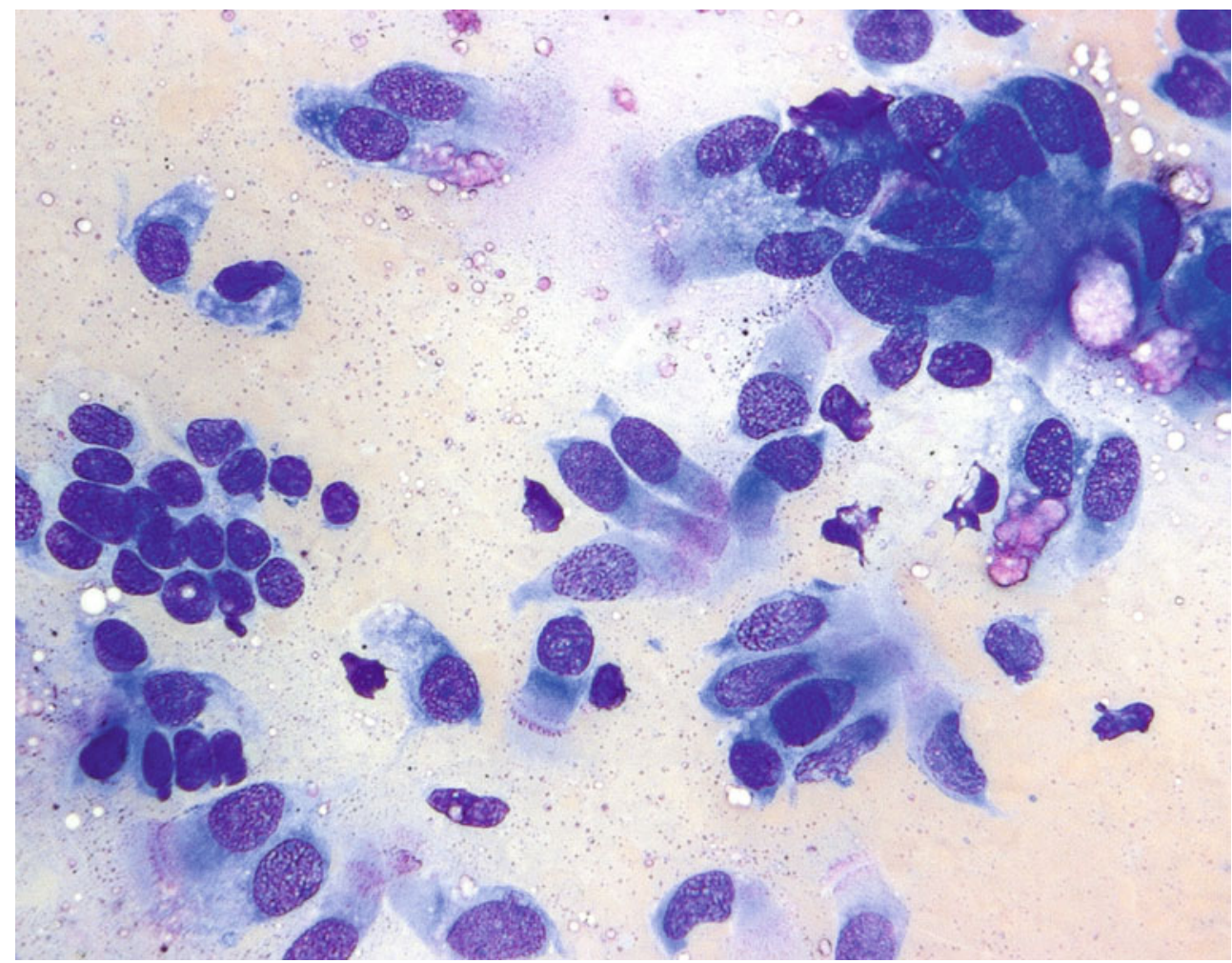

epithelium on the other hand is pseudostratified and columnar, meaning that all of the cells lie individually along the basement membrane. Different heights of cells and their nuclei or different positions of their nuclei give the impression of layering. These cells have surface cilia embedded in a terminal end plate or bar which beat and provide an "escalator" by which mucus is transported proximally for expulsion. Interspersed with the respiratory cells are mucin-secreting goblet cells and scattered neuroendocrine cells (also known as Kulchitsky cells). Goblet cells are present in a ratio of about 1:5 with the epithelial cells, but their number is increased in chronic obstructive pulmonary disease. This epithelium lines all of the conducting parts of the tract to the terminal bronchioles. From here to the alveoli, a flatter-unilayered configuration of epithelial cells allows gas exchange with the blood in the capillaries. Here there are type 1 and type 2 pneumocytes (the latter being the progenitors of the former) and another population of neuroendocrine cells, the Clara cells.

\section{Normal Constituents of Cytological Respiratory Tract Samples (More or Less Depending on the Type of Sample)}

A wide range of cells may appear in respiratory tract cytological samples with larger numbers of squamous cells in sputum and few in FNAs. All may contain ciliated columnar cells (Fig. 3.2), goblet cells, reserve cells, pneumocytes, and alveolar macrophages (Fig. 3.3). The latter are usually easily recognized by their phagocytosed cytoplasmic particles (Fig. 3.4). Mucus, produced by goblet cells, may be manifest as acellular stringy material or become apparent by trapping streaks of cells within it (Fig. 3.5). Clumps and casts of mucus from smaller airways can form basophilic structures called Curschmann's spirals (Figs. 3.6 and 3.7). Sometimes eosinophilic granule concretions known as Charcot-Leyden crystals may be present in the absence of asthma or any other eosinophilic condition (Figs. 3.8, 3.9, and 3.10). Other incidental findings include oxalate crystals, corpora amylacea, psammoma bodies, so-called blue bodies, and other calcified bodies. Some of these may be found in certain pathological conditions (see below). Rarely one may find contaminants such as pollen or food material which also may be incidental (Figs. 3.11 and 3.12).

\section{Nonneoplastic Reactive Changes}

As the respiratory tract mucosa is constantly exposed to irritant and other external stimulants, and is frequently involved in systemic conditions, it is not surprising that it is common to find reactive or irritative changes in the samples obtained. Commonly encountered irritants include such as smoking, airborne toxins, and dusts. Internal reactions to drugs and immunological diseases are also frequent, and less regular situations such as radiation exposure can influence the appearance of the cells in respiratory samples. 
Fig. 3.3 Streaks of alveolar macrophages trapped in mucus in this sputum sample

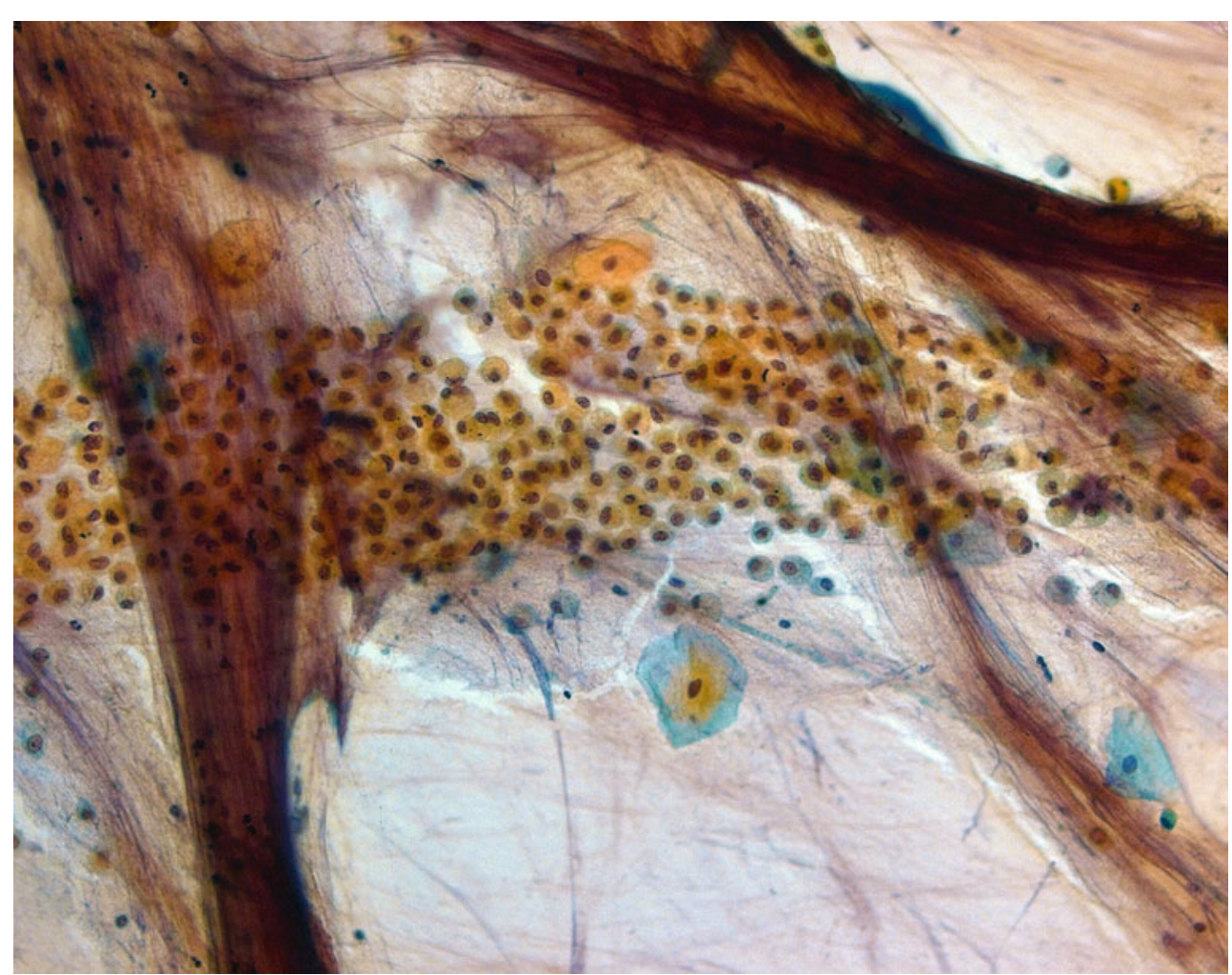

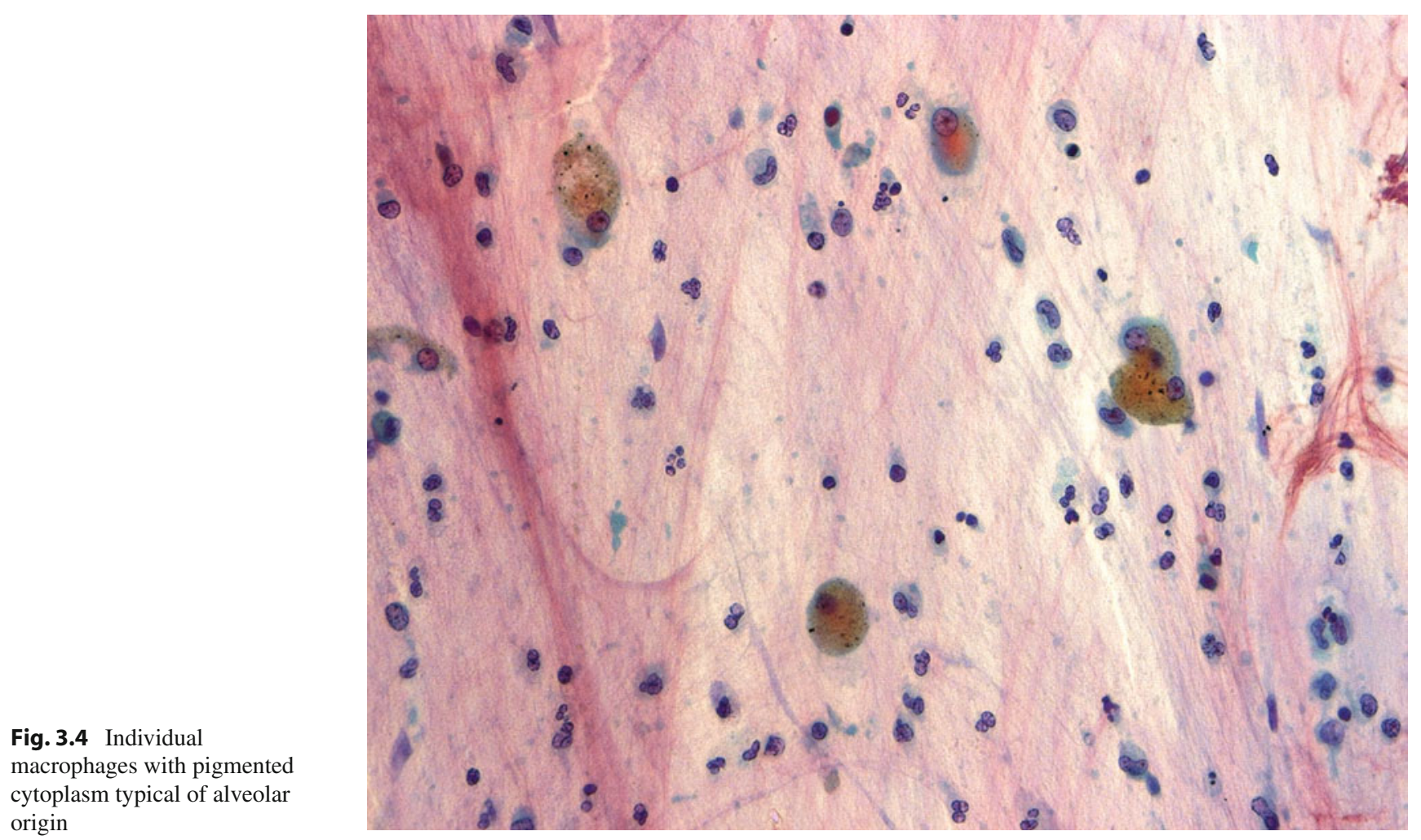

Fig. 3.4 Individual

macrophages with pigmented cytoplasm typical of alveolar origin 
Fig. 3.5 Alveolar macrophages and degenerate epithelial cells with a few inflammatory cells are present in this sputum sample
Fig. 3.6 Mucus commonly aggregates to form Curschmann's spirals
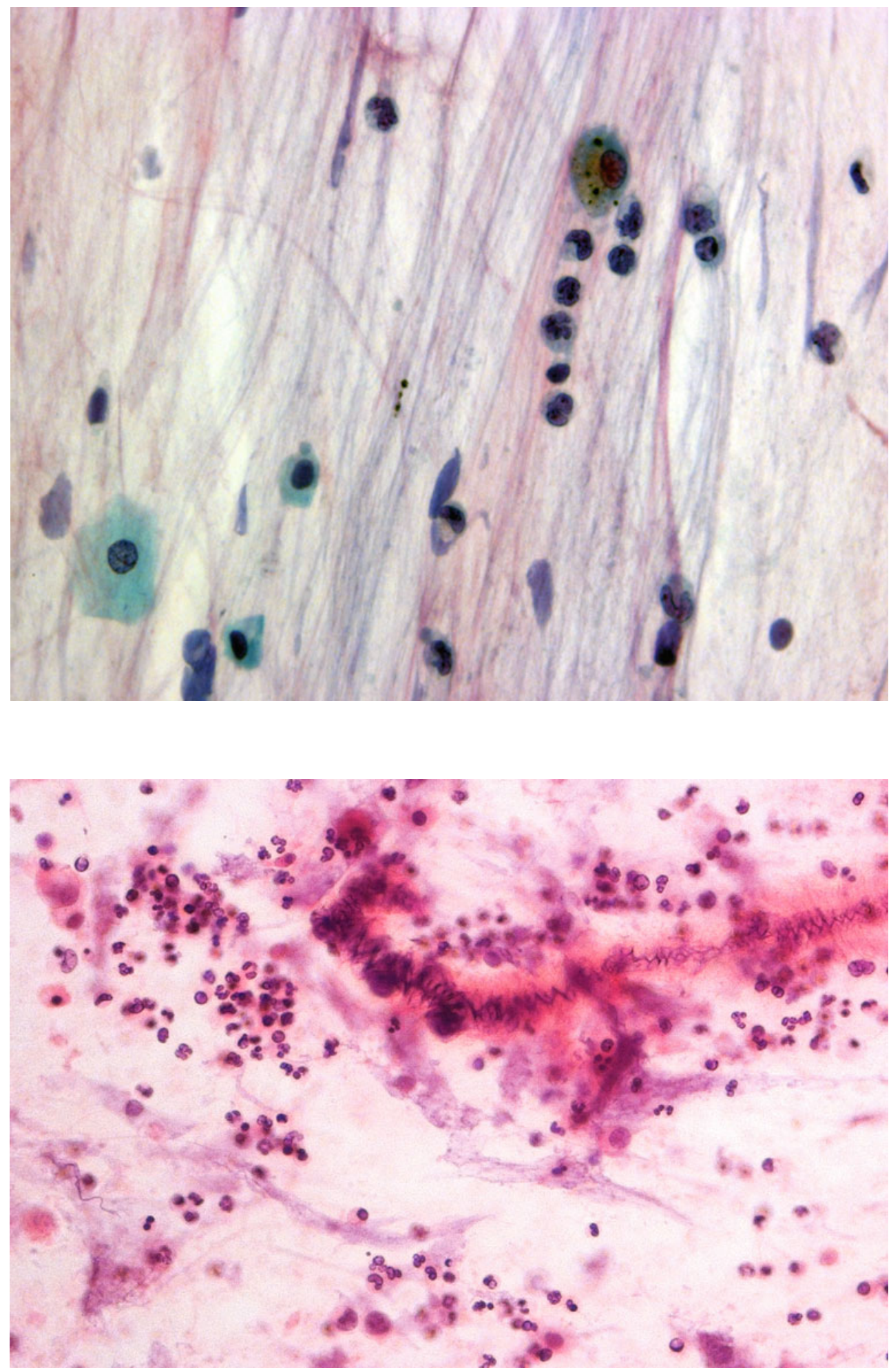
Fig. 3.7 Curschmann's spirals in a sputum sample
Figure 3.8 Charcot-Leyden crystals are seen in eosinophilrich inflammatory conditions
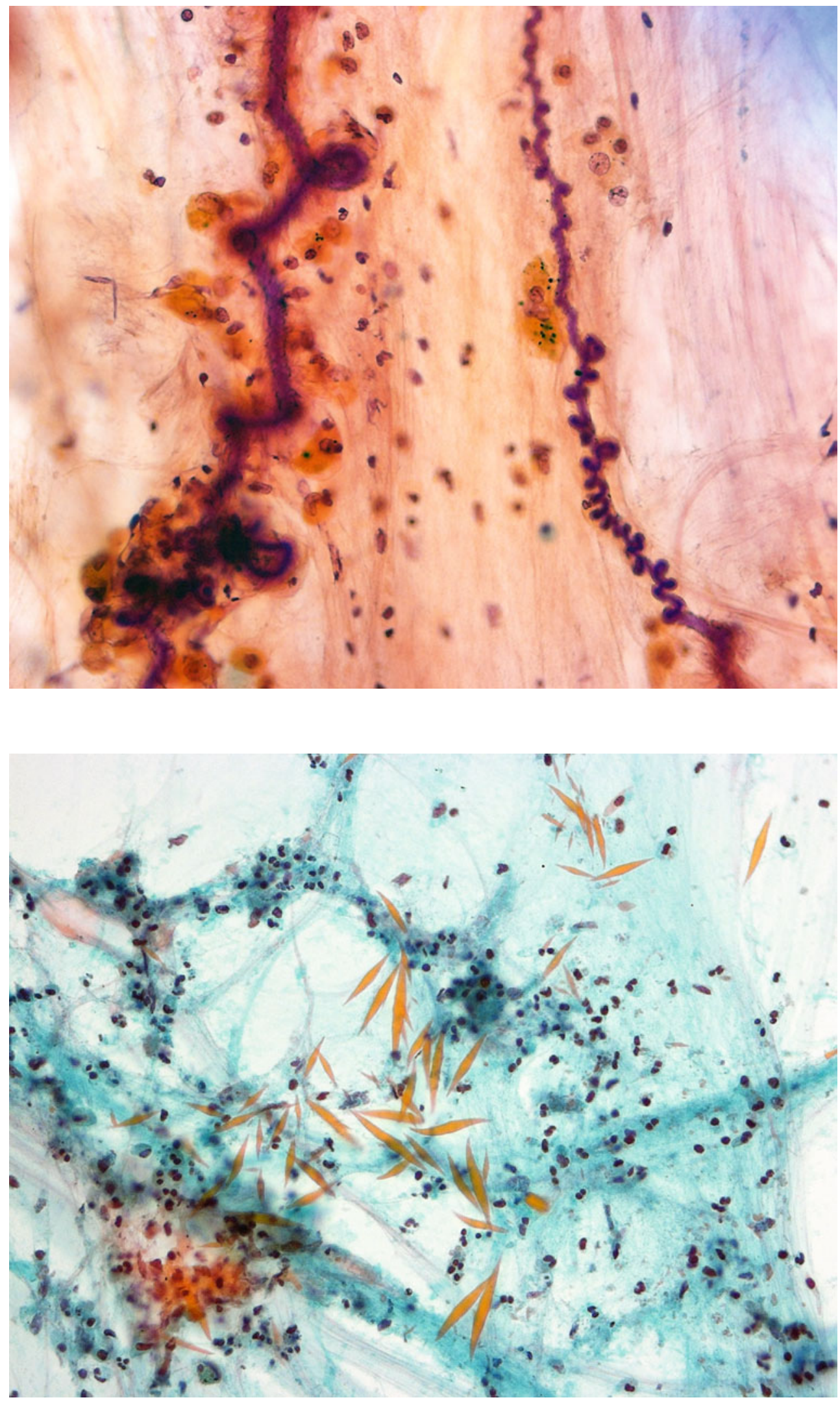
Fig. 3.9 Charcot-Leyden crystals at high power with their typical rhomboid shape and sharp edges
Fig.3.10 Numerous

eosinophils, often degranulating, are present around these Charcot-Leyden crystals
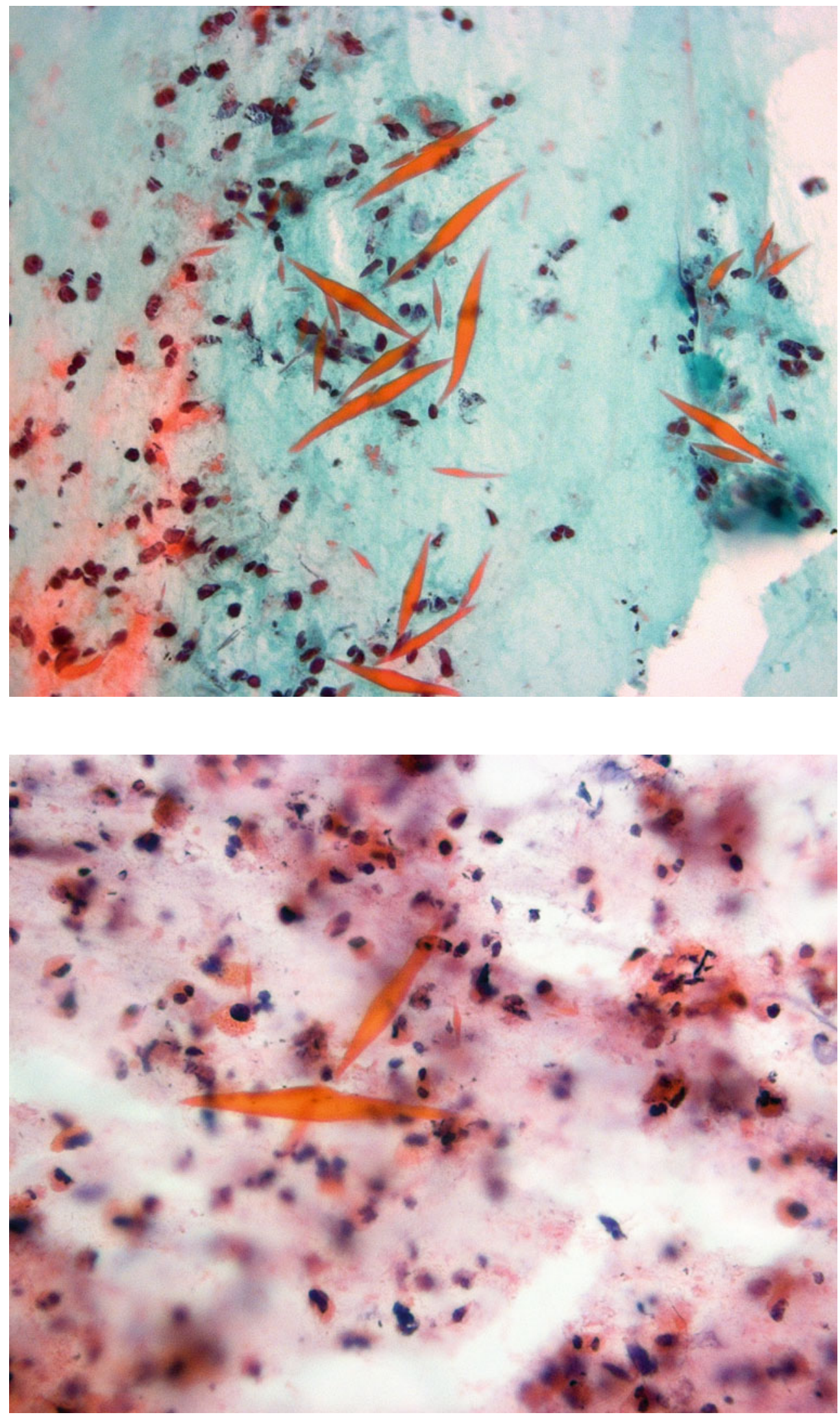
Fig. 3.11 Vegetable matter should not be mistaken for genuine respiratory tissue fragments
Fig. 3.12 Food material, such as this striated muscle fragment from a meaty meal, is frequently present and usually represents contaminant oral content in respiratory samples
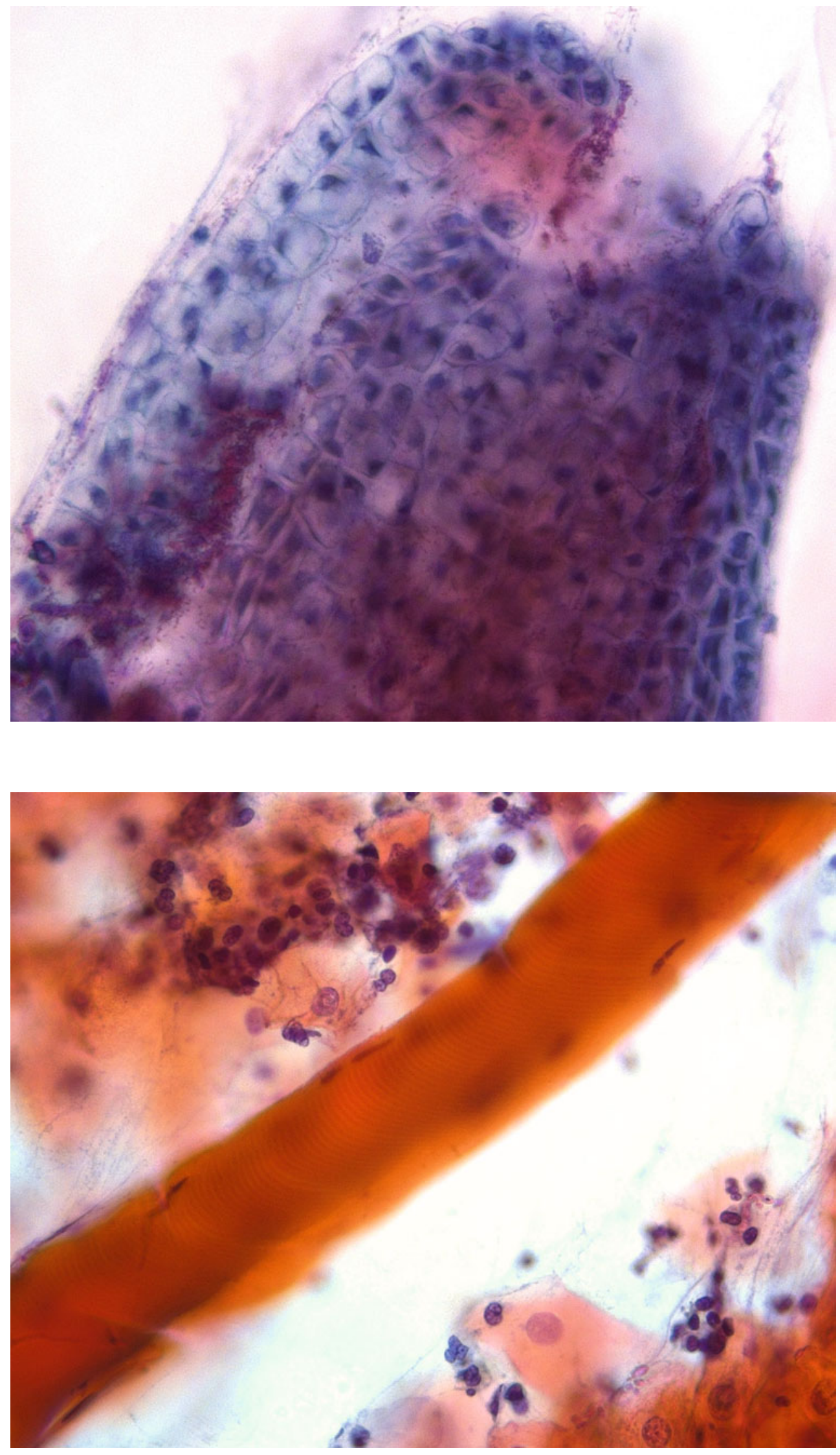
Fig. 3.13 Cilia are a reassuring feature and are not present on neoplastic cells, as a general rule

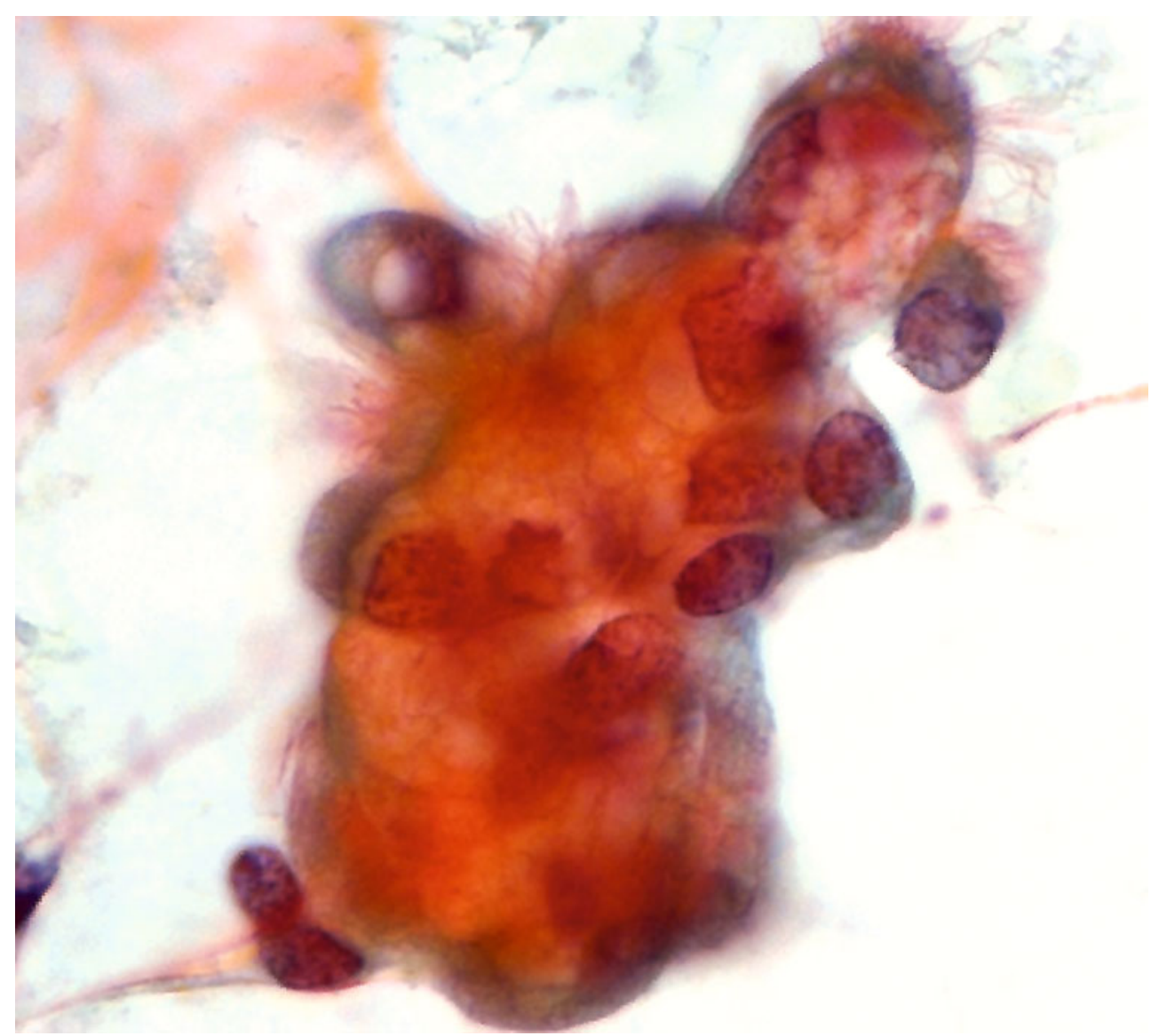

\section{Hyperplastic Changes}

Many pulmonary conditions are associated with a hyperplastic increase in epithelial cell number, either of the airway epithelium or alveolar airspace epithelium. These are generally a reactive proliferation, and the cells concerned will show reactive cellular changes. The most frequent feature of reactive cells is enlargement of the nuclei. Bronchial cell hyperplasia often presents as sheets of actively regenerating cuboidal and columnar cells which retain their cilia (Fig. 3.13). The nuclear chromatin is not altered however, a useful feature when trying to differentiate with a well-differentiated adenocarcinoma. Occasionally, these hyperplastic changes can lead to the formation of structured curled up strips of epithelium called Creola bodies which are particularly seen in asthmatics, and these may cause confusion with adenocarcinoma. However, the epithelial cells within Creola bodies lack macronucleoli and may retain their surface cilia (Fig. 3.14). In asthma and other chronic obstructive lung disease, the goblet cells may be also be hyperplastic. Reserve cell hyperplasia is also frequently seen as a response to any local insult. These reserve calls are arranged in groups and are small columnar or cuboidal cells with a high nuclear:cytoplasmic ratio. They may show molding, but their nuclei are always regular, and there is no associated necrosis. Type 2 pneumocyte hyperplasia follows injury to the more distal epithelial cells lining the alveolar walls. These are seen as grouped or individual polygonal or rectangular cells with small nucleoli, no cilia, and sometimes cytoplasmic vacuolation.

\section{Metaplastic Changes}

A range of metaplastic changes may also occur in the respiratory epithelium, and these can also mimic certain tumors. Squamous metaplasia is often manifested as groups of parabasal-type cells with bland nuclei. Metaplastic squamous cells (especially if showing some atypia) and reserve cells may be mistaken for squamous cell carcinoma and small cell carcinoma, respectively.

\section{Reparative Changes}

Reparative changes can also cause problems with interpretation and may be so florid that they mimic malignancy. Another change which may be seen is ciliocytophthoria. The respiratory epithelial cells here show loss of their apical 
Fig. 3.14 Sometimes epithelial cells curl up and appear hyperchromatic, but their innocent nature is recognized by their surface cilia

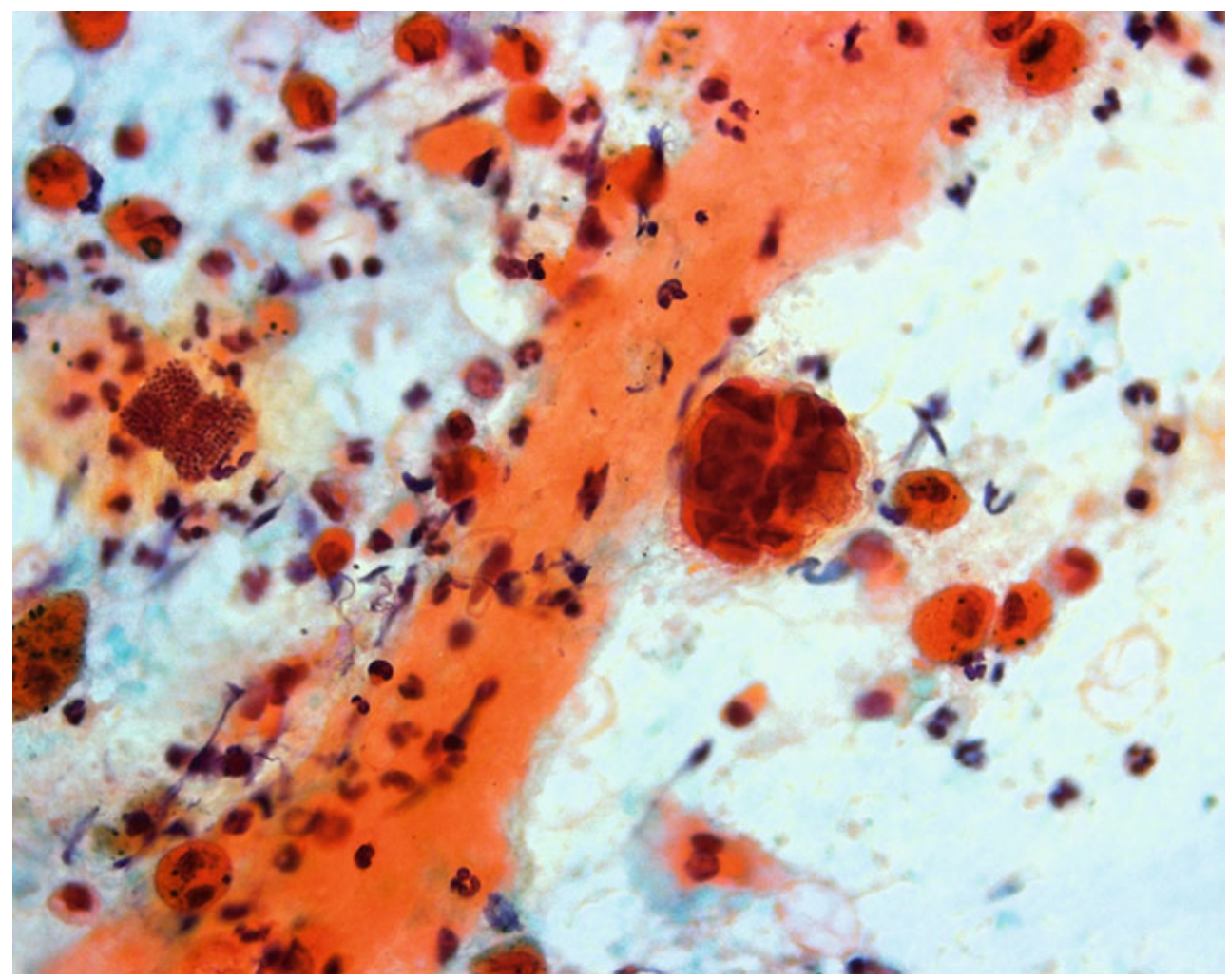

cytoplasm with detached tufts of ciliated bodies lying away from the more cuboidal looking cell bodies. These were originally thought to be only associated with viral infections of the lung, but it is now clear that they can be seen in a range of other infections and also in association with cancers. Other processes which can cause marked cytological atypia and thereby cause confusion with malignancy include acute pneumonia, granulomatous inflammation, fibrosing alveolitis, pulmonary infarcts, and rarely other conditions. It is crucial, as with any cytological sample, to correlate the findings with the clinical and radiological impression, within a multidisciplinary environment if appropriate and possible.

\section{Inflammation}

Inflammation of any cause usually leads to small numbers of epithelial cells becoming detached and expelled, and these can be round, polyhedral, oval, or sometimes spindleshaped. Occasionally, there is syncytial aggregation of the cells with multinucleation, knobbly nuclear contours, and "open petal" or cartwheel arrangement. These cell clusters are flatter than those seen with bronchioloalveolar carcinomas which are often three-dimensional. The cytoplasm can be bubbly and therefore raise the specter of adenocarcinoma or even look like signet ring cells which heighten the suspicion.

\section{Chronic Obstructive Pulmonary Disease}

In chronic obstructive pulmonary disease (COPD), especially chronic bronchitis, one may see conspicuous respiratory epithelial cells, retaining their cilia, with increased numbers of goblet cells. Reserve cells may be prominent, causing confusion with small cell carcinoma, and there may be ciliocytophthoria, squamous metaplasia, Curschmann's spirals, and macrophages together with polymorphonuclear neutrophils, especially if there is a current infection.

\section{Bronchiectasis}

Bronchiectasis may be suspected clinically when patients complain of dirty foul-smelling sputum production, and of course this can be confirmed on radiology without the need for pathological confirmation. Samples from bronchiectatic patients usually show numerous neutrophils and follicle center lymphocytes. The epithelial cells either show the regenerative changes described above or occasionally metaplastic squamous cells which may appear atypical. 
Fig. 3.15 Atypical squamous cells after radiotherapy may be difficult to differentiate from recurrent squamous cell carcinoma

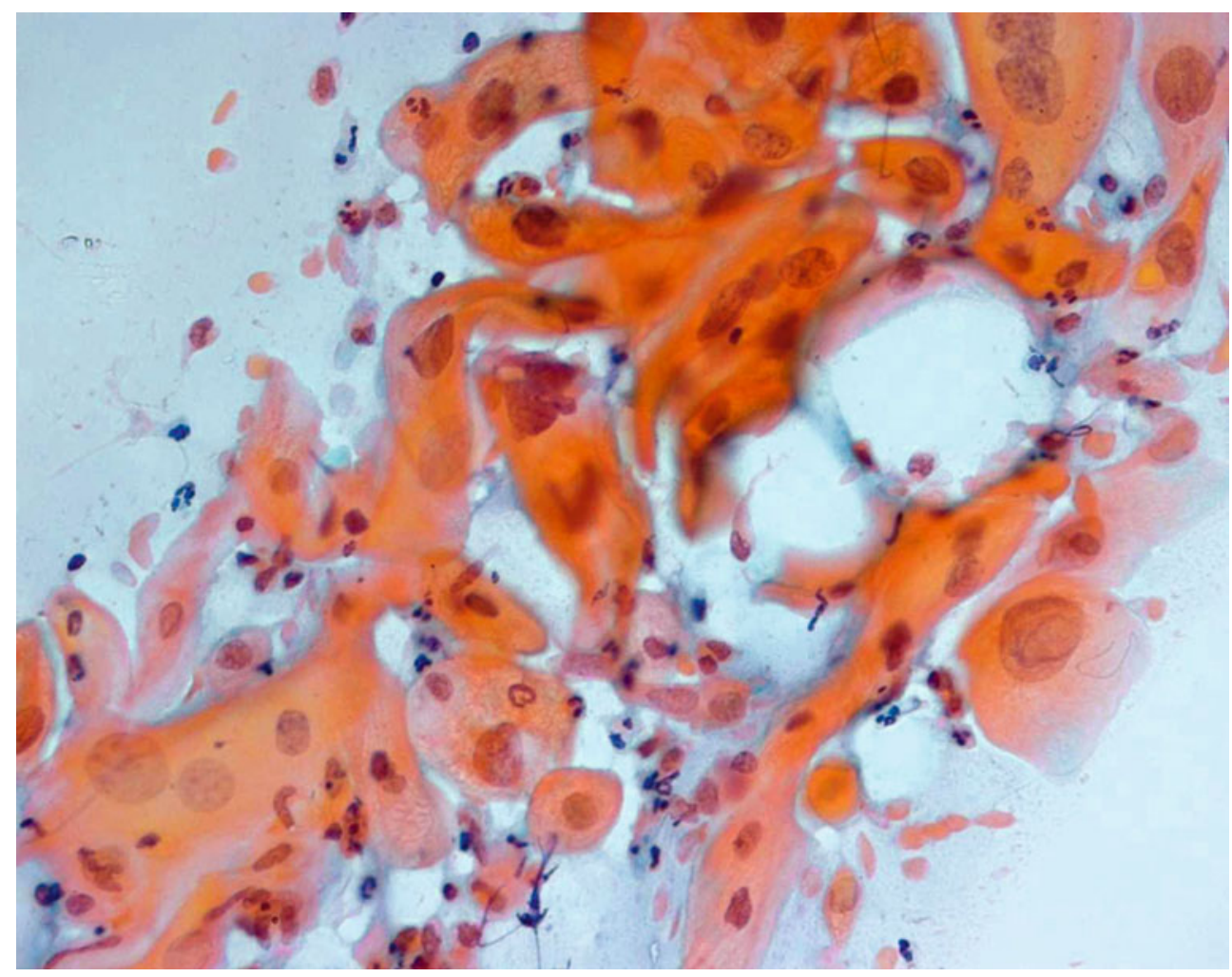

\section{Acute Respiratory Distress Syndrome (ARDS)}

ARDS is the clinical state characterized by respiratory difficulty caused by significant acute lung injury. Histologically, the picture is one of diffuse alveolar damage (DAD). There are many possible causes of DAD, the final diagnosis requiring correlation with clinical and radiological findings. Cytologically, this presents exactly as described for the nonspecific injurious and responsive changes outlined above.

\section{Radiation}

Radiation has been recognized as a mimic of sinister pathology for many years. The changes associated with radiation therapy can affect all types of cells including stromal, endothelial, and epithelial cells. The epithelial cells in particular can have bizarre shapes with striking angulation, swollen and vacuolated cytoplasm, and large nuclei with margination of the nuclear content. There may be cytoplasmic vacuoles which typically do not indent the nuclei in contrast to neoplastic cells. On occasion, the atypia may mimic squamous cell carcinoma, and care needs to be taken to avoid overcalling malignancy. Although there may be clues such as a clean background, uniform homogeneous chromatin, and intranuclear or cytoplasmic vacuoles, it is sometimes impossible to be sure whether the cytological changes are due to irradiation or recurrent/residual cancer (Fig. 3.15).

\section{Drug-Induced Changes}

Drug-induced changes can also cause confusion with neoplasia. They may also produce characteristic patterns and populations of cells in cytological samples. For example, busulfan can be recognized by large rectangular epithelial cells with nucleomegaly, multinucleation, and macronucleoli. Amiodarone induces the accumulation of phospholipids in the cytoplasm of macrophages giving a typical foamy appearance. Most drug reactions however are nonspecific. They provoke recognized patterns of response but without clues to the underlying cause. For example, busulfan, cyclophosphamide, chlorambucil, bleomycin, methotrexate, and azathioprine can all cause eosinophilic infiltrates, organizing pneumonia and diffuse alveolar damage. The reaction is reported to be worse in combination than with individual drugs. Rapamune/sirolimus can cause a variety of changes which includes a fibrosing interstitial pneumonitis. Clofazimine, used in the treatment of atypical mycobacteria (including MAI) and leprosy, can produce characteristic crystalline profiles in macrophages, but these dissolve 
Fig. 3.16 Elongated macrophages typify granulomatous conditions

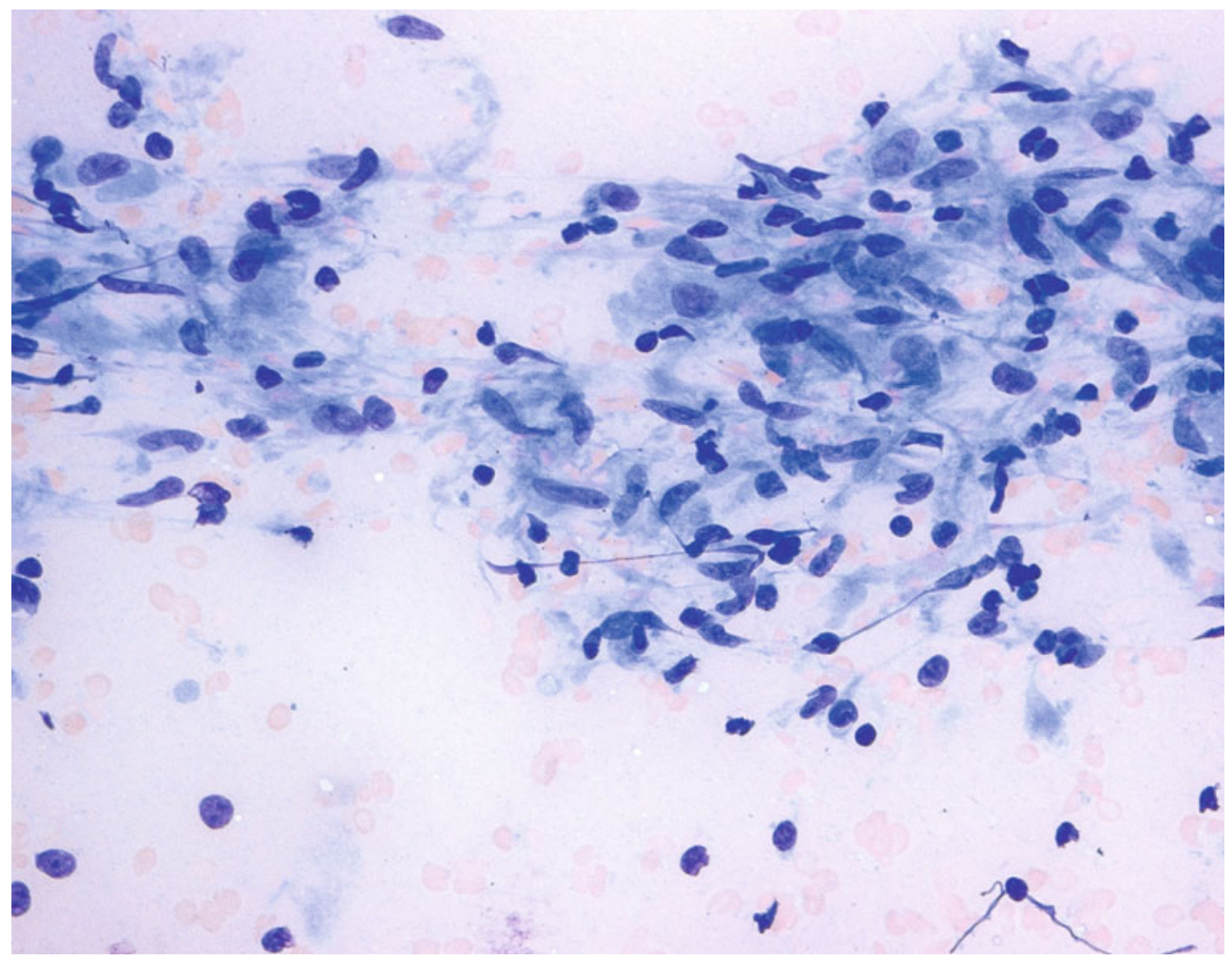

during preparation and leave a telltale negative impression. The most ominous differential diagnosis of all of these drug reactions is bronchioloalveolar carcinoma.

\section{Other Noninfective Inflammatory and Immunological Disorders}

A range of other noninfective inflammatory and immunological disorders can present with their own suggestive cytological features, but essentially the following are clinical or radiological diagnoses which can be supported or sometimes excluded by the cytological appearance.

In asthma, the bronchospasm is associated with sloughed epithelial fragments, prominent hypersecretory goblet cells with round or triangular nuclei, and Curschmann's spirals. The epithelial cell clumps may form Creola bodies. In the accompanying mucus streaks, there are usually plenty of eosinophils with their cytoplasmic disintegration products, Charcot-Leyden crystals. Eosinophilic pneumonia can appear similar, and when eosinophils are conspicuous, a search should be made for fungal organisms or a history of appropriate allergic response.

Sarcoid can be associated with multinucleated giant cells in a clean background, which may be helpful when trying to differentiate this condition from granulomatous infections (Figs. 3.16 and 3.17). The multinucleate cells have variable sized and shaped nuclei. Rarely, they may contain calcified
Schaumann bodies or oxalate crystals. There are usually numerous lymphocytes which are predominantly of $\mathrm{T}$ helper type (see Table 3.2). This is not surprising as sarcoid is generally thought to be an immunological response to an as yet unrecognized provoking agent.

Extrinsic allergic alveolitis (hypersensitivity pneumonitis) can produce a picture very much like sarcoid as can heavy metal exposure, and clinical input is required to take this distinction further. The wider differential diagnosis is with rheumatoid arthritis, systemic lupus erythematosus, and Wegener's granulomatosis, although there are no specific cytological features to refine this distinction further and clinical and radiological correlation is, as always, essential.

Goodpasture's syndrome and other hemorrhagic conditions such as idiopathic hemosiderosis typically produce cellular samples with numerous hemosiderin-laden macrophages. The nature of the pigment can be confirmed with Perl's stain.

Alveolar proteinosis is a fascinating reaction of the macrophages in the lung to a range of insults including certain toxins, infections, hematological malignancies, and chemotherapy. The condition may well be suspected clinically in a patient with severe radiological signs but few clinical symptoms and copious milky fluid at bronchoscopy. On BAL, there is typically granular material covering much of the slide which is PAS positive and diastase resistant. The differential diagnosis (mainly histological) is with amyloid which of course can be clarified by Congo red staining. 
Fig. 3.17 Granuloma formation can be predicted by finding round, epithelioid macrophages

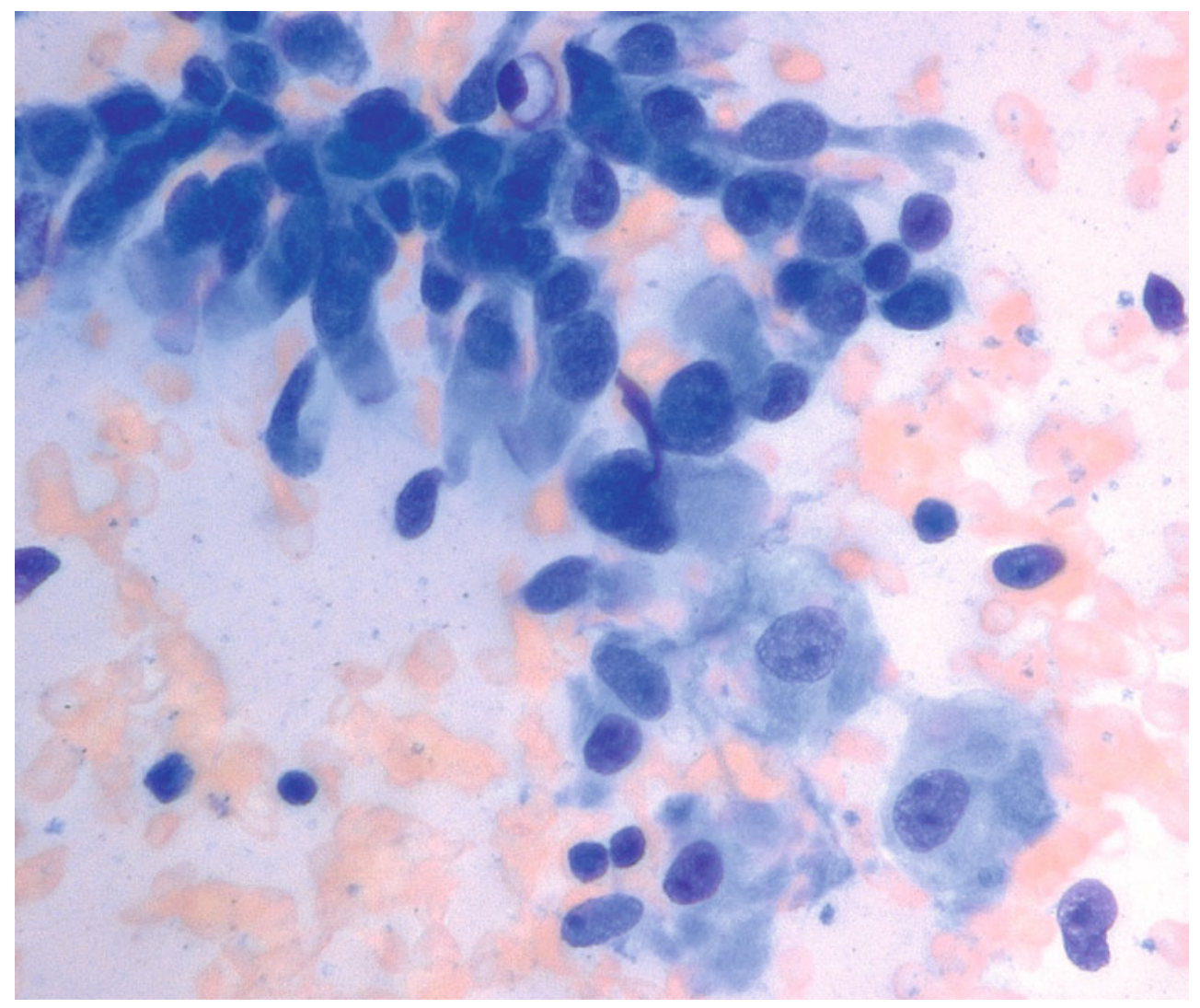

Electron microscopy can be useful, looking for osmophilic bodies and cholesterol crystals.

Lipoid pneumonia is relatively common and may be endogenous, especially if there is an obstructing lesion such as a cancer, or exogenous, often associated with aspiration of oily material such as cod liver oil. Cholesterol clefts may be present. The differential diagnosis includes drug reactions (amiodarone), metastatic liposarcoma, nonspecific accumulation of lipid-laden macrophages, and other causes of giant cells as described above. An oil red O stain will be helpful in this situation for confirmation of lipid-laden macrophages but not in determining the cause for this picture.

Interstitial lung disease is essentially a clinicoradiological diagnosis with pathological contribution where necessary. The latter is usually by histology of a transbronchial, video-assisted thoracoscopic, or open biopsy. Occasionally, however, the culprit may be visible on cytological samples, and one may be able to assess cell populations in lavage fluid. The latter should provide a relatively good representation of the airspace material, if necessary removing any excess epithelial cells by filtering so that they make up less than $5 \%$ of the cellular content. Using an MGG or diff quick stain, the differential is determined by counting 300-500 cells and recording their type. This technique has been recommended to differentiate between a range of conditions including idiopathic pulmonary fibrosis, sarcoid, occupational lung disease, infections, malignancy, transplant surveillance, and various pediatric conditions.

Normal counts have been established historically. It has been determined that alveolar macrophages should contribute $>80-90 \%$ of the cells present, eosinophils no more than $4-5 \%$, neutrophils less than $3 \%$, and lymphocytes $<10-15 \%$, with $<0.5 \%$ mast cells. The typical picture found with a range of pathological conditions is outlined in Table 3.2. Occasionally, EM may be needed, which can identify and measure the level of any inhaled substance, causing the respiratory abnormality. With idiopathic pulmonary fibrosis, the lavage fluid often shows increased PMNs initially but increased lymphocytes and macrophages with type 2 pneumocytes later on. Hard metals may produce giant cells of both macrophage and epithelial cell origin together with eosinophils. Asbestos, silica, and other ferruginous bodies may be recognized (Fig. 3.18), and these can be highlighted by Perl's stain.

\section{Infections}

Infections of the respiratory tract are generally diagnosed by microbiology, and cytology is usually requested as a means of excluding the possibility of tumor. Some infective organisms however are reasonably easy to pick up on cytological samples. Tumors are frequently associated with 
Table 3.2 Conditions that may be managed or suspected by their BAL cell count

\begin{tabular}{|c|c|}
\hline Condition & Characteristic cell population (BAL) \\
\hline $\begin{array}{l}\text { Usual interstitial } \\
\text { pneumonia (UIP) }\end{array}$ & Increased neutrophils \\
\hline $\begin{array}{l}\text { Nonspecific interstitial } \\
\text { pneumonia (NSIP) }\end{array}$ & Increased neutrophils and lymphocytes \\
\hline $\begin{array}{l}\text { Hypersensitivity } \\
\text { pneumonitis }\end{array}$ & Decreased CD4:CD8 ratio \\
\hline Sarcoidosis & $\begin{array}{l}\text { Increased lymphocytes including } \\
\text { CD4:CD8 ratio }(>3.5)\end{array}$ \\
\hline Smokers & $\begin{array}{l}\text { Cell number greatly increased with } \\
\text { carbon laden macrophages increased, } \\
\text { relative lymphocytes count decreased, } \\
\text { and neutrophils increased }\end{array}$ \\
\hline $\begin{array}{l}\text { Langerhans cell } \\
\text { histiocytosis }\end{array}$ & CD1a positive Langerhans cells $>5 \%$ \\
\hline Asbestosis & $\begin{array}{l}\text { Mixed cell increase including lympho- } \\
\text { cytes, neutrophils and eosinophils, } \\
\text { asbestos bodies }\end{array}$ \\
\hline Berylliosis & $\begin{array}{l}\text { Increased macrophages and CD } 4 \\
\text { lymphocytes }\end{array}$ \\
\hline $\begin{array}{l}\text { Cryptogenic organizing } \\
\text { pneumonia }\end{array}$ & Decreased CD4:CD8 ratio \\
\hline Lung transplant rejection & Lymphocytosis and molecular analysis \\
\hline Eosinophilic pneumonia & Increased eosinophils \\
\hline Pulmonary hemorrhage & Iron-laden macrophages (Golde score ${ }^{a}$ ) \\
\hline \multicolumn{2}{|c|}{$\begin{array}{l}\text { a Golde score is based upon Perl's staining the BAL sample and assess- } \\
\text { ing a grade between } 0 \text { and } 4 \text { for the hemosiderin content of } 200-300 \\
\text { macrophages and then giving an average for } 100 \text { cells providing an } \\
\text { overall score between } 0 \text { (least) and } 100 \text { (most); Golde DW, et al. Occult } \\
\text { pulmonary haemorrhage in leukaemia. BMJ. } 1975 ; 2: 166-8\end{array}$} \\
\hline
\end{tabular}

secondary infections, and some tumors can mimic infections clinically and radiologically. For bacterial infections in particular, microbiology is usually required to make a specific diagnosis. However, there are often nonspecific changes associated with such infections including a conspicuous numbers of neutrophil polymorphs. There may be degeneration of local epithelial cells and debris. The exfoliated cell groups may have vacuoles and look cytologically atypical. There may also be ciliocytophthoria. Special stains may be relevant, but it is wise to refer to the microbiological and serological results in order to avoid unnecessarily repeating certain tests. Many specific organisms can be identified by their morphology and staining characteristics (Fig. 3.19). Atypical infections show no obvious or specific cytological pattern and will need microbiology and/or serology for diagnosis.

Worldwide, the resurgence of tuberculosis (TB) and the development of drug resistance have become major health issues. In pulmonary TB washings and brushings may reveal mixed inflammatory cells, histiocytes (often epithelioid), rarely Langhans-type multinucleate giant cells, and necrosis. The granulomatous features may be more obvious in FNA samples than washings/lavage or brushings. Acid-fast bacilli may be identified by Ziehl-Neelsen stain (Figs. 3.20 and 3.21), rhodamine-auramine fluorescence, or other more rarely used stains. Sometimes a negative impression of the bacilli can be discerned on MGG. The bacillus, originally identified in 1852 by Koch, is 1-4 $\mu \mathrm{m}$ long and shows
Fig. 3.18 Ferruginous (in this case asbestos) body with its characteristic beaded dumbbell appearance and central fibrous core

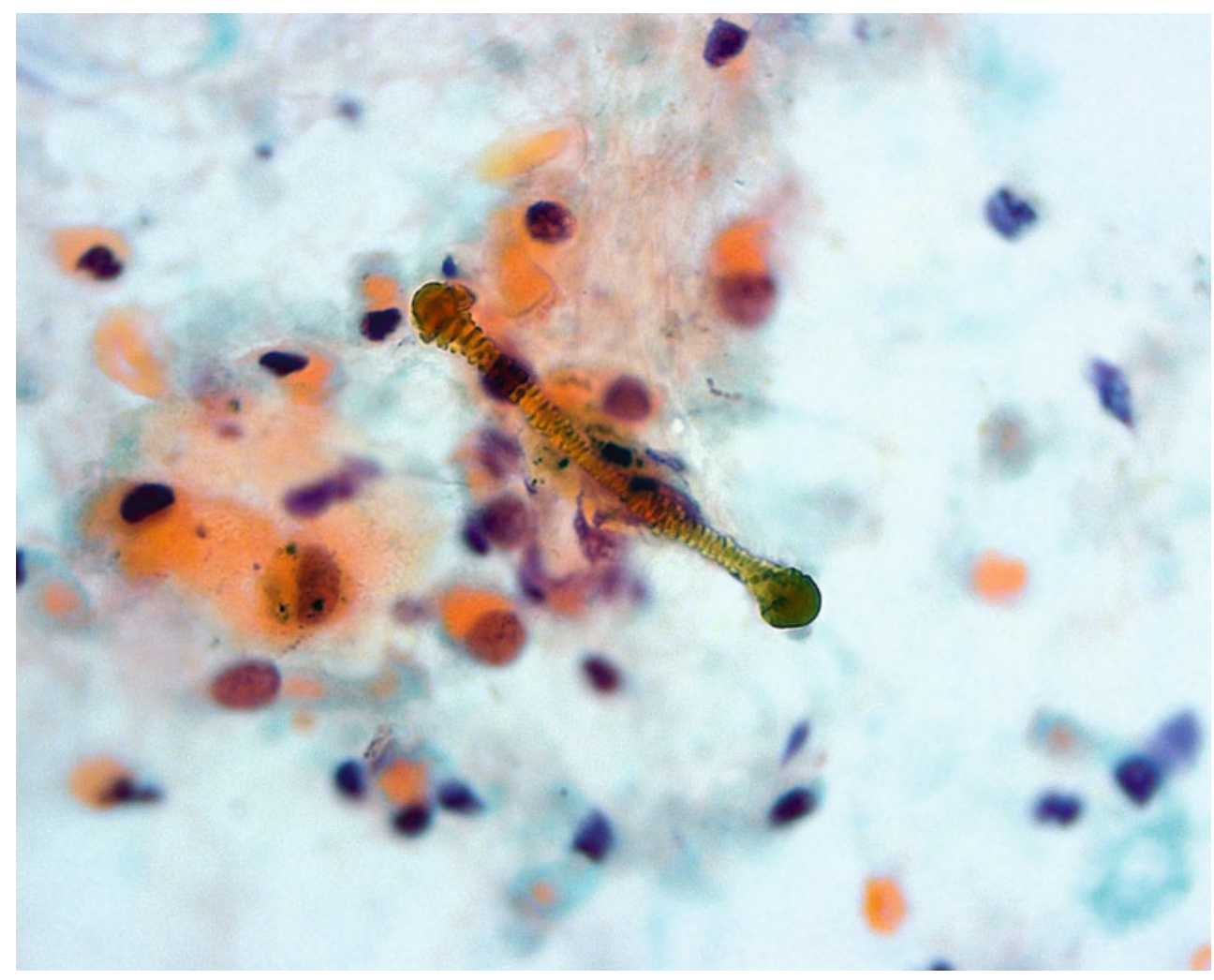


Fig. 3.19 Occasionally

actinomycosis can present in respiratory cytological specimens
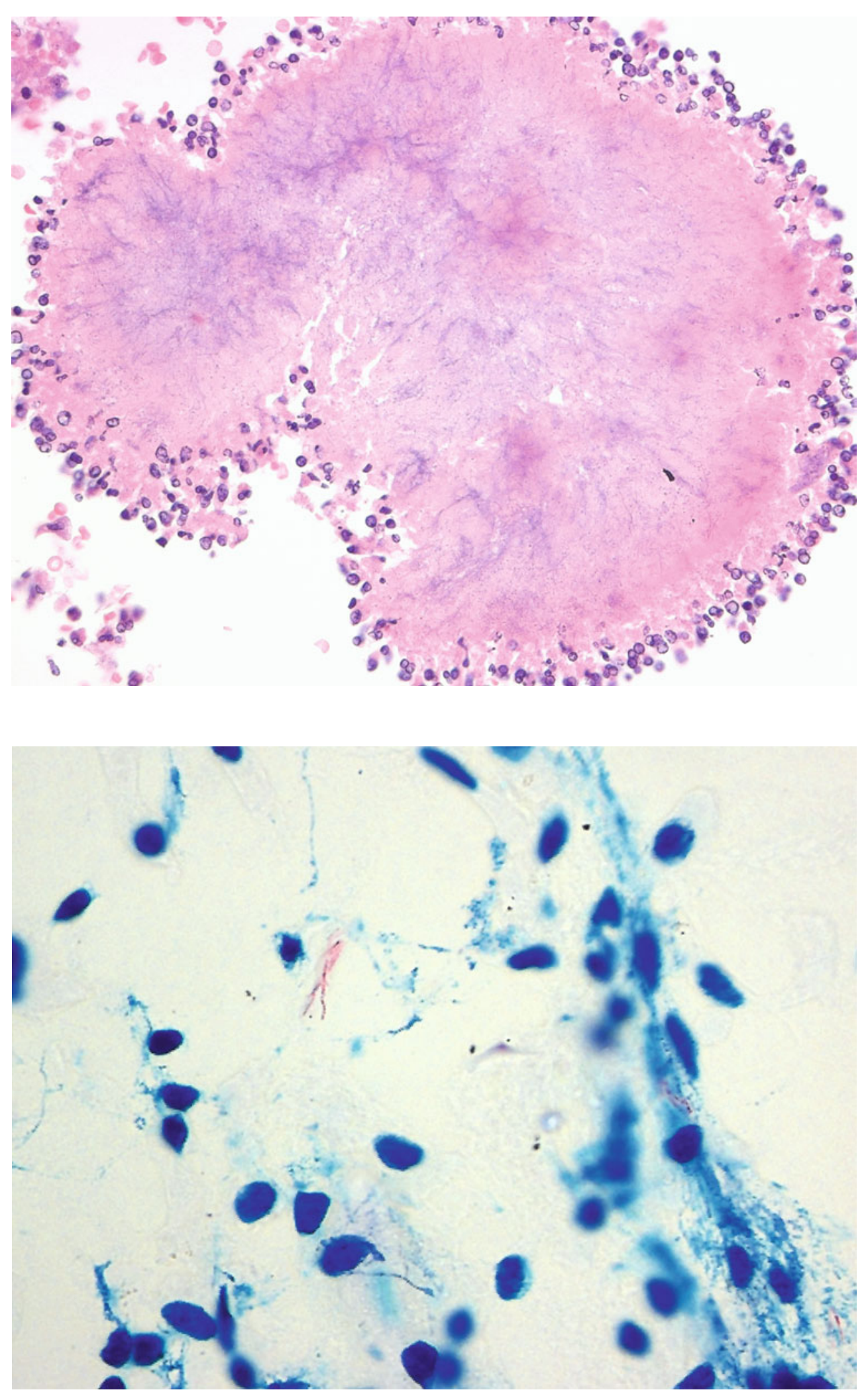

Fig. 3.20 Acid-fast bacilli may be identified on Ziehl-Neelsen stain 
Fig. 3.21 Mycobacteria have a typical beaded appearance

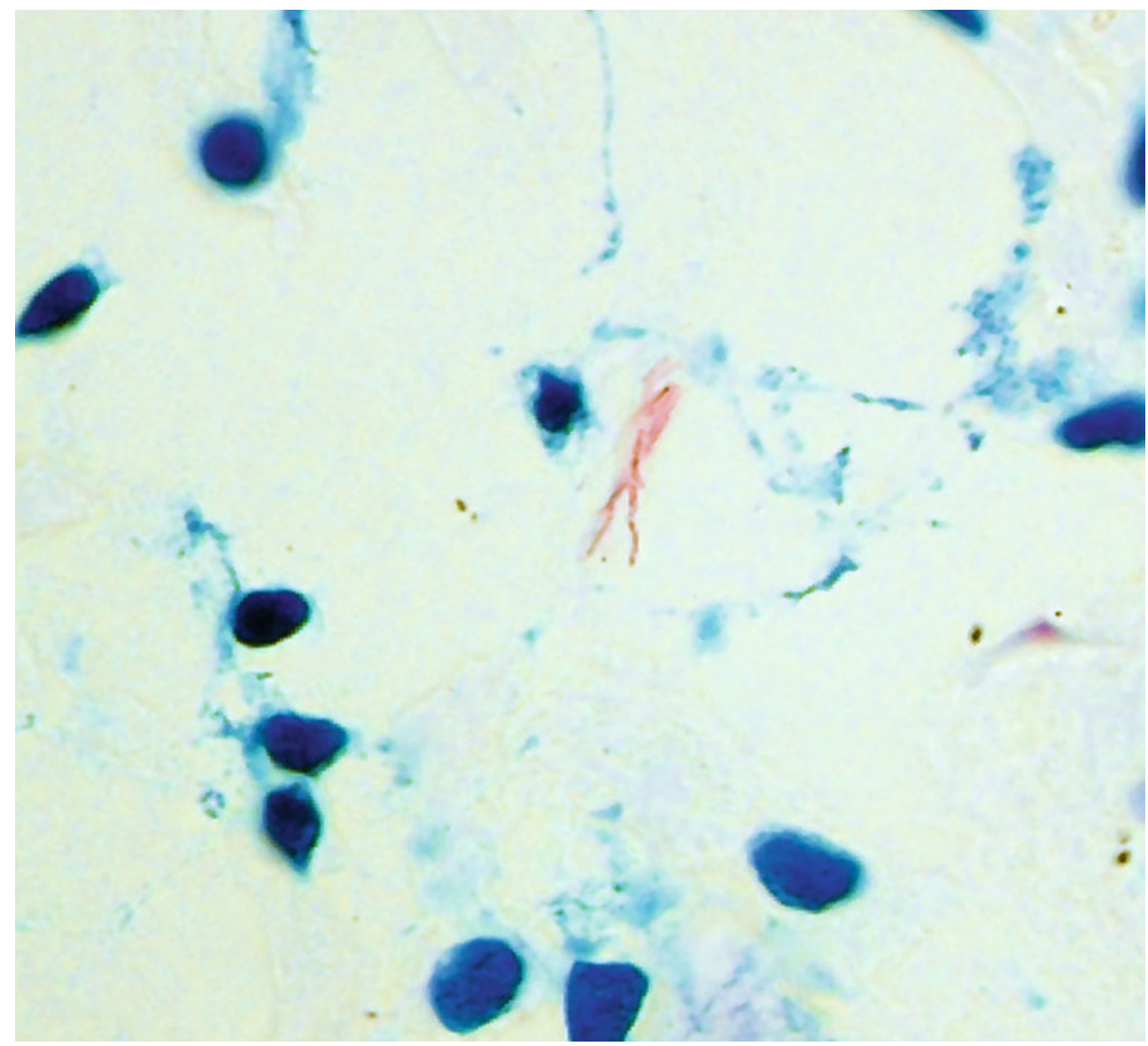

terminal angulation or a bent shape. It is often described as beaded, and it may be possible to differentiate it from other mycobacteria by routine morphology (although culture is preferred for formal typing). if material is limited than the stained slide can be destained and restained, but ideally material should be offered to the microbiology department for smear, staining, culture, molecular work up if possible, and sensitivities. The differential diagnosis will often include other infections, a range of noninfective granulomatous diseases, and tumors especially necrotic squamous cell carcinoma.

\section{Viruses}

Viruses may or may not be pathological when they are encountered in respiratory cytology samples. All viral pneumonias are more common in immunocompromised individuals. Infection with herpes simplex virus (HSV) typically shows multinucleation, smooth nuclear inclusions, nuclear clustering, and molding with loss of the normal chromatin pattern. The nucleus looks empty (Fig. 3.22) and classically appears to have a ground glass appearance and Cowdry A inclusions. These are triangular or wedge- shaped intranuclear structures that are refractile. The background is usually clean. Varicella zoster virus (VZV) causing chicken pox will have a virtually identical appearance. Measles though is different and typically produces numerous nuclei in epithelial cells with cytoplasmic eosinophilia. Respiratory syncytial virus (RSV) also shows multinucleation with basophilic inclusions. Adenovirus is difficult to diagnose but may be recognized by radiating nuclear chromatin and a rosette arrangement. Small eosinophilic intranuclear inclusions may be visible. Cytomegalovirus (CMV) may be found in macrophages and other cells, with their characteristic halos and owl eye inclusions (Fig. 3.23). The ease with which inclusions are found correlates with the severity of the infection. A consistent feature of viral diseases of the respiratory tract is ciliocytophthoria. The main differential diagnosis is with adenocarcinoma. The latter often produces sheets or aggregates of cells, while virally infected cells usually present as single cells. Critical examination of the nuclear content for inclusions, loss of chromatin, and multinucleation will point toward viral disease rather than cancer. To avoid misinterpretation, there are stages one can go through including conferring with the virology department or performing immunocytochemistry for viral antigens if possible. PCR 
Fig. 3.22 Herpes simplex infection. Note the typical glassy nuclear changes
Fig.3.23 Cytomegalovirus infection with characteristic eosinophilic nuclear inclusions
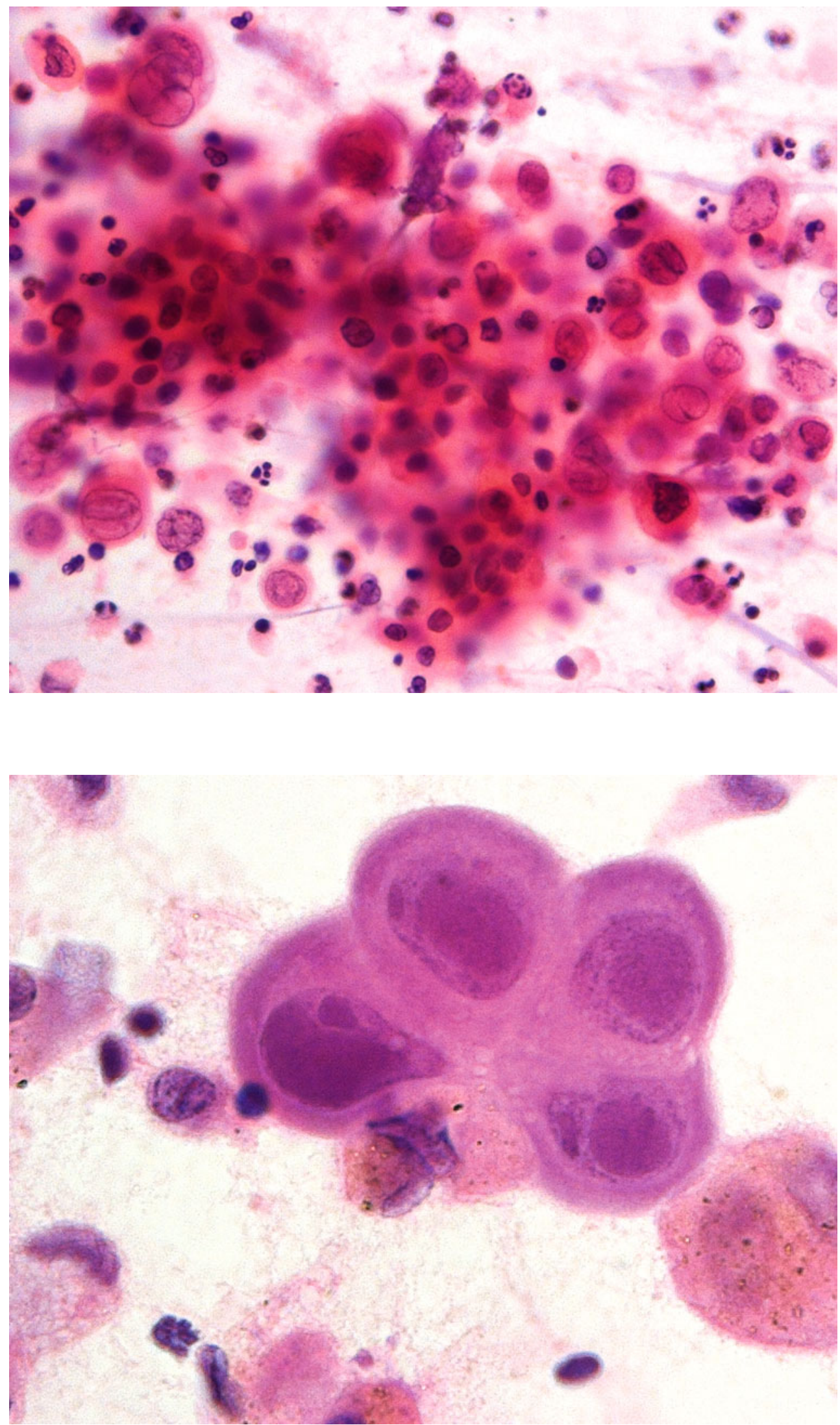
Fig. 3.24 Aspergillus can be identified in sputum samples. Note the $45^{\circ}$ angle of hyphal branching

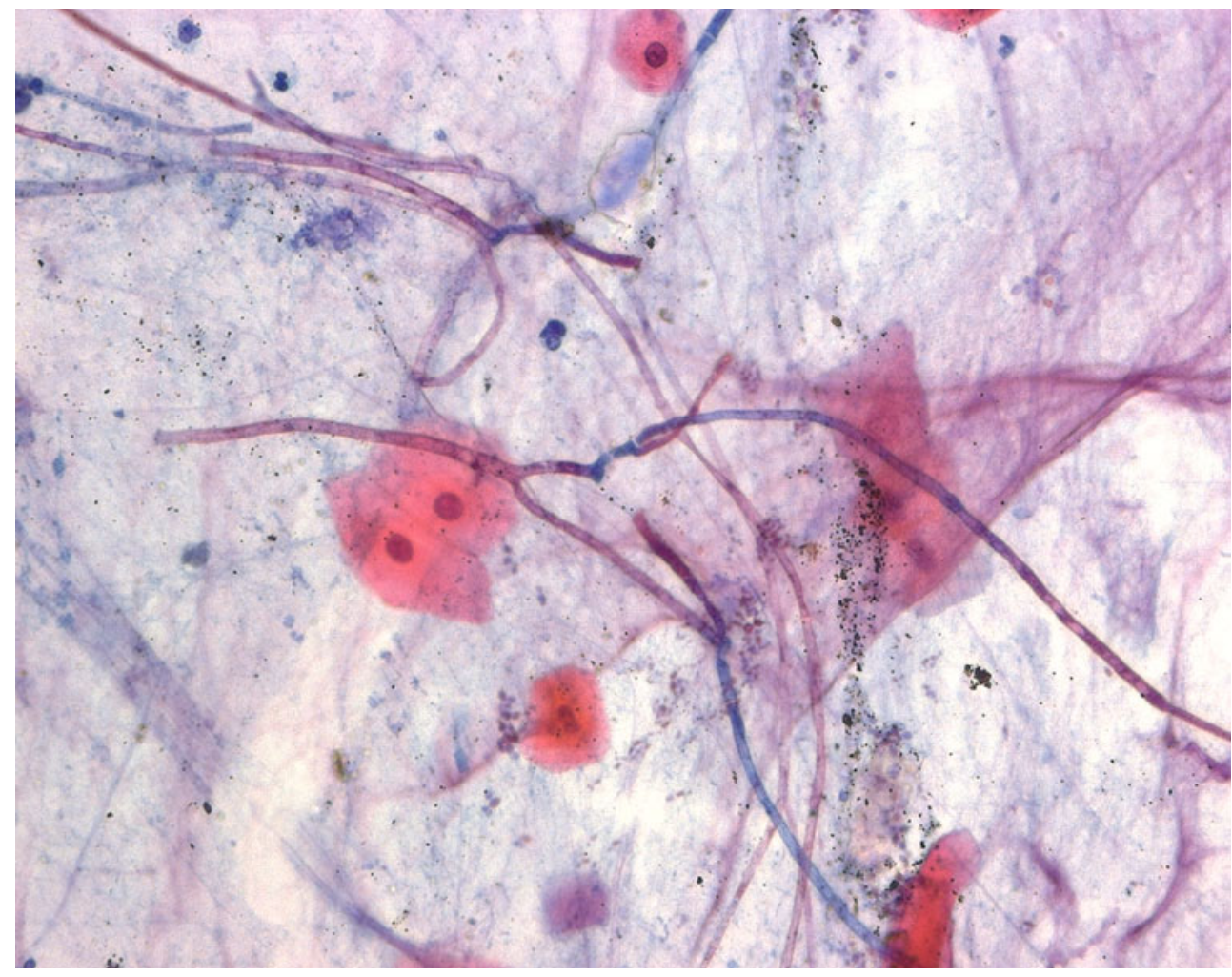

may be helpful, and it should be remembered that when $\mathrm{CMV}$ is present in the setting of immunosuppression, there is often coinfection with PCP.

\section{Fungi}

Fungi can affect the lung by primary direct infection or part of systemic infection or cause an allergic reaction. Many are saprophytic, only really causing problems in a compromised host and just harmlessly residing on mucosal surfaces of tissues in healthy individuals. The presence of fungi in respiratory samples therefore does not necessarily imply disease. While they can of course be causing an active infection, fungi may be innocent bystanders to an alternative disease, or they may be contaminants from the mouth or solutions/ water used in the preparation or staining of the slides. Usually this differentiation can be made easily, but occasionally clinical correlation may be required to clarify their significance. The presence of intimately associated inflammatory cells in the sample suggests that there may be active infection.

Candida is a very common commensal, inhabiting many areas of the body. It occurs as yeasts $2-4 \mu \mathrm{m}$ in diameter and chains of yeasts forming pseudohyphae 3-5 $\mu \mathrm{m}$ in width. Genuine hyphae may occasionally be formed. Every person will be colonized somewhere by Candida, and it is usually harmless, but occasionally it can be pathogenic. Most commonly encountered in the body is $C$. albicans, but there are other types/species especially Candida (also called Torulopsis) glabrata. To cause disease, it usually requires a degree of immunocompromise, such as a hematological abnormality, diabetes, or therapeutic steroid use. In this situation, or after aspiration of oropharyngeal contents, the fungus can be found in the lungs, causing a pneumonia. It is easily seen on Papanicolaou and H\&E but can be highlighted using PAS or Grocott stains. The problem is usually not the identification of Candida but rather determining the significance of its presence. The latter will obviously require clinical correlation.

Aspergillus occurs as several species ( 600), but less than 10 are pathogenic to man. In the lung, this is mainly $A$. fumigatus which is seen as a septate hyphal form, 3-4 $\mu \mathrm{m}$ in width, with dichotomous branching at $45^{\circ}$ (Figs. 3.24 and 3.25). A fruiting head may be visible if the fungus is growing in aerobic conditions, such as in a cavity. It is recommended that its presence should always be reported, but it should be recognized that it may be a contaminant. PAS and Grocott stains may aid visualization (Fig. 3.26), and oxalate crystals are often present which are refractile and often show an ill-defined Maltese cross appearance in polarized light. The main differential is with other fungi especially Mucor (see below). Aspergillus may be saprophytic in the presence of bronchiectasis, but it can lead to an allergic reaction in bronchopulmonary aspergillosis, an aspergilloma (colonization of a preexisting cavity) and invasive aspergillosis. When the associated inflammation is marked, there can be florid 
Fig. 3.25 Aspergillus may also be recognized in bronchial washings or bronchoalveolar lavage
Fig.3.26 A variety of silver stains can be used and highlight the Aspergillus fungal elements; in this case Grocott
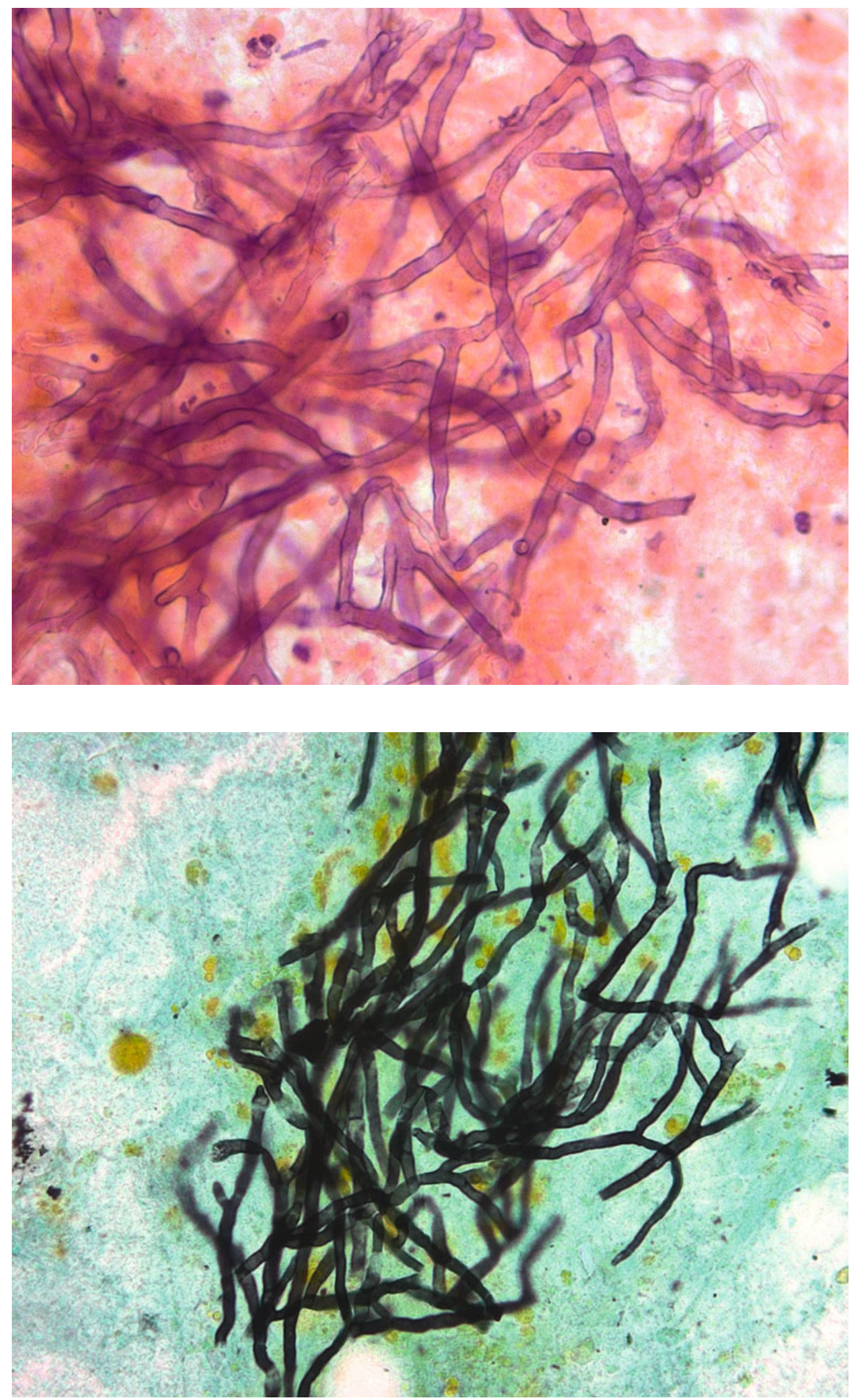
Fig. 3.27 Gomori's methenamine silver decorates pneumocystis carinii (jiroveci)

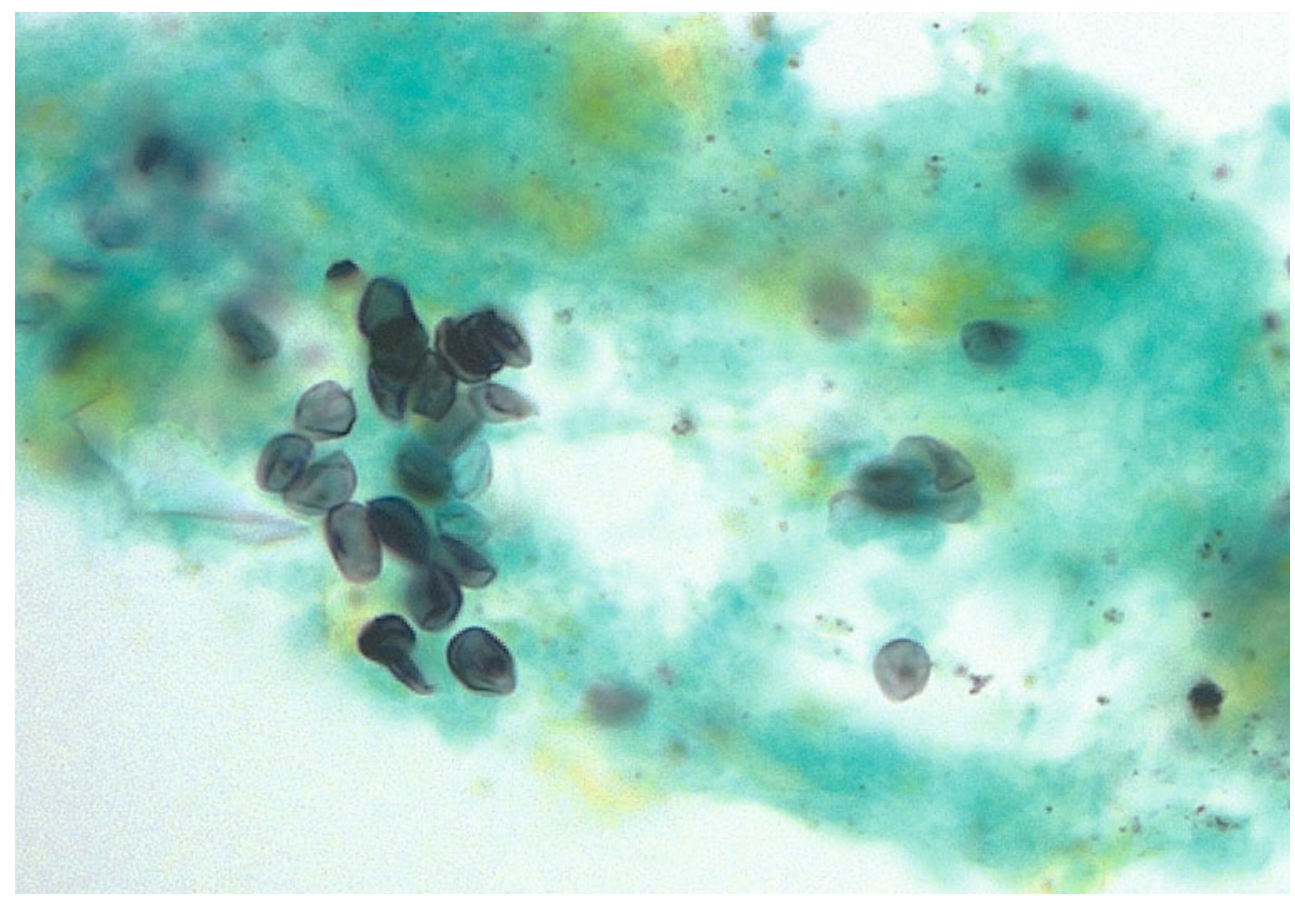

reaction within the local epithelial cells which may appear atypical. There may also be granulomatous inflammation.

Mucormycosis can involve the upper respiratory tract or even the lower tract occasionally. Mucor is one of the phycomycoses together with Rhizopus and others. For this to cause clinical disease, there is almost invariably an immune problem in the infected individual. Most often this is an underlying lymphoma, leukemia, or chemotherapy. This fungus readily invades blood vessels to produce thrombosis and infarcts. It is characterized by hyphae which are nonseptate, 5-50 $\mu \mathrm{m}$ in diameter, and show irregular branching typically at $90^{\circ}$. The hyphae are broad, pale, and very fragile-looking, decorated by PAS and Grocott stains as expected.

Pneumocystis carinii (now termed $P$. jiroveci) is a relatively frequently found fungus in routine cytological practice. It was previously thought to be a protozoan organism but for many years now has been classified as a fungus. It is found worldwide in the soil and atmosphere. It is most notorious for infecting those with HIV (AIDS) and after transplantation. It lives as a $1-5-\mu \mathrm{m}$ trophozoite that adheres to type 1 pneumocytes by filopodia. The trophozoites develop into cysts $5-8 \mu \mathrm{m}$ in diameter which show a focal thickening of the capsule and contain merozoites. The cyst form contains sporozoites. The cysts autofluoresce with Papanicolaou and can be identified with the aid of toluidine blue, Giemsa, Gram-Weigert, PAS, and silver stains (Fig. 3.27). The best sample for detection is BAL, but sputum may reveal the organism, especially in an induced sputum sample. Typically there are alveolar granular casts with a honeycomb appearance (Fig. 3.28). When treated or punctured, the cysts collapse and form crescent-shaped structures. The number of cysts is related to severity of infection. PCR can be performed as an additional or alternative method of confirmation. It should be remembered that in the setting of immunocompromise, PCP may occur with other coexistent infections, especially CMV (Fig. 3.29).

Histoplasma is a dimorphic organism, found in soil and bird droppings mainly in Africa and the Americas. In tissue, it can be recognized as an intracellular $2-5-\mu$ m yeast with a peripheral halo, decorated better by Grocott than by other fungal stains. Histoplasma capsulatum has a refractile capsule, is an obligatory pathogen, and requires macrophage ingestion. Other similar fungi with which it may be confused include Blastomyces and Cryptococcus, and of course Candida. Cryptococcus is found worldwide and measures 5-20 $\mu \mathrm{m}$. It may produce a granulomatous reaction. The fungus is round with a clear but thick mucopolysaccharide capsule that is reasonably easily identified on Papanicolaou but better appreciated on PAS, mucicarmine, or Grocott stains. Healthy individuals may be exposed to this fungus but mount an immunological response that is able to combat and either destroy the organism or contain it within the lung. However, reinfection may occur, or the fungus can lie dormant before reactivating later in life and spreading through the lungs. It is a neurotropic organism best known for causing meningitis in immunosuppressed individuals. It can also cause a pneumonia which can occasionally mimic malignancy on radiology.

Other fungi rarely crop up in routine practice in Europe and North America, but with global travel, they may occasionally cause diagnostic difficulty. These include paracoccidioidomycosis in South and Central America (brasiliensi). This is caused by a 6-60- $\mathrm{mm}$ budding yeast which can cause a bronchopneumonia or systemic disease and may be associ- 
Fig. 3.28 Pneumocystis carinii typically forms alveolar casts which can be recognized on Papanicolaou stain

Fig.3.29 Cytomegalovirus and pneumocystis can occasionally be present at the same time, especially in the setting of immunocompromise
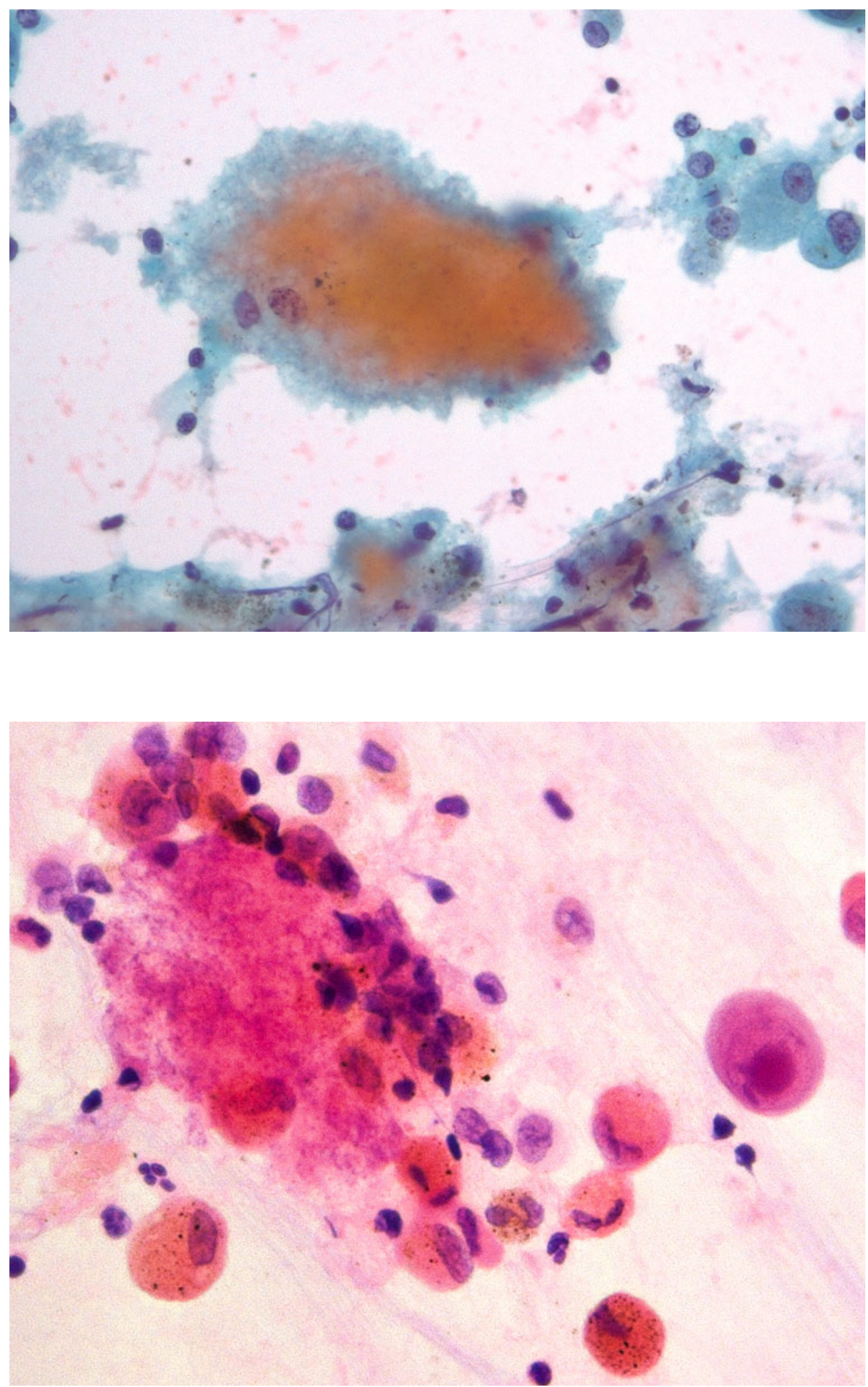
Fig. 3.30 An aspirate from a hydatid cyst in the lung with the characteristic protoscolex hooks

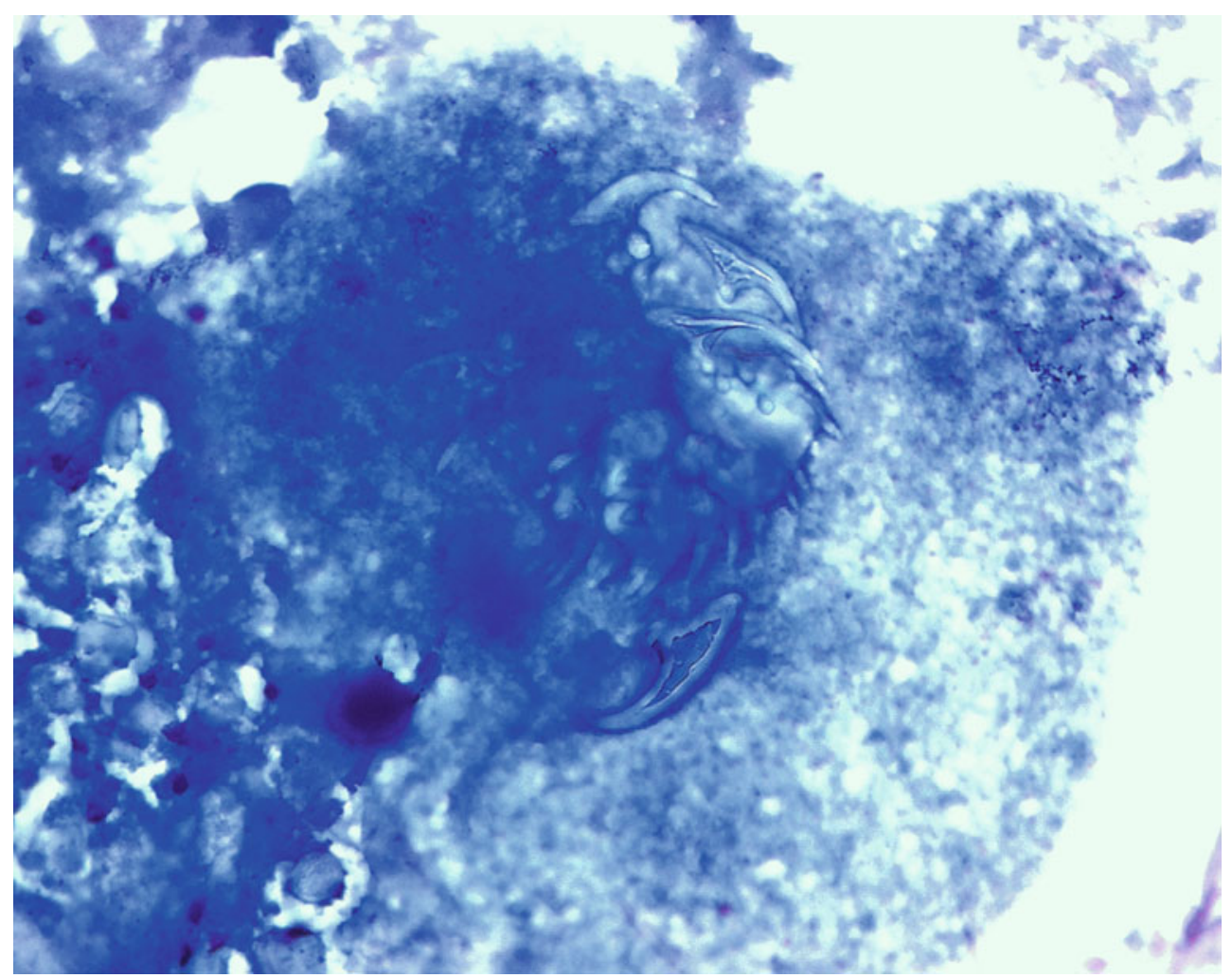

ated with alveolar lipoproteinosis. Penicillium is a $2-6-\mu \mathrm{m}$ dimorphic fungus seen in Asia and China which is sometimes mistaken for PCP or histoplasmosis. Coccidioidomycosis is another dimorphic fungus found in Southern USA and South America. It can become airborne and get access to the lungs from the soil to produce a granulomatous and fibrotic condition that resembles tuberculosis. The organism has a unique life cycle that includes 20-60- $\mu \mathrm{m}$ spherules and endospores of 1-2- $\mu \mathrm{m}$ diameter.

\section{Parasites}

These tend to affect those in warmer climates but may be seen in patients in more temperate regions, especially with immunosuppression, and particularly in the setting of HIV. The organism may be a protozoan, but many organisms have been described including nematodes, trematodes, and cestodes (ascariasis, dirofilariasis, echinococcus, filariasis, paragonimiasis). Hydatid disease can rarely involve the lung (Fig. 3.30) as can Enterobius vermicularis. Strongyloides, a $400-500-\mu \mathrm{m}$ long elongated worm, may be seen in immunosuppressed individuals (Fig. 3.31). It has a notch at the end of its tail, and eosinophils may be present in the sample or the blood. These organisms may lead to pneumonia (sometimes an eosinophilic pneumonia). Toxoplasmosis can involve the lung and infects cells forming the pseudocysts containing tachyzoites. Cryptosporidium and microsporidium have been recorded but are very rare.

\section{Transplantation}

The principles of cytological assessment of lung transplant cytology are well known. The critical diagnoses to consider can be grouped into infections related to immunosuppression, including PCP, HSV and Aspergillus, complications of transplant rejection especially bronchiolitis obliterans, drugrelated lung injury, and transplant-related neoplasia. BAL is used as a monitoring tool for lung transplant patients, but any organ or hematological transplant can lead to a secondary lung disease, and the likely diagnosis includes a range of common and unusual infections, drug toxicity, radiation change, interstitial lung diseases, and PTLD.

Early after lung transplantation, the BAL cell count is abnormal with a mild increase in neutrophils and lymphocytes, reflecting a nonspecific reaction to surgery and graft injury. Bacterial infection obviously leads to a more significant granulocytosis. Over time, the CD4:CD8 ratio decreases as the CD4 lymphocytes disappear, but acute and chronic forms of lung transplant rejection produce increased lymphocytes in the BAL with a change in the CD4:CD8 ratio and sometimes donor-specific antibodies. Viral pneumonitis often needs to be considered in 
Fig. 3.31 Strongyloides in a BAL sample from an HIVinfected individual

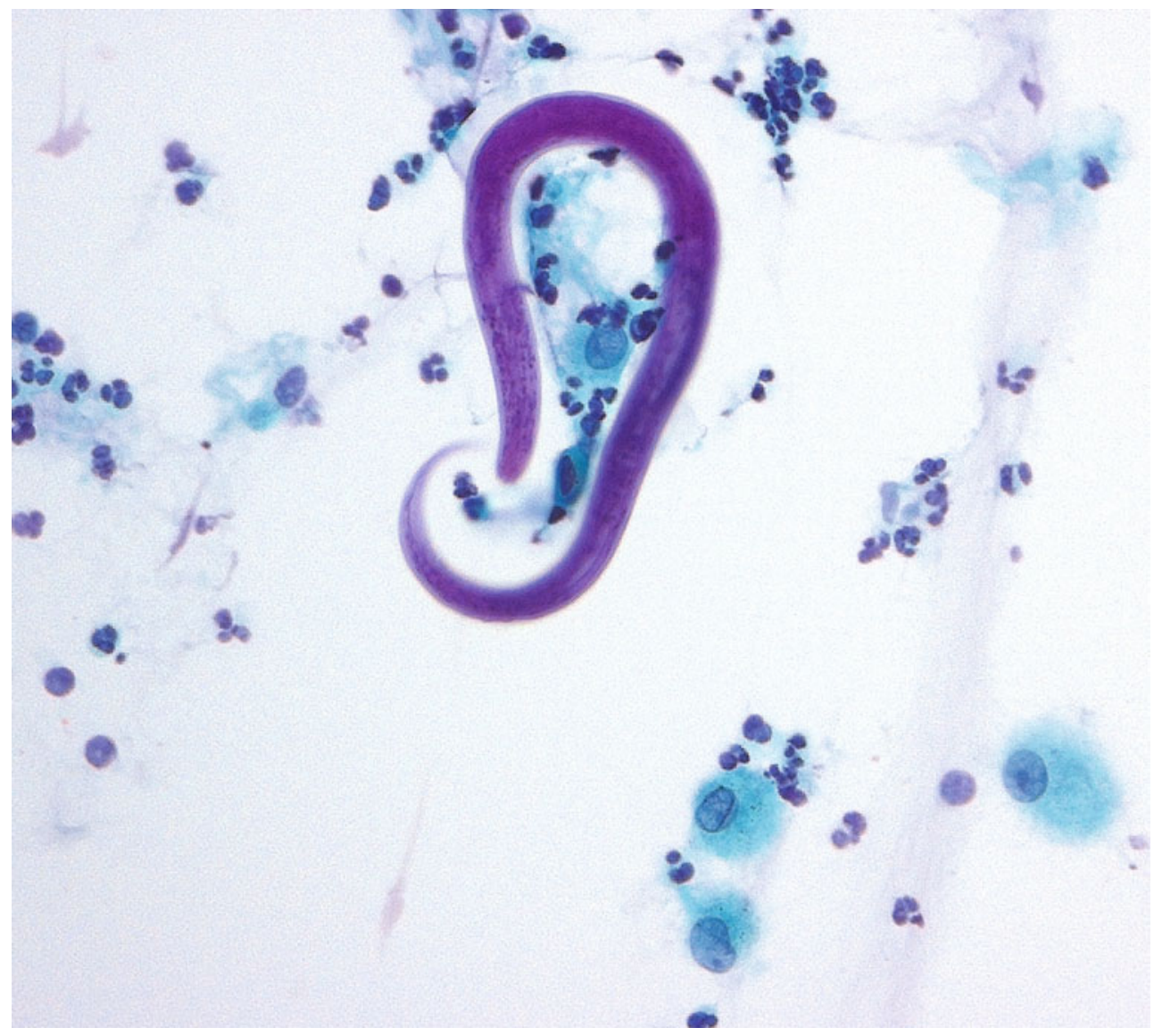

the differential. It has been shown that functional changes in the BAL lymphocytes can be shown by more sophisticated analysis, often before morphological changes are seen histologically. These studies point to the important role of activated, alloreactive, and donor-specific lymphocytes in acute and chronic lung rejection. Investigations are ongoing as to whether proteins and other soluble components of BAL fluid may provide additional information regarding the immunological processes after lung transplantation and whether their levels may give important prognostic or management information.

\section{Pediatric Practice}

Children can suffer from many of the infective and noninfective diseases described above, and as a rule, the cytological appearance is no different from the adult setting. Most of the more specific pediatric lung conditions are diagnosed on clinical and radiological grounds. Cytology may be useful however for picking up some of the rarer infections, aspiration, idiopathic pulmonary hemosiderosis, chronic granulomatous disease of childhood, acute chest syndrome in sickle cell disease, alveolar proteinosis, sarcoid, and Langerhans cell histiocytosis (LCH). A Langerhans cell count of $<1 \%$ is normal in a BAL, but a count of $>5 \%$ is reported to be diagnostic of $\mathrm{LCH}$. Immunohistochemistry and flow cytometry can often be helpful here using antibodies to CD1a, S100, and langerin. The use of special stains can obviously be useful in the childhood disease with oil red $\mathrm{O}$ for fat-laden macrophages. This is used to highlight fat globules within alveolar macrophages - a marker of aspiration-induced pulmonary abnormalities and cough (Fig. 3.32). Perl's stain can be useful for hemosiderosis and PAS for alveolar proteinosis. Electron microscopy might also be helpful in alveolar proteinosis.

Tumors obviously do occur, albeit rarely, in children but pleuropulmonary blastoma (Askins tumor) and metastatic involvement of the lungs by Wilms tumor, Ewing's sarcoma, hepatoblastoma and other primitive tumors will often require clinical input and further more sophisticated studies on FNA or biopsy material to confirm the diagnosis.

\section{Tumor-like Lesions}

\section{Extramedullary Hematopoiesis}

Extramedullary hematopoiesis (EMH) can present as a mass in the lung or pleura, most commonly as a manifestation of 
Fig. 3.32 A fat-laden macrophage stained with oil red $\mathrm{O}$

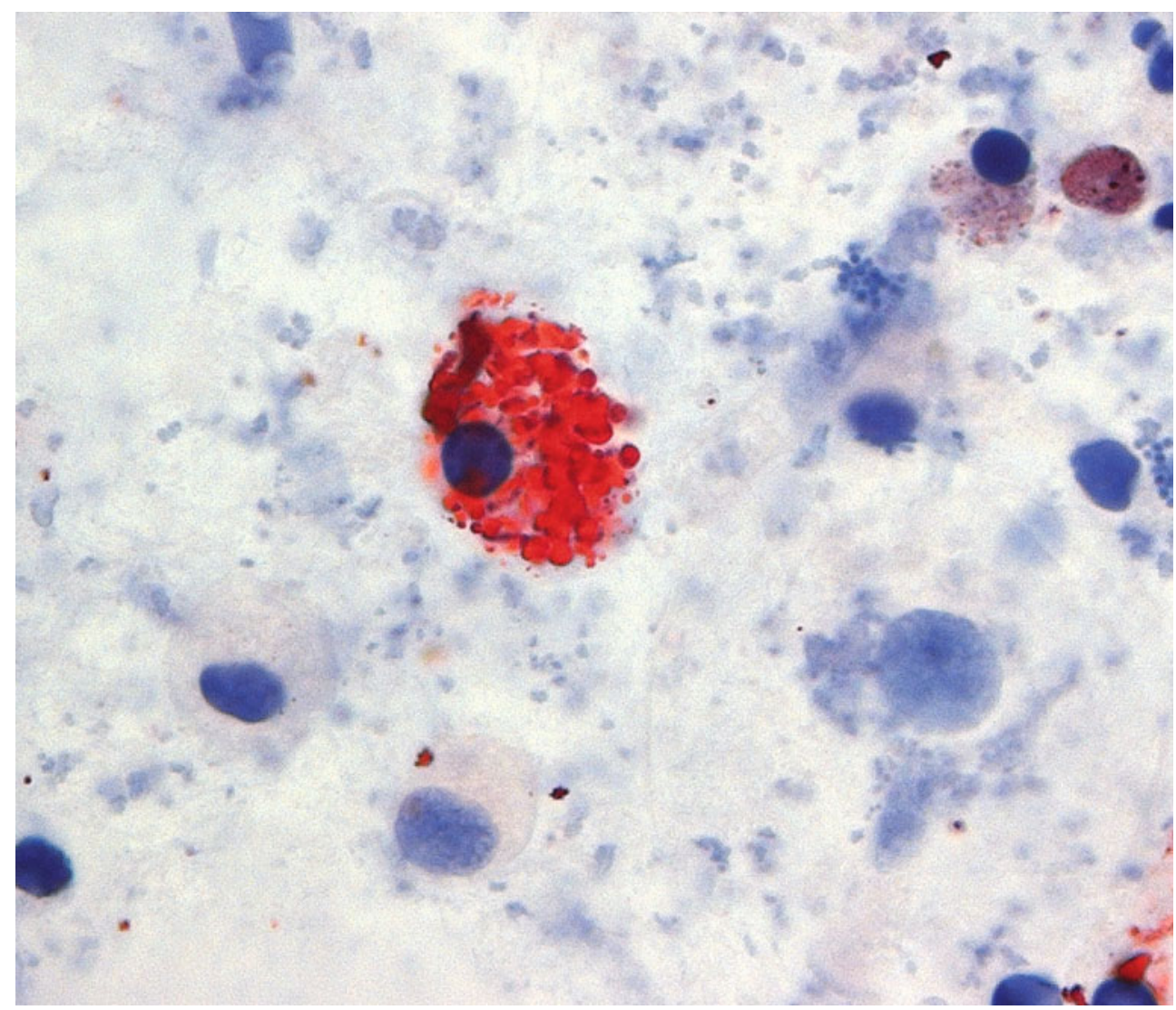

marrow dysfunction in patients with a hemoglobinopathy, hematological neoplasia (especially myelofibrosis), or bone marrow replacement by metastatic cancer. It has also been described after anticoagulant use. Typical blast cells of various lineages can be identified on FNA material or within serous effusions, and it is usually the megakaryocytes that on the one hand alarm the cytologist and on the other reveal the true nature of the lesion.

\section{Endometriosis}

Endometriosis in the lung or pleura is very uncommon, but the diagnosis may occasionally be made on FNA with bland glandular epithelial cells and spindle cells of the stroma accompanied by conspicuous hemosiderin-laden macrophages.

\section{Inflammatory Myofibroblastic Tumor}

Inflammatory myofibroblastic tumor (IMFT; previously known as inflammatory pseudotumor) shows mixed inflammatory cells, foamy histiocytes, plasma cells, and spindle cells on bronchial brushings and on FNA. It typically presents in young adults as a radiological mass that develops following a respiratory tract infection. The presence of xanthoma cells, plump fibroblasts, and some giant cells may lead the unwary to make a diagnosis of malignancy. This may not be too disastrous as the lesion may well need resection surgery anyway as, although usually benign, rare examples behave in a locally aggressive manner.

\section{Amyloidosis}

Amyloidosis of the lung has been described in bronchial brush and FNA samples of pulmonary material. Typically there are aggregates of uniform eosinophilic material which turn out to be Congo red positive and show apple-green birefringence. Clinically, one needs to determine if the case represents primary localized (the commonest form in the lung), secondary, or systemic amyloid.

\section{Malakoplakia}

Malakoplakia can occur in the lung although it is much more frequently observed in the urinary tract or gut. It has the same features as found at these sites, but Rhodococcus equi has been isolated in thoracic material in AIDS patients. The lesions often cavitate in the lung and are composed of granular vacuolated histiocytes and the classical von Hansemann 
cells with their inclusions (Michaelis-Gutmann bodies). The latter are intracellular structures, 3-20 $\mu \mathrm{m}$ in diameter, that are typically positive with PAS, Brown and Brenn, acid-fast, and GMS stains. They contain iron and calcium and may also be identified with Perls and von Kossa stains. It may be possible to identify the diagnostic cells in brush and FNA samples, and one may see bacteria in Giemsa but not on the Papanicolaou stain. Ultrastructurally, one may identify the causative bacteria within phagolysosomes. The differential diagnosis is with lipoid pneumonia, fungal infection, atypical mycobacterial infection, inflammatory myofibroblastic tumor, and Erdheim-Chester disease. The latter is a nonLangerhans type of histiocytosis that requires clinical correlation and histological confirmation for diagnosis.

\section{Classification of Tumors}

There is a wide range of histological types of primary lung tumors. These types are based upon their histological features, and therefore although one might be able to predict the final classification of a lung tumor on cytology, histological examination may reveal something rather different. However, the cytological appearance of most, if not all, types of lung cancer have been described, and cytology is now accepted as a means of typing the majority tumors. There are many sources which outline the varied forms of lung cancer, and lung tumors in general, but most units refer to the WHO classification which was most recently updated in 2004.

Cytology is a reliable way of making a diagnosis of lung cancer, but as with any test, there is a risk of overcalling and undercalling. Sensitivity depends on the technique and varies between studies and the site of the tumor. Sputum sensitivity overall is $60-90 \%$ with three samples, and bronchoscopic sample sensitivity overall is $48 \%$ for washings and $52 \%$ for brushings. The false positive rate is quoted to be between 0 and $2 \%$. Sputum cytology and bronchoscopic material however provide a correct diagnosis more frequently when the tumor is central rather than peripheral. For the former, sputum cytology has a sensitivity of 70-85\%, and bronchial wash and brush are diagnostic in around 80-90\% of cases. For comparison, endobronchial biopsy shows $90 \%$ sensitivity if the lesion is central. All endobronchial cytology samples have a specificity of approximately $99 \%$. Sputum cytology has a sensitivity of 50-60\% if the lesion is peripheral, and sensitivity for peripheral lesions falls to $70-80 \%$ with washings and brushings. Transthoracic FNA has a sensitivity of $90-96 \%$ with a low false positive rate $(0.8 \%)$. It is clear from many audits that the specificity of positive cytology for tumor type groupings is very accurate with $98 \%$ accuracy for small cell versus non-small cell carcinoma. Occasionally, it may be difficult to type the tumor, and in this situation, it is important to correlate cytol- ogy with histology. Some prefer to do this before issuing the final report as this may be preferable to giving conflicting or confusing clinical messages.

A range of well-recognized and important pitfalls can occur when reporting respiratory tract cytology, and every pathologist who regularly reports such cases will remember at least one example of an error they have made when they were "sure" they were looking at cancer cells. Florid inflammatory changes, granulomatous disease, necrotic infections or infarcts, postradiation alterations, and cavitating lesions with secondary changes in the lining epithelium have all been mistaken for malignancy, even by experienced cytologists. Some of the more specific mimics are discussed below with the various types of lung cancer. As with any sample, one must be confident beyond doubt that malignancy is expected before issuing report with this conclusion, but even then there will be a definite (but small) risk of misdiagnosis. Many pathologists would probably resort to a "suspicious" type of report if they are not absolutely sure.

It is now well established that many lung cancers arise from early precancerous lesions, and squamous cell carcinoma and adenocarcinoma both share this characteristic. In the case of squamous cell carcinoma, this sequence follows a change from metaplasia to dysplasia to carcinoma in situ to conventional invasive squamous cell carcinoma, and it is becoming clear that similar principles apply to glandular tumors, developing from atypical pneumocyte (adenomatous) hyperplasia to adenocarcinoma.

\section{Squamous Cell Carcinoma}

Squamous cell carcinomas tend to be central tumors, and while tumor cells usually look the same irrespective of the method of collection, the samples may occasionally appear different depending on the specimen. For example, sputum may contain a lot of necrotic material with only a few viable tumor cells, while brush samples usually present viable tumor cells well. There may be clumps of tumor cells in wash and lavage specimens which can obscure individual cell detail. FNA samples may also occasionally produce necrotic material only. It should be remembered that just as squamous cell carcinomas are not uniform histologically, the cytological appearance can vary depending on whether the tumor is of conventional type or an alternative such as welldifferentiated papillary squamous cell carcinoma, a small cell type of squamous cell carcinoma, a basaloid type, or a clear cell variant.

All types may shed similar bizarre-shaped tumor cells with angulation, abnormal keratinization, cell dissociation, tumor diathesis, anucleate ghost cells, and keratin debris (Figs. 3.33, 3.34, 3.35, 3.36, 3.37, 3.38, 3.39, 3.40, 3.41, and 3.42). There may be spindle-shaped cells, tadpole 
Fig.3.33 Misshapen

keratinized cancer cells from a squamous cell carcinoma

(sputum). Occasionally they are anucleate
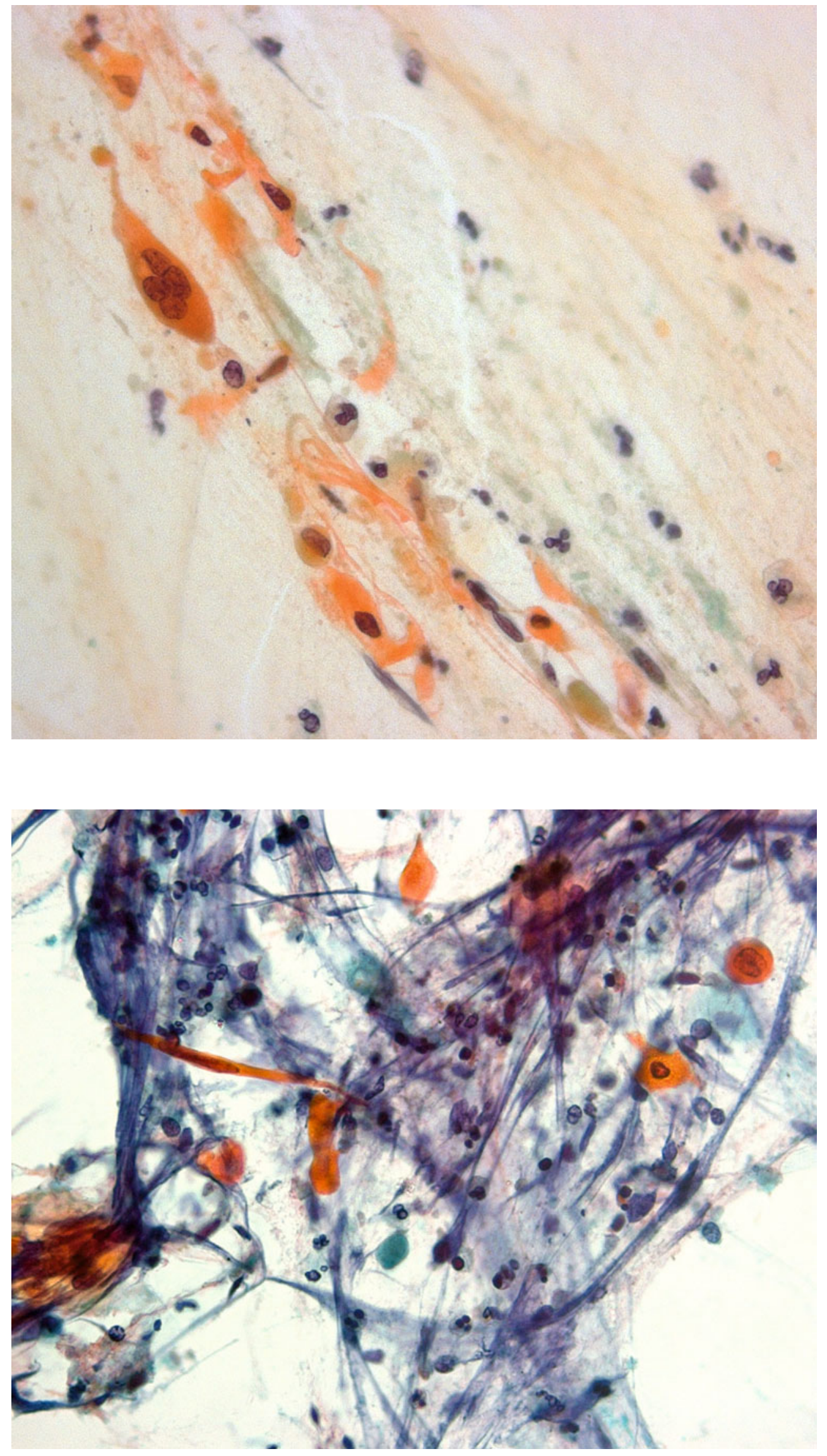

Fig. 3.34 Elongated fiber-type cells are often found in squamous cell carcinoma (bronchial washings) 
Fig. 3.35 Bizarre elongated cells of a squamous cells carcinoma (washings)
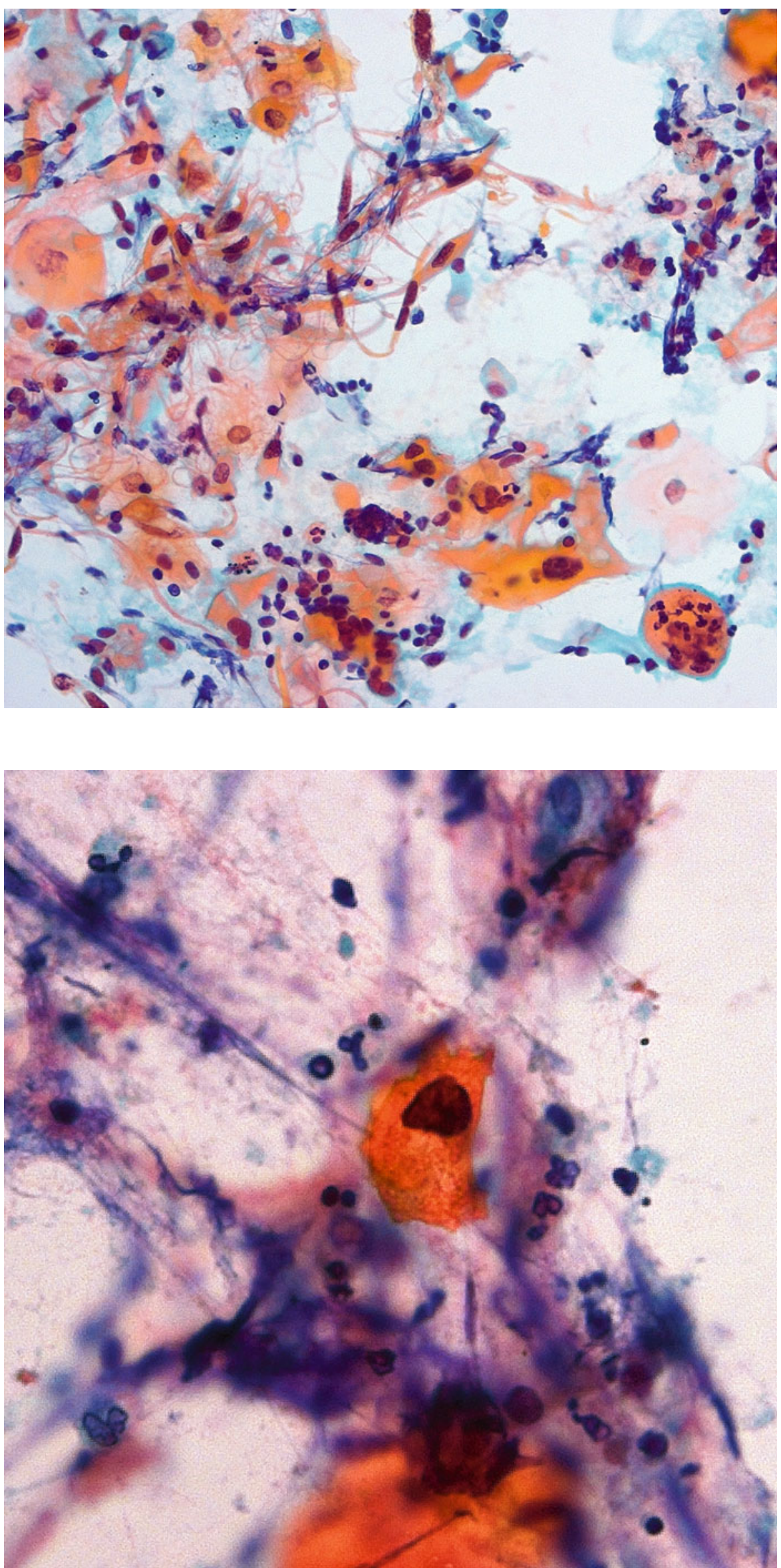

Fig. 3.36 Squamous carcinoma cells often have a very dark nucleus and "beaten out" cytoplasm 
Fig. 3.37 Squamous cell carcinoma in bronchial brushings is characterized by keratinizing tumor cells
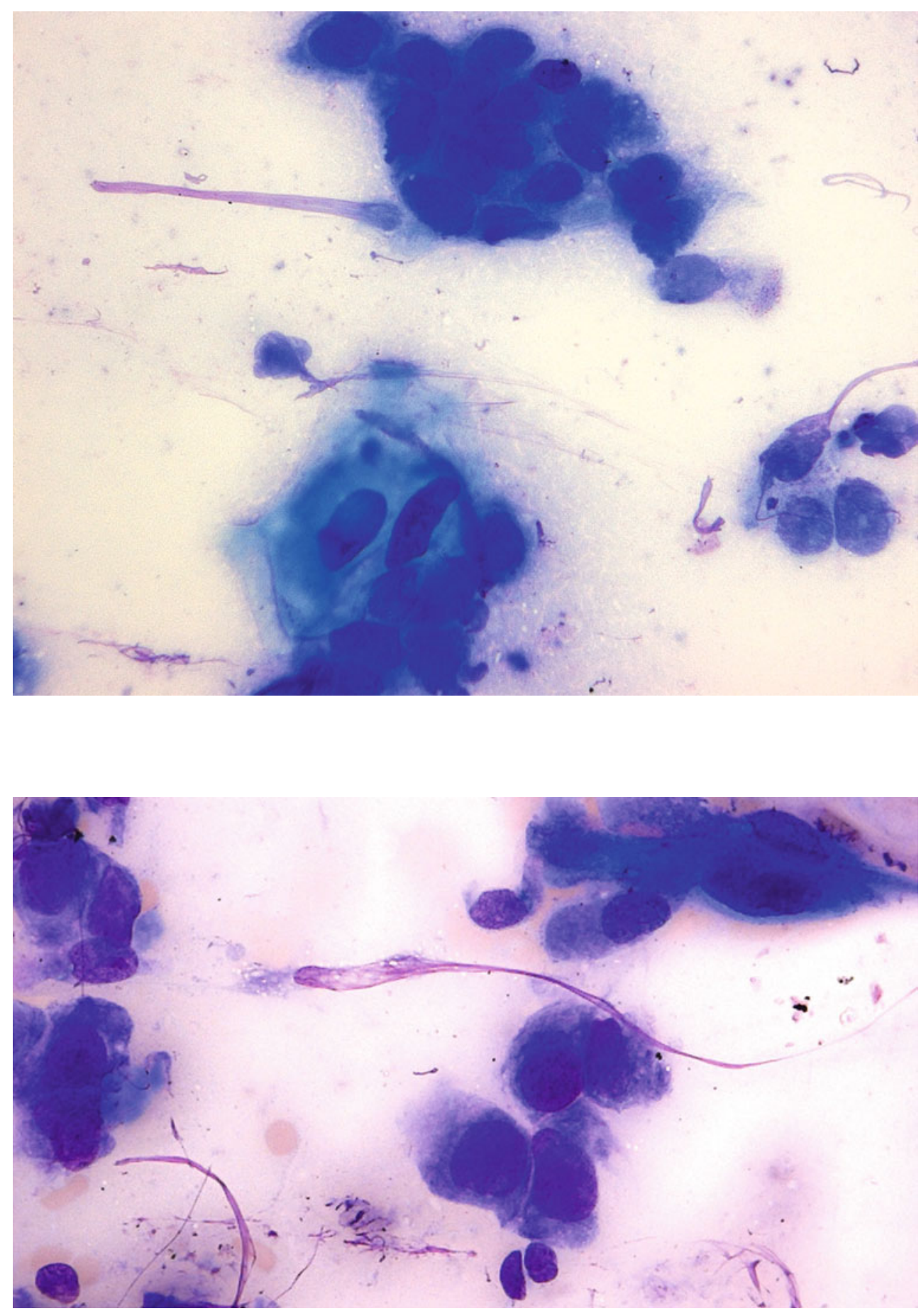

Fig. 3.38 The diagnosis of squamous cell carcinoma may be difficult when there are isolated tumor cells surrounded by respiratory epithelial cells (bronchial brush) 
Fig. 3.39 This is another squamous cell carcinoma of the lung diagnosed on only a few tumor cells (brush sample)
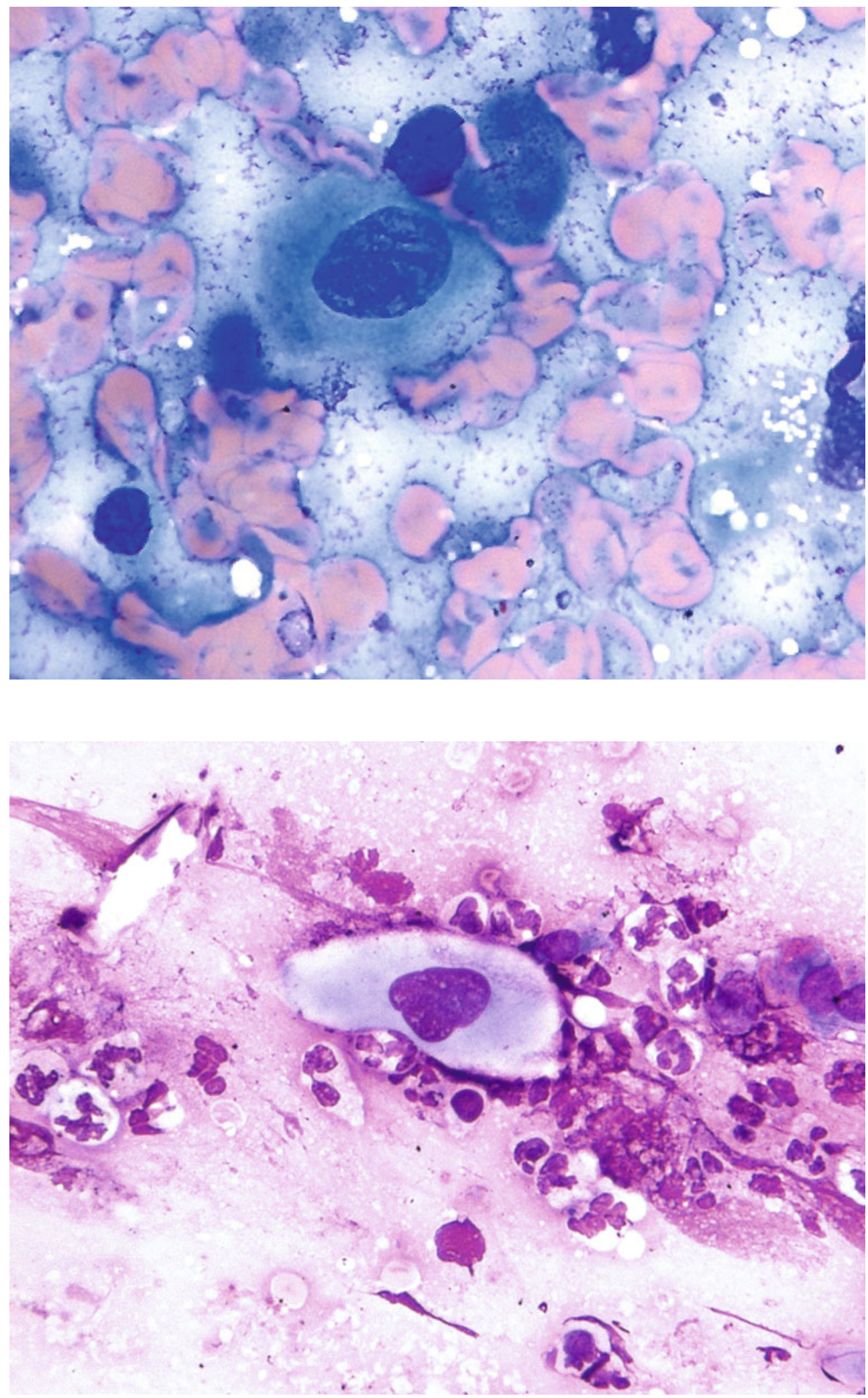

Fig. 3.40 Squamous cell carcinomas are often necrotic, and the tumor cells may be surrounded by mixed inflammatory cells 
Fig. 3.41 Squamous cell carcinoma of the lung (percutaneous fine needle aspiration sample)

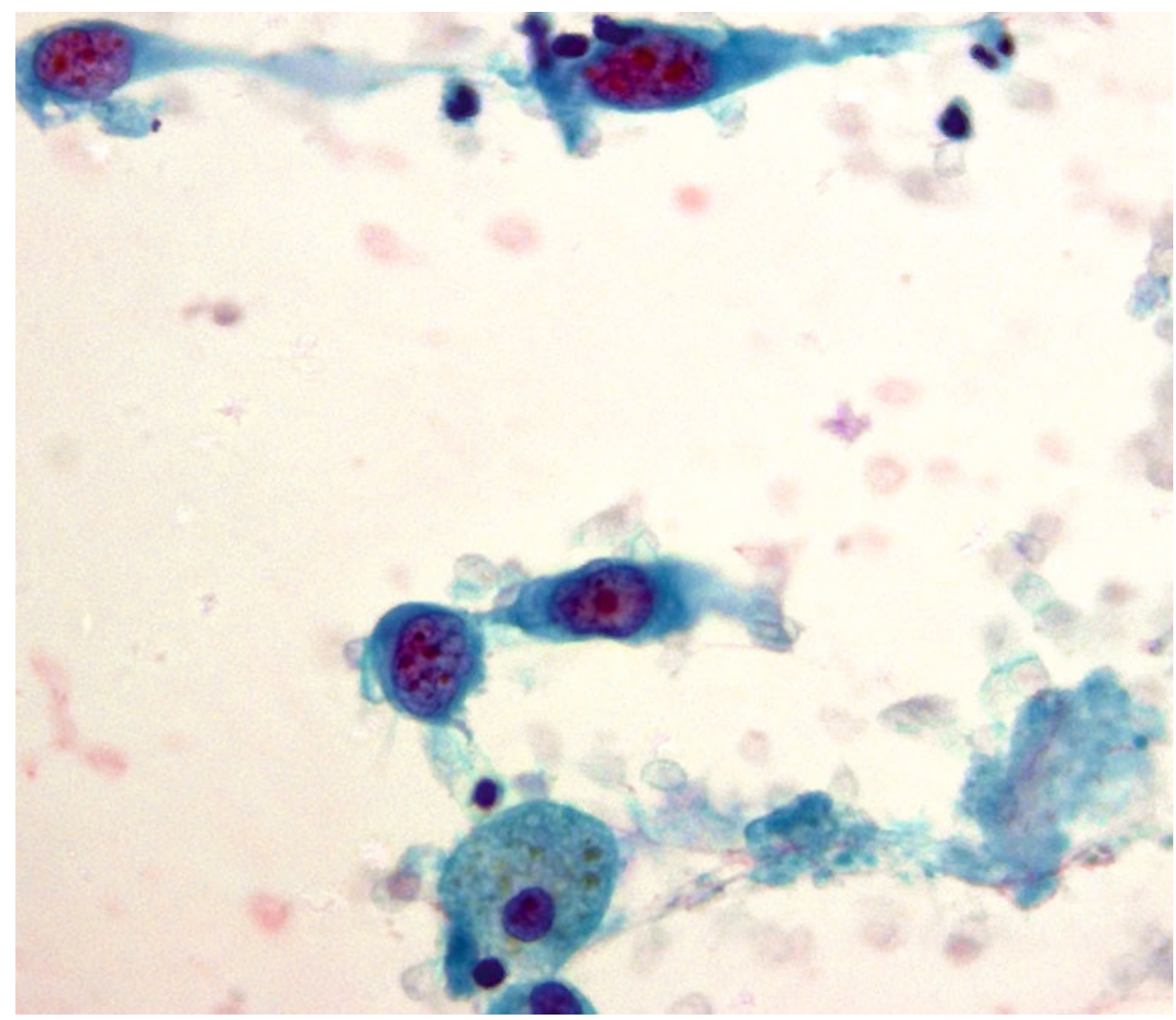

Fig. 3.42 An isolated tumor cell is identified among inflammatory cells and necrotic debris in this squamous cell carcinoma (FNA)

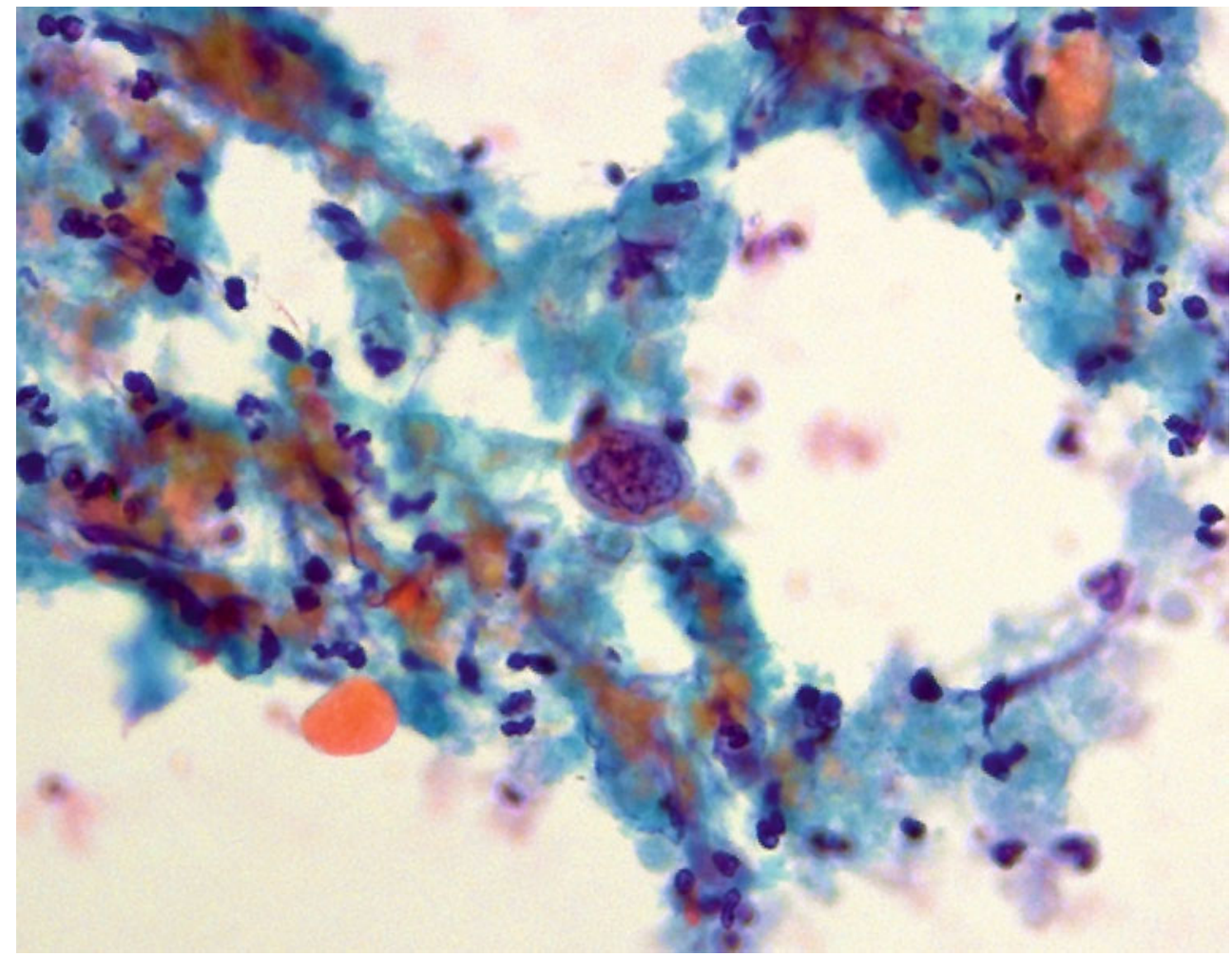


cells, or caudate cells, and there may be cell engulfment/ cannibalism. The cells themselves often have large or pyknotic, hyperchromatic nuclei, "ink" black nuclei, and irregular coarse chromatin patterns, and although nucleoli are usually not large, if they are present they tend to indicate invasive disease. Ultrastructurally, the typical tonofibrils and desmosomes of squamous cells are generally apparent. Immunohistochemistry may occasionally be required on fluid samples or cell blocks. Antibodies frequently used to support a squamous type of tumor include CK5/6, CK14, and p63. p40 may become useful in the future.

There are many different difficulties and traps that need to be appreciated when attempting to make a diagnosis of invasive squamous cell carcinoma of the lung on cytology. Atypical squamous metaplasia (squamous cell dysplasia) will not provoke the same aggressive management route as a squamous cell carcinoma and should not be over interpreted. These lesions tend to have a clean background and are often single celled and not as bizarre as true invasive tumors. Nucleolar prominence is said to be good indicator of invasive malignancy. Occasionally, one may have difficulty in differentiating genuine squamous cancer cells from oral cavity contaminants (especially vegetable cells), oral lesions such as parakeratosis, tracheostomy-related atypia, the so-called Pap cells of laryngitis which have very dark nuclei but regular nuclear outlines, degenerate columnar cells, and epithelial cell atypia associated with severe infections that cavitate, chronic bronchitis, tuberculosis, previous radiotherapy or chemotherapy, bronchiectasis, a mycetoma, viral infections such as HSV and changes associated with infarcts/pulmonary emboli. Sometimes there may be evident squamous metaplasia or dysplasia overlying a different type of tumor, and a mistaken report leads to inappropriate management decisions. In FNA samples, it is also possible to misinterpret a granulomatous picture for squamous cell carcinoma. With reparative changes, there is often a lack of single cells, the cells have abundant cytoplasm, and there is a low nuclear-to-cytoplasmic ratio. Of course, all of these changes may be present as well as the tumor, and this adds a further dimension to the diagnostic difficulty.

It should always be remembered that cells originating from any of the different types of aerodigestive tumor that invade locally such as those developing in the mouth, pharynx, larynx, and esophagus can also be picked up during bronchial sampling. Also, necrotic tumor cells of other types may take on a pseudokeratinized or "squamoid" appearance when they degenerate. This is true for many tumor types and is recognized as a common feature of malignant mesothelioma which should not be mistaken for metastatic squamous cell carcinoma in a serous fluid sample.

\section{Adenocarcinoma}

Adenocarcinoma of the lung is also a heterogeneous group of tumors morphologically, and several of the types will have their own unique cytological appearance. The types encountered most commonly include acinar adenocarcinomas and bronchioloalveolar carcinomas, but there are several other variants including papillary, solid with mucin production, micropapillary, and clear cell. Most believe that premalignant glandular lesions cannot be diagnosed on cytology.

By definition, all adenocarcinomas will have a degree of glandular differentiation with or without mucin production or secretory features on electron microscopy. The latter include mucin granules, intracytoplasmic lumina, microvilli, and a surface glycocalyx. They are often peripheral tumors, and so they may not be directly visible on bronchoscopy. The appearance is similar in brushings and washings, but there may be some differences (see below).

Adenocarcinomas tend to shed their cells as aggregates or single cells, sometimes in streaks of mucus. There may be an acinar or papillary arrangement to the cells groups, or they may form round or oval clusters often with smooth outlines and a three-dimensional configuration. The individual cells have eccentric nuclei and conspicuous nucleoli, either small and multiple or large and single (Figs. 3.43, 3.44, 3.45, 3.46, and 3.47). The cytoplasm is usually abundant and pale, or it may be vacuolated. Psammoma bodies may be present. In FNA samples, the arrangement is more frequently monolayered with sheets or rosettes of columnar cells containing round nuclei with prominent nucleoli often within a clean background.

Bronchioloalveolar carcinomas make up around $7 \%$ of adenocarcinomas in the lung, and they can be of mucinous or non-mucinous types. The tumor cells often lie within a clean mucoid background, and if inflammation is obvious, care should be taken before committing to a firm diagnosis of cancer. Their nuclei have powdery chromatin with inclusions and grooves, especially in FNA samples. When the cells are dissociated and single, they may resemble histiocytes (Figs. 3.48 and 3.49). Differentiating histiocytes from dissociated, pale BAC cells can be difficult, but if the cells are particularly numerous, they should be viewed with suspicion. In this situation, it is crucial to correlate the findings with the radiological and clinical context. If this does not clarify the situation, the clinical team may need to repeat the procedure after a course of antibiotic treatment to see if the abnormality resolves or not.

One rare type of pulmonary adenocarcinoma that has caused difficulties to the cytologist is the fetal adenocarcinoma. This may produce an unusual pattern for adenocarcinoma with a more neuroendocrine appearance, combining columnar cells with rounded cells which have little cytoplasm 
Fig. 3.43 Adenocarcinoma of the lung (bronchial washings). Compare the tumor cells on the left with macrophages on the right

Fig. 3.44 Adenocarcinoma cells adjacent to pigment-laden macrophages and with an admixed respiratory epithelial cell
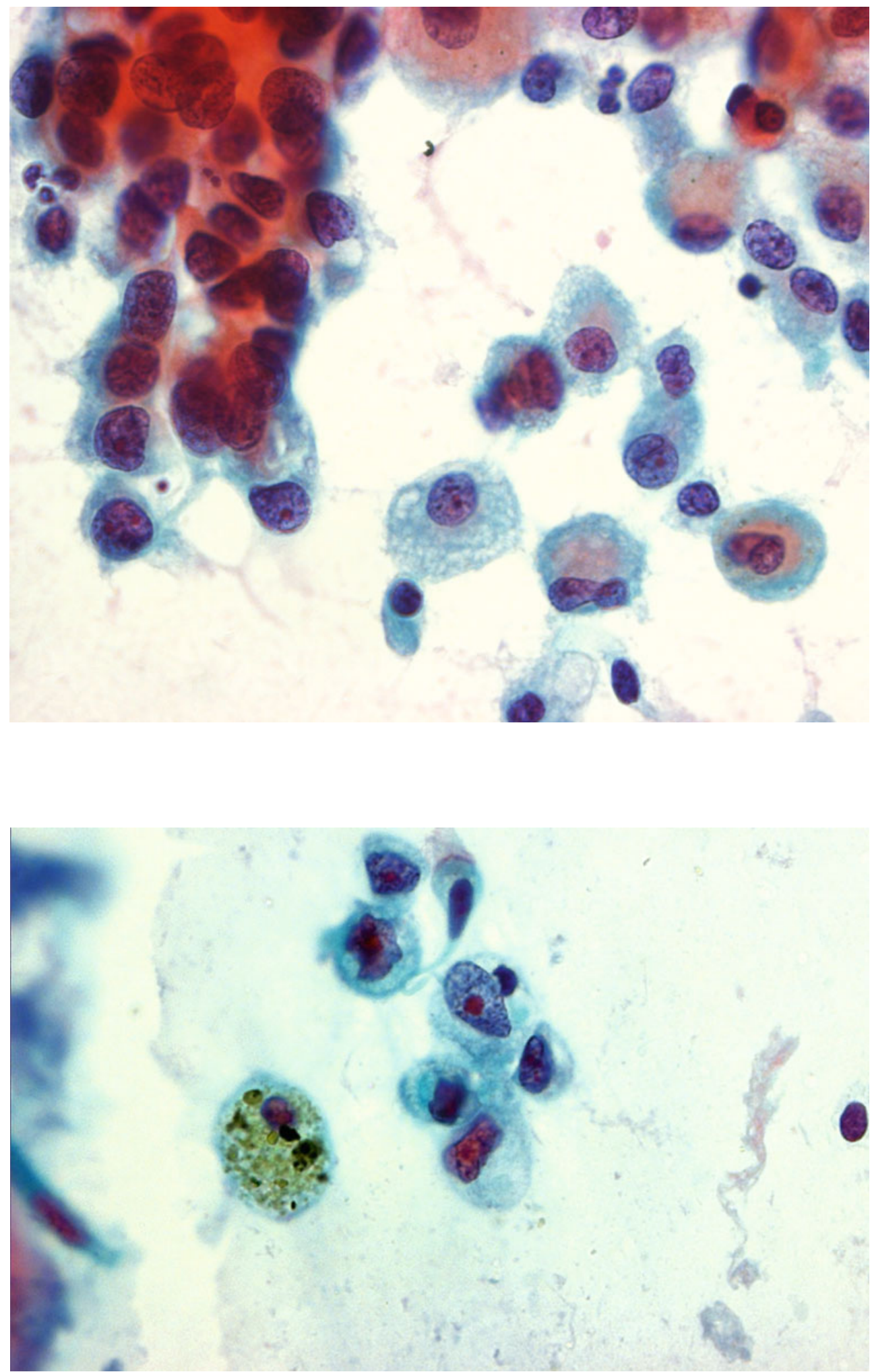
Fig. 3.45 Another

adenocarcinoma of the lung (bronchial washings). Note the prominent nucleoli
Fig.3.46 A group of adenocarcinoma cells with a vague acinar arrangement, little cytoplasm but nucleoli (bronchial brushings)
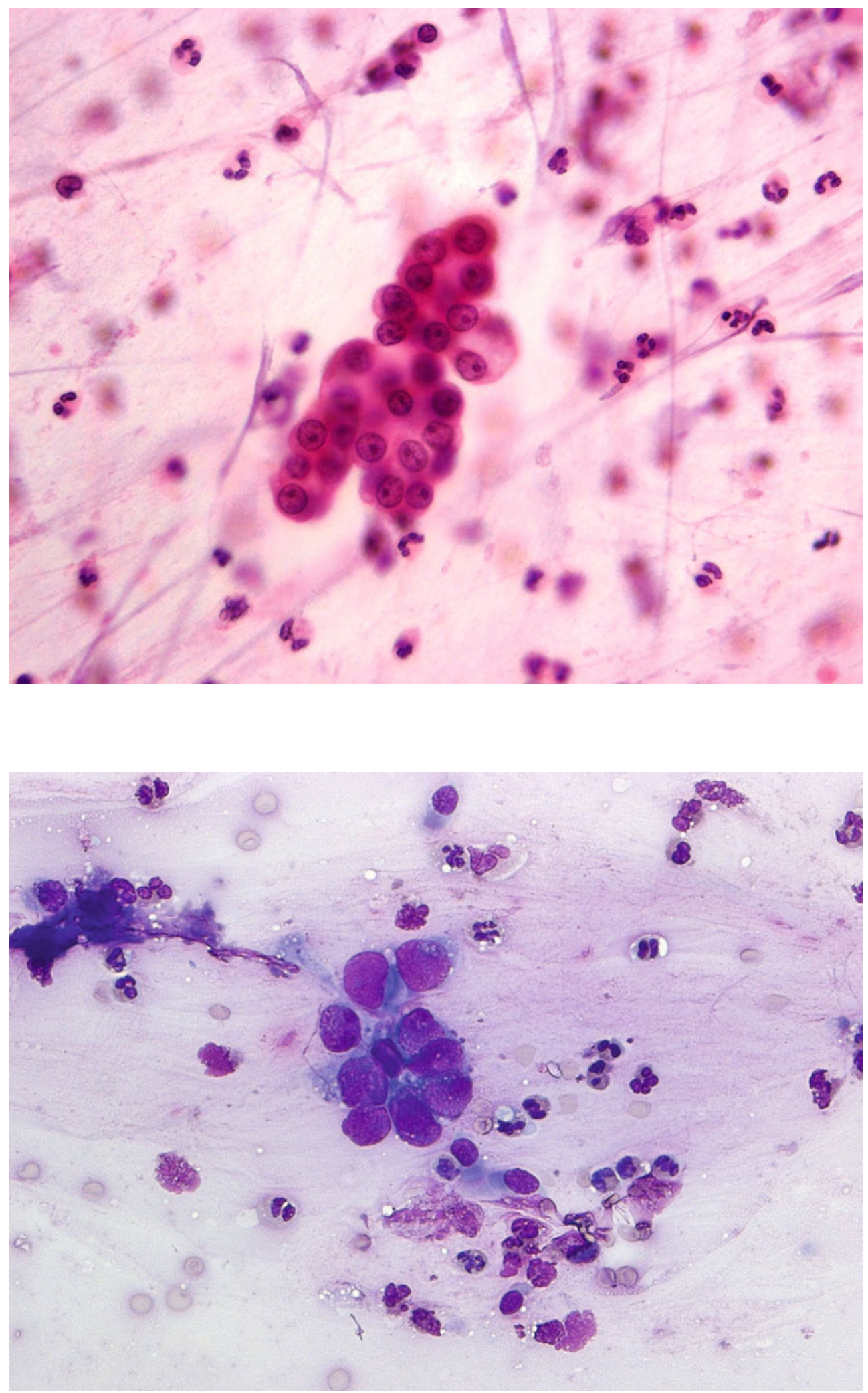
Fig. 3.47 A microbiopsy of adenocarcinoma in this lung mass FNA
Fig. 3.48 Adenocarcinoma cells can be difficult to distinguish from macrophages, especially in washings from a bronchioloalveolar carcinoma
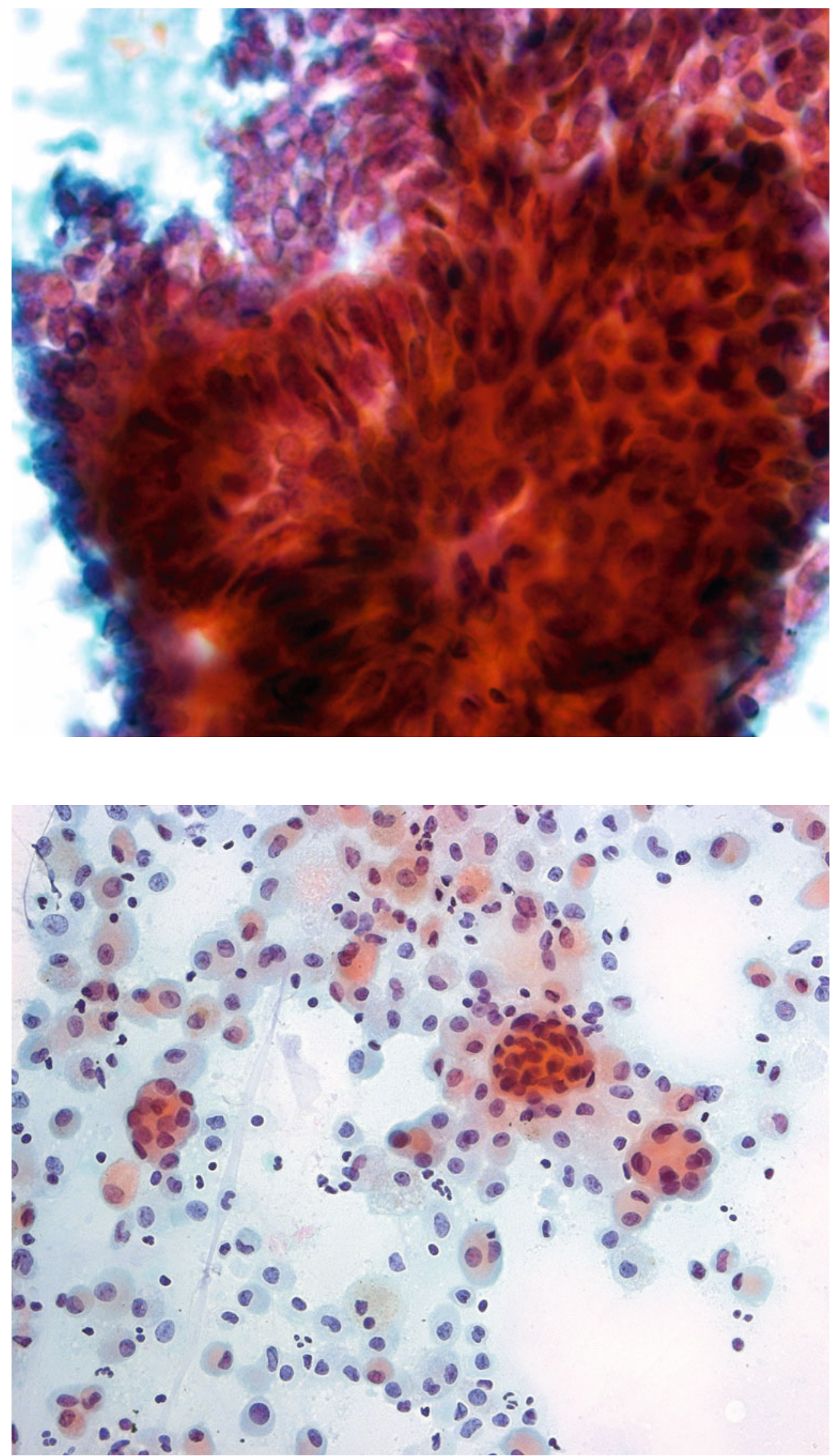
Fig. 3.49 Close inspection of this bronchial wash shows the difference between the tumor cells and macrophages in the bronchioloalveolar carcinoma

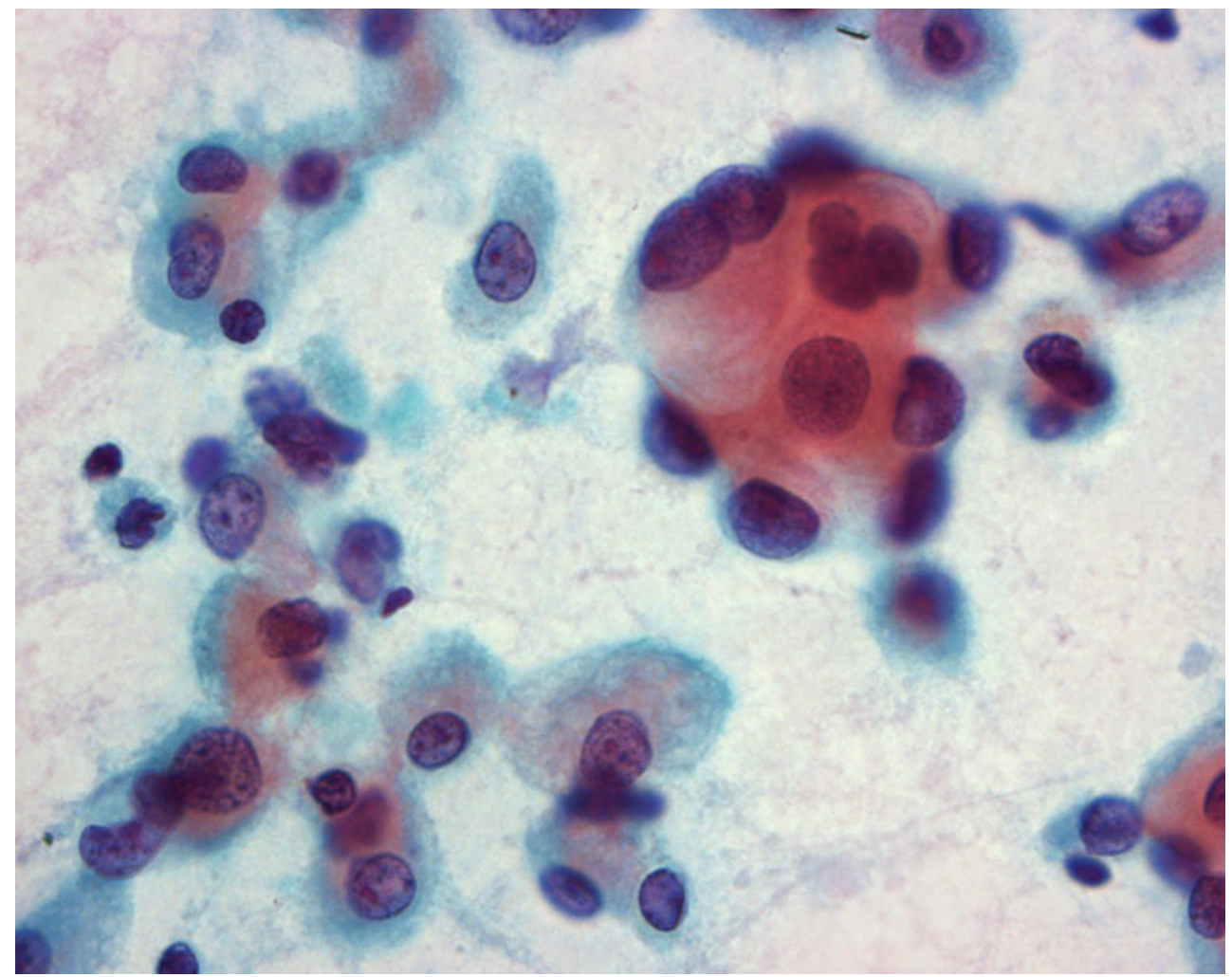

and speckled chromatin. Mucinous, solid, papillary, and other types are rarely diagnosed specifically on cytology.

In any clear-cut adenocarcinoma, one must always reflect on the possibility of a metastatic tumor and sometimes mesothelioma, beforeissuing the finalreport.Immunohistochemistry can be invaluable in this situation. TTF1 and napsin A have become very useful and relatively specific markers for primary lung cancer although must always bear in mind the possibility of a thyroid or renal metastasis and the clinical/ radiological features (a small number of TTF1-positive tumors from other sites are now being described in the literature).

Adenosquamous carcinoma is very difficult to diagnose specifically on cytology, and one generally relies on histology.

Difficulties in the diagnosis of, and mimics of, adenocarcinoma include chronic asthma, acute lung injury, infarcts, pulmonary emboli, viral pneumonitis, type 2 pneumocyte hyperplasia, and tuberculosis. To avoid making a mistake, one should look for cilia, a terminal end bar, the well-defined cell borders typical of type 2 pneumocyte hyperplasia, eosinophils, and of course the clinical context.

\section{Neuroendocrine Tumors}

A range of neuroendocrine lesions are found in the lung, from incidental small tumorlets through a spectrum of classical carcinoid and atypical carcinoid tumors to the most aggressive of the primary lung carcinomas, small cell carcinoma. Tumorlets are not identifiable cytologically, but all of the tumors can be diagnosed on cytology. There is continued debate as to whether carcinoid tumors and small cell carcinomas arise from the same pulmonary neuroendocrine cell. There is good evidence that they do not as they show differing locations and TTF1 staining. There are several types of neuroendocrine cell within the lungs that are part of the APUD system, and these are chromaffin, argentaffin, and/or argyrophil. Kulchitsky cells lie in the central airways between respiratory epithelial cells and goblet cells. Clara cells are located in the peripheral lung parenchyma admixed with the pneumocytes lining the alveoli. Both are characterized by cytoplasmic neurosecretory granules; these are membrane-bound dense-core secretory granules that are between 50 and $500 \mathrm{~nm}$ in diameter. When the cells are not lying individually, they all tend to form organoid structures such as nests, alveoli, festoons, or ribbons. Typically the nucleus contains coarse chromatin which is uniformly dispersed within the nucleus, and nucleoli are undetectable.

The vast majority of carcinoid tumors $(85 \%)$ are found in proximal parts of the lung, and most are submucosal. Therefore, it is very unusual to identify tumor cells in sputum samples. It is possible though to pick up lesional cells in vigorous brushings or FNA specimens. As a rule, the cells are either single or arranged in small acini, but rarely there may be palisading or a trabecular pattern. The individual cells are often plasmacytoid, cuboidal cells which are extremely uniform and well preserved unlike the fragile cells of a small cell carcinoma. The nuclei are round or oval, and 
Fig. 3.50 Small cell carcinoma cells in a sputum sample

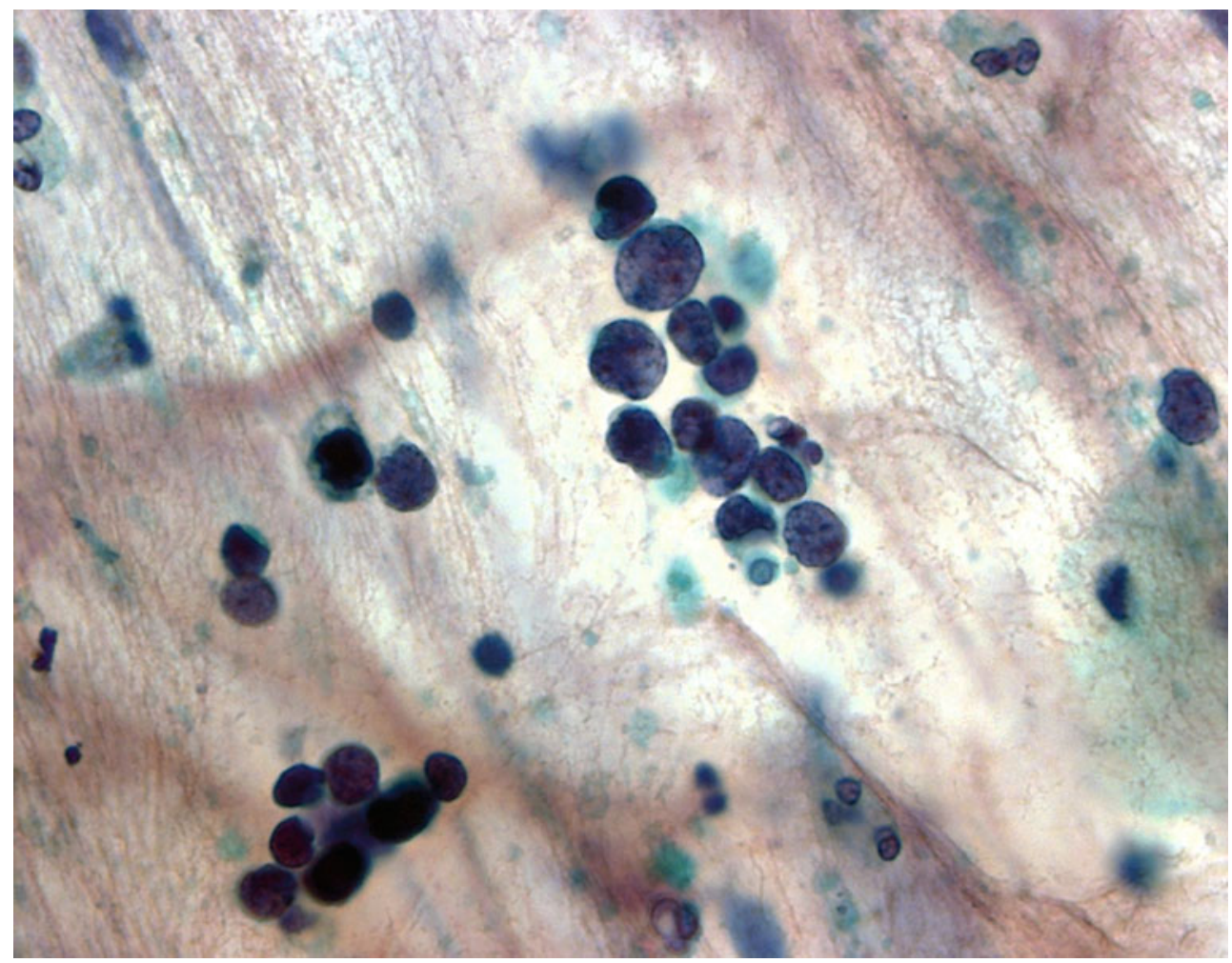

the nuclear content has the characteristic "salt-and-pepper" or stippled pattern of chromatin with inconspicuous nucleoli which typifies these tumors. The nuclear membrane is smooth and regular, but the cell borders are poorly defined. There may be nuclear molding, and very occasional mitoses may be present (see below). Cytoplasm is absent or limited, and often the nuclei are bare. Necrosis is absent. A capillary network may be visible, and in FNA samples, a perivascular arrangement of tumor cells may be appreciated. Atypical carcinoid tumors comprise less than $10 \%$ of pulmonary carcinoids and the diagnostic features of these tumors, namely, areas of necrosis, and a mitotic count between 2 and $10 / 2 \mathrm{~mm}^{2}$ requires histological assessment which cannot be reliably determined on cytology. It may be difficult to differentiate atypical carcinoid tumors from either the classical variant or small cell carcinoma. Carcinoid tumors in general may show similar features to sclerosing hemangiomas (see later). Immunohistochemistry may be useful in some cases utilizing chromogranin A, TTF1, and Ki67. Carcinoid tumors are positive for chromogranin A and a minority express TTF1. Sclerosing hemangiomas express TTF1 but not chromogranin. Ki67 should reveal a low proliferation fraction although this can be difficult to assess on cytological material.

Large cell neuroendocrine carcinomas also generally require histological assessment for confident diagnosis as the cytological features overlap with small cell carcinoma and large cell carcinomas, either undifferentiated or showing neuroendocrine differentiation. The cytological features of large cell neuroendocrine carcinomas have not been well described.

Small cell carcinomas usually arise centrally (hilar) and may be associated with paraneoplastic syndromes. Around $10 \%$ are combined with a form of non-small cell carcinoma. The cells may be difficult to identify confidently on cytology. There are often degenerate tumor cells lying in streaks of mucus. The cells are small (to medium sized) and look like grains of wheat (oat cells). At first sight, the cells look rounded, but on closer inspection, the nuclei are irregular with pointed edges, and degenerative changes are common. They have scant or no cytoplasm, tiny or inconspicuous nucleoli, and indistinct cell borders and show intimate intercellular relationships with nuclear molding. This close intimacy leads to elongated groups of cells forming piles of pennies or rounded groups showing onion skinning. There is often a tumor diathesis, with karhyorrhexis, necrosis and mitoses. Light blue inclusions may be present closely applied to the edge of nuclei often within a nuclear indentation. Apoptosis is commonly present, and this can be helpful as it is not seen in most small celled pulmonary lymphomas.

All of these features are better appreciated in brush and FNA samples rather than sputum, and there may be complications to the appearance in sputum with larger nuclei, more open chromatin, small nucleoli, and extensive cell smearing/crushing (Figs. 3.50, 3.51, 3.52, 3.53, 3.54, and 3.55 ). In washings, the tumor cells may form balls, and molding may not be so apparent. Immunocytochemistry for CD56, 
Fig. 3.51 Small cell carcinoma cells can be hidden by accompanying inflammatory cells when the cells are dispersed
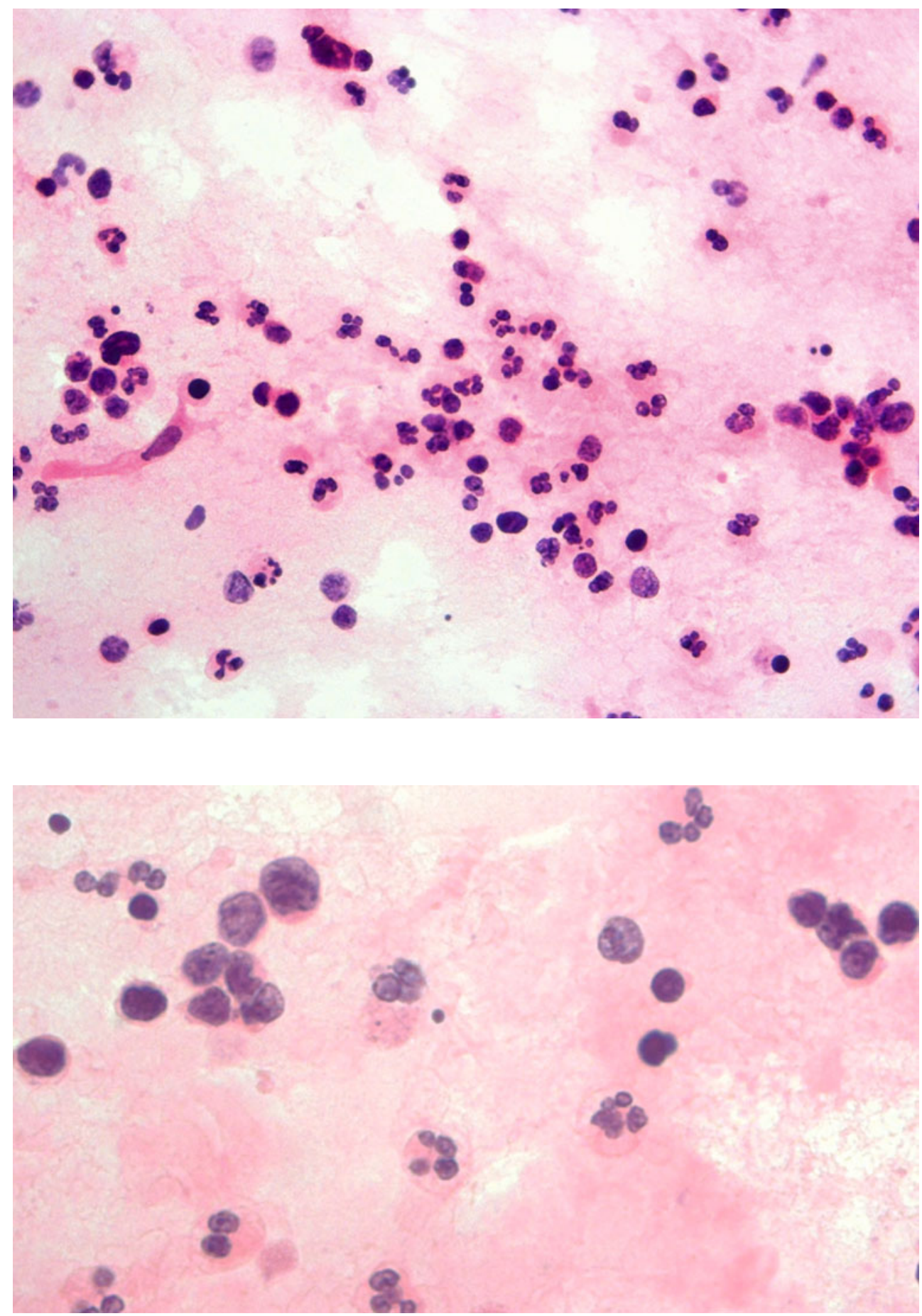

Fig. 3.52 Closer inspection reveals the small cell carcinoma cells
TTF1, and synaptophysin may be helpful as the majority of small cell carcinomas are positive for CD56 and TTF1 with around $50 \%$ positive for synaptophysin.

The differential diagnosis of small cells in cytology samples is frequently with lymphocytes - either as a component of chronic inflammation or lymphoma. Small cell carcinoma cells tend to aggregate more than lymphoid cells although the latter are more often grouped than generally appreciated. Small cell carcinoma cells are more frequently streaked and have pointed ends to their nuclei. Other potential difficulties include the obscuring of tumor cells within inspissated mucus in sputum samples, background atypical squamous cells which divert attention toward a concern for squamous cell carcinoma, and certain metastatic adenocarcinomas that are composed of small cells, especially lobular carcinoma of the breast and prostate carcinoma. These frequently show single-cell arrangement or "Indian" filing, stripped nuclei, and pointed nuclear edges. Other pitfalls include misinterpreting air-dried 
Fig. 3.53 Small cell carcinoma cells are usually closely applied to each other and show characteristic molding

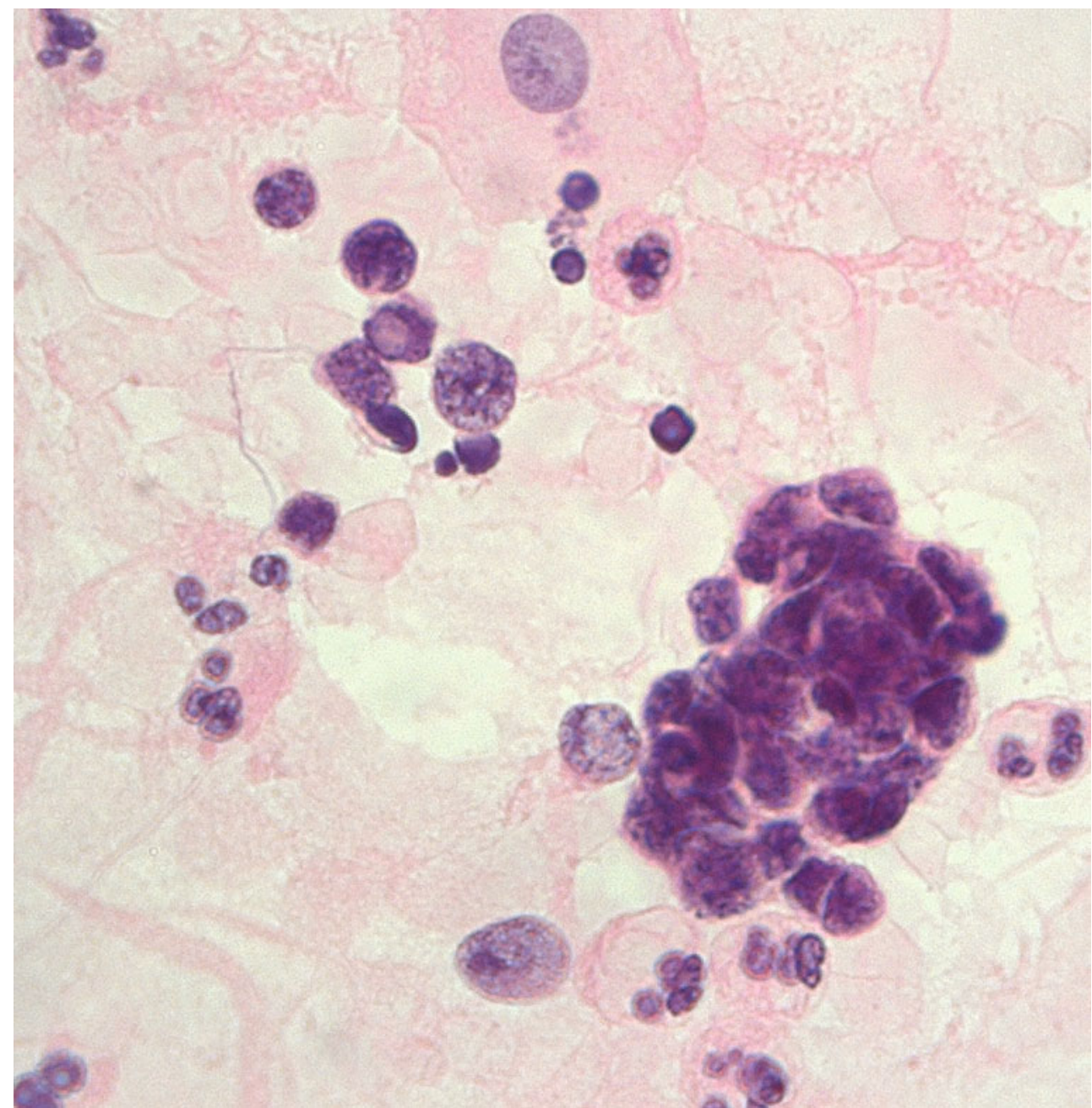

tumor cells as large cell carcinomas, overcalling clusters of stripped normal epithelial cell nuclei or reserve cell groups, and not fully appreciating the occurrence of combined tumors or the frequent presence of small cell carcinoma with overlying dysplasia or atypia in surface squamous epithelium.

\section{Large Cell Undifferentiated Carcinoma}

By light microscopy, this is a high-grade tumor composed of large neoplastic cells which, by definition, show no differentiation, in particular no features of squamous or glandular differentiation (although some features may be visible by electron microscopy). A robust diagnosis is only made after histological assessment. Cells will look the same in sputum, washings, brushings, and FNA. The cells are large with welldefined cell borders. They may be single, syncytial or multinucleate, and giant in appearance. The cell groups are disorganized. Individual cells are large with pleomorphic nuclei, variable amounts of cytoplasm, and a high nuclearto-cytoplasmic ratio (Figs. 3.56, 3.57, 3.58, and 3.59). Curiously, they often have intracytoplasmic neutrophils.

\section{Other Primary Carcinomas}

Other specific types of lung carcinoma are recognized, but as they are less common and often only diagnosable on histology, the cytological features are not well defined. Nevertheless there are individual or small series cytological descriptions of basaloid carcinoma, lymphoepithelial carcinoma, clear cell carcinoma, large cell carcinoma with rhabdoid phenotype, and others. The cytological appearance of such tumors may be misinterpreted as necrotic squamous cell carcinoma, a drug or chemotherapeutic effect, radiotherapy-induced changes, a viral infection such as herpes, or even metastatic tumor.

\section{Sarcomatoid Carcinomas}

These form a group of primary malignant tumors which include pleomorphic carcinoma, carcinosarcoma, blastomas, and others. They all share the same individual cell appearance which frequently includes spindle-shaped cells, often with admixed giant cells. Cytology plays a limited role in their specific diagnosis as it is difficult to categorize these 
Fig. 3.54 There is often much blood in small cell carcinoma specimens and one needs to search for the tumor cells. Note the speckled chromatin and nuclear molding
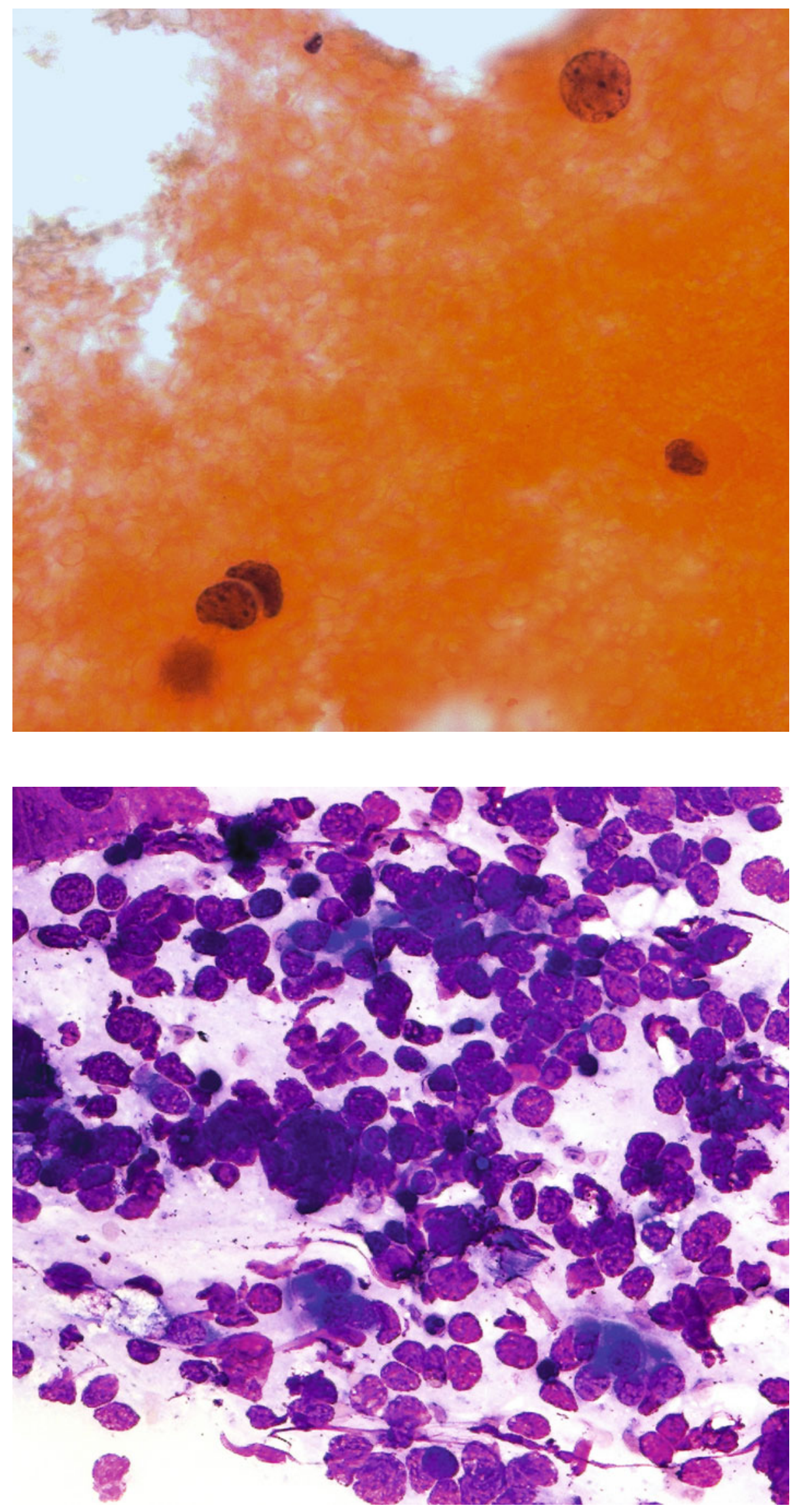

Fig. 3.55 Small cell carcinoma in bronchial brushings. Note the typical small cell features (molding and "salt-and-pepper" chromatin) and occasional admixed respiratory epithelial cells 
Fig. 3.56 Another small cell carcinoma with scanty cytoplasm and nuclear molding (EBUS specimen from subcarinal lymph nodes)
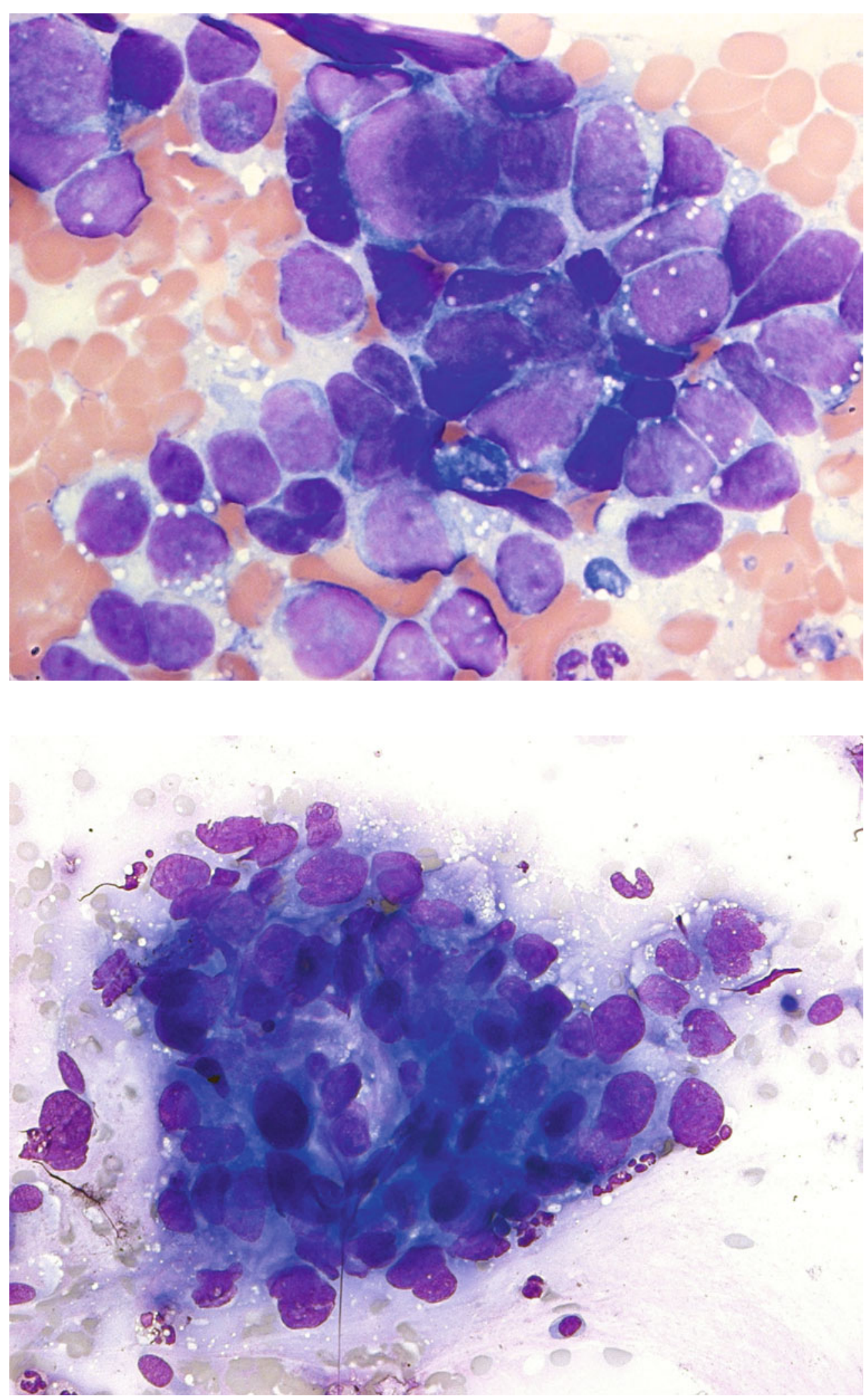

?
Fig. 3.57 Sometimes it is difficult to be certain what type of carcinoma one is dealing with although the cytology is clearly malignant (brush specimen)

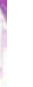


Fig. 3.58 Although there are squamoid features here, this may be better reported as a non-small cell or large cell carcinoma and correlated with the washings and biopsy findings
Fig. 3.59 The cytology of this lung mass aspirate clearly indicates a malignant tumor, but typing beyond non-small cell carcinoma may be problematic
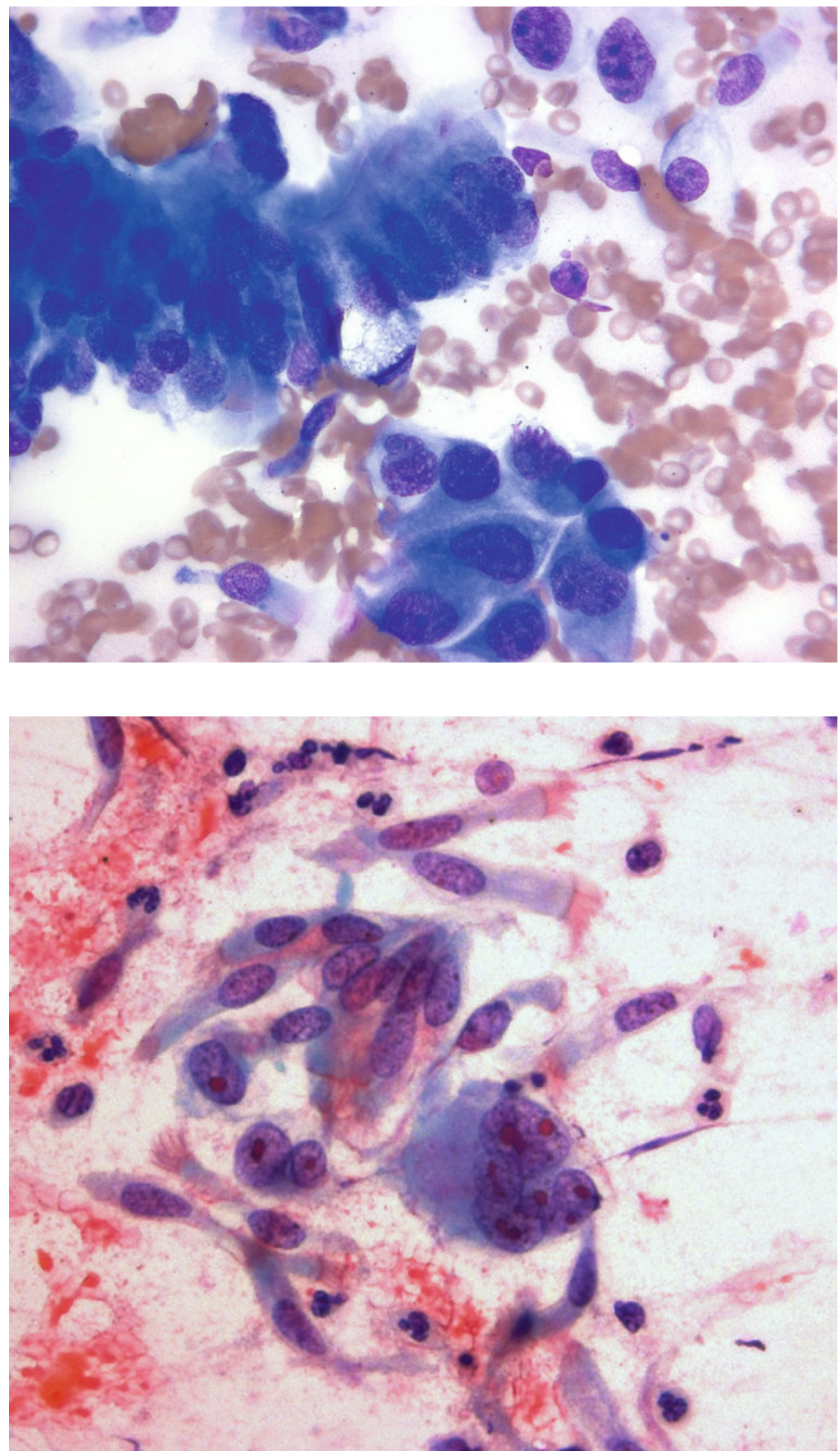
tumors with confidence without histological support. Usually one is able to confirm the presence of malignancy but not the type. Furthermore, one is often unsure whether the malignancy is primary or secondary on cytology alone.

\section{Sarcomas}

Sarcomas make up less than $0.5 \%$ of primary tumors in the lung, and metastatic sarcomas are probably more common. All types have been described including malignant fibrous histiocytoma, leiomyosarcoma, angiosarcoma, pulmonary intimal sarcoma, Kaposi sarcoma, synovial sarcoma, and others. These tumors are very rarely diagnosed in sputum. FNA may provide a better yield. Tumor cells are spindleshaped and often pleomorphic with fragile cytoplasm. Nuclei contain granular chromatin, small or large nucleoli. They can be mistaken for almost another type of pleomorphic tumor in the lung, and specific labeling will usually require a biopsy or resection specimen for diagnosis. Immunohistochemistry and molecular techniques may occasionally offer some utility in this situation.

\section{Metastases from Lung Cancers}

Squamous cell carcinomas commonly metastasize to other sites around the body. Occasionally these may be more accessible than the primary and therefore sampled. Presentation of malignant squamous cells in a pleural fluid sample is rare unless a bronchopleural fistula is present. Angulated atypical squamous cells with dense keratinized cytoplasm and very dark to black nuclei are present individually or in clusters. The cells may have a whorled configuration in fluids. Metastatic pulmonary squamous cell carcinoma within cervical or supraclavicular lymph nodes looks just like local head and neck tumor spread with necrosis and atypical cells with duck-egg blue cytoplasm. As a rule, squamous cell carcinoma metastases are similar to any other squamous cell carcinoma with dyskeratosis, welldefined cell borders, and central nuclei, although they may occasionally be pseudoglandular.

Adenocarcinomas produce a spectrum of morphology in fluids both architecturally and cytologically. They may be single or grouped, with eccentric nuclei, poorly defined cell borders and pale, clear, or vacuolated cytoplasm (for a more complete description and discussion see Chap. 4). Metastatic lung adenocarcinoma cells in cerebrospinal fluid may be difficult to appreciate.

Small cell carcinomas often disseminate widely and in serous effusions may arrange themselves into a concentric onionskin-type pattern or in single file. There may be budding with angles, and molding may not be obvious (also see
Chap. 4). In the CSF, the tumor cells are lymphocyte like. FNAs of involved lymph nodes do tend retain the classical neuroendocrine features described earlier for tumor aspirated form the lung or mediastinal lymph nodes by fine needle sampling.

\section{Metastases to the Lung}

As a rule, it will not be possible to offer a specific diagnosis of metastatic tumor in the lung, unless it is clear that the tumor cells have originated from a non-pulmonary type lesion, such as typical pigmented epithelioid and spindleshaped cells of a malignant melanoma. In most instances, the diagnosis will be inferred from the clinical information provided and radiological appearances. The cytologist might however get a clue and consider metastasis in particular when the background is very clean, or there is much necrotic debris with palisaded columnar cells of a colorectal metastasis, cells with clear or granular cytoplasm of a renal primary, or the single file arrangement of a lobular breast carcinoma. Of course, a clean background is also characteristic of bronchioloalveolar carcinoma, but metastases can sometimes mimic this tumor cytologically and histologically, especially pancreatic, ovarian, and prostatic adenocarcinoma. Cell blocks are extremely useful in this situation to allow additional stains and immunohistochemistry. Rarely mesothelioma presents in pulmonary cytology specimens with potential for misdiagnosis as adenocarcinoma - clinical, immunohistochemical, and radiological information can prevent avoidable errors. Typical features of mesothelial cells are described in Chap. 4.

\section{Uncommon Tumors}

A range of other tumors occur in the lung, and although it is feasible to make a specific diagnosis on cytology, it is generally more likely that cytology will either support or exclude a diagnosis suspected on clinical and radiological grounds, and often histology will be required to make a firm diagnosis. For example, benign papillomas of squamous or glandular type, or lesions of juvenile papillomatosis may be associated bland squamous or glandular cells in the cytology samples. As a rule though, it is very likely that a definitive diagnosis will rely on the results of a subsequent biopsy.

Some of the rarer tumors can be identified in bronchoscopic samples. These include granular cell tumor and mucoepidermoid carcinomas. Around 5-10\% of the former are found in the upper airways. Bland large cells with plentiful granular cytoplasm can be found in the washings or brushings. There may be a degree of pleomorphism which 
Fig. 3.60 Adenoid cystic carcinoma may be diagnosed on washings if the typical cribriform architecture and acellular globules are present

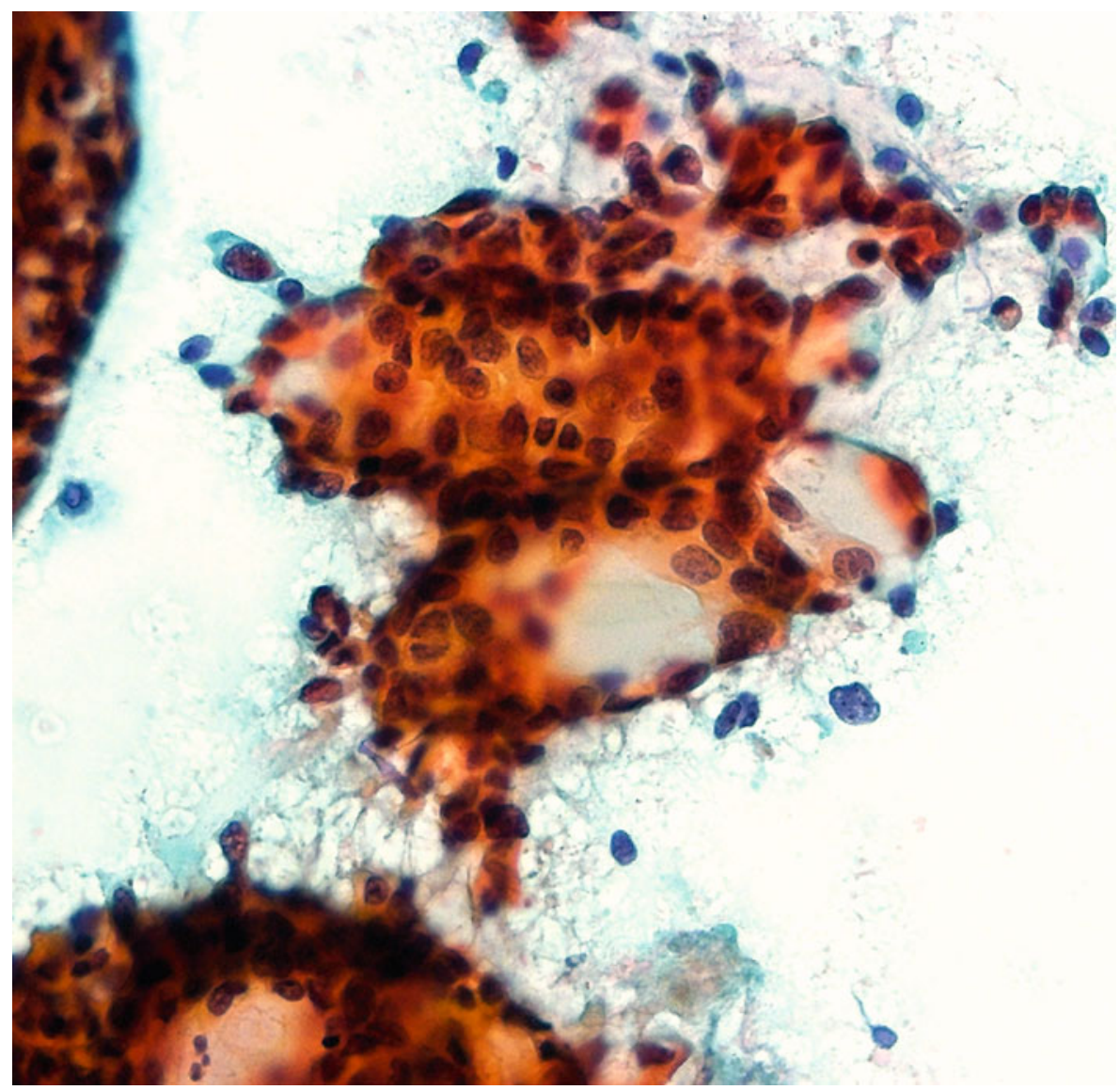

raises the possibility of a metastatic oncocytic tumor, but the diagnosis can be confirmed by positive immunohistochemistry for S100 and positivity for PAS.

Mucoepidermoid carcinoma can also be diagnosed with limited confidence on cytology. These tumors occur in the large airways and often present with obstruction by a polypoid growth. Cytologically, there is a mixture of variable glandular, squamous, and intermediate/transitional cells. They do not usually exfoliate, and so tumor cells are not usually identified in sputum. High-grade tumors will be indistinguishable from conventional lung carcinomas of squamous type, some adenocarcinomas, or even the cytologically identical adenosquamous carcinomas.

Adenoid cystic carcinomas tend to arise from the large airways and expand locally, often growing along the bronchial wall. The cytological appearance is identical to the more frequent tumors of the salivary gland. The tumor cells are small and dark with a high nuclear-to-cytoplasmic ratio. The histological architecture may be apparent in cytological specimens with a cribriform arrangement (sometimes cylindroma-like), trabeculae, solid islands, tubules, or acini, with the typical hyaline eosinophilic basement membrane material that is frequently spherical in outline with myxoid background stroma (Figs. 3.60, 3.61, 3.62, 3.63, and 3.64). The tumor cells may appear basaloid and show palisading peripherally. They usually show no cytological atypia, mitoses, or necrosis. Perineural invasion cannot be assessed. The tumor is said to be better appreciated in MGG than in Papanicolaou. The differential diagnosis is quite wide with small cell carcinoma and adenocarcinoma entering the frame. These tumors are more often metastases than primary especially when multiple and peripheral in location, so the results of clinical and radiological findings are crucial. Most of the tumors however cannot be diagnosed on bronchoscopic assessment and require fine needle aspiration for diagnosis.

Solitary fibrous tumor (SFT) can present in the lung or the pleura, although the latter is more frequent. It is composed of spindle cells set in a collagenous background that can show myxoid change. Therefore, the cytological appearance will be one of cells with bland elongated spindle-shaped nuclei with finely granular chromatin, inconspicuous nucleoli, and collagen or myxoid material in background. Many are benign, but some behave more aggressively with local invasion and rare metastases. These often show more sinister features on tissue and cytological sampling such as pleomorphism, mitoses, and necrosis. The differential diagnosis clearly includes other soft tissue tumors and malignant mesothelioma. Histology and immunohistochemistry are usually necessary to define the tumor confidently. CD34 is nearly always positive in SFTs. 
Fig. 3.61 The typical cylindroma like appearance of adenoid cystic carcinoma (washings)
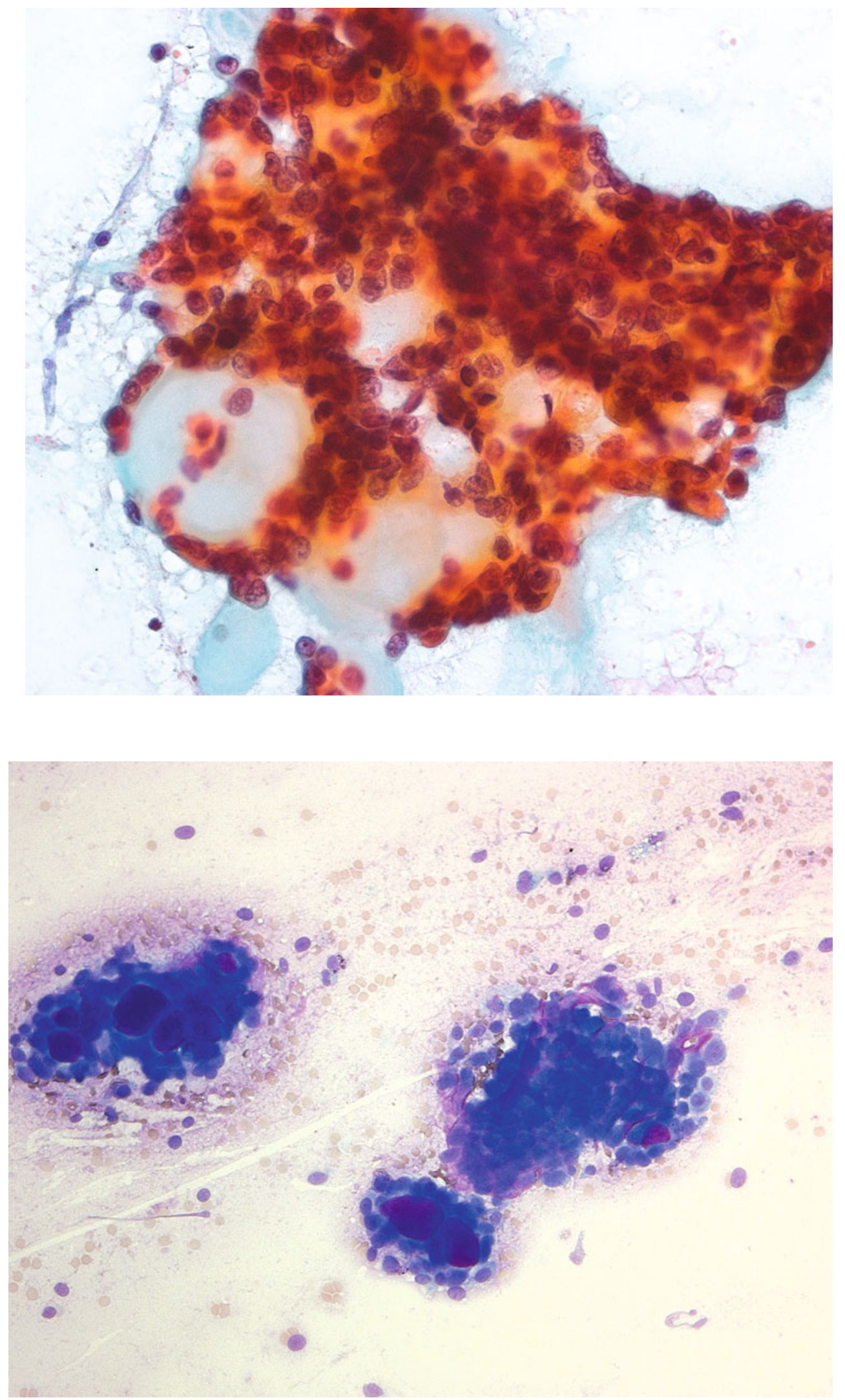

Fig. 3.62 Low power of adenoid cystic carcinoma (brush sample) 
Fig. 3.63 Adenoid cystic carcinoma with typical magenta globules (brush)
Fig. 3.64 Close inspection of this adenoid cystic carcinoma shows cellular atypia
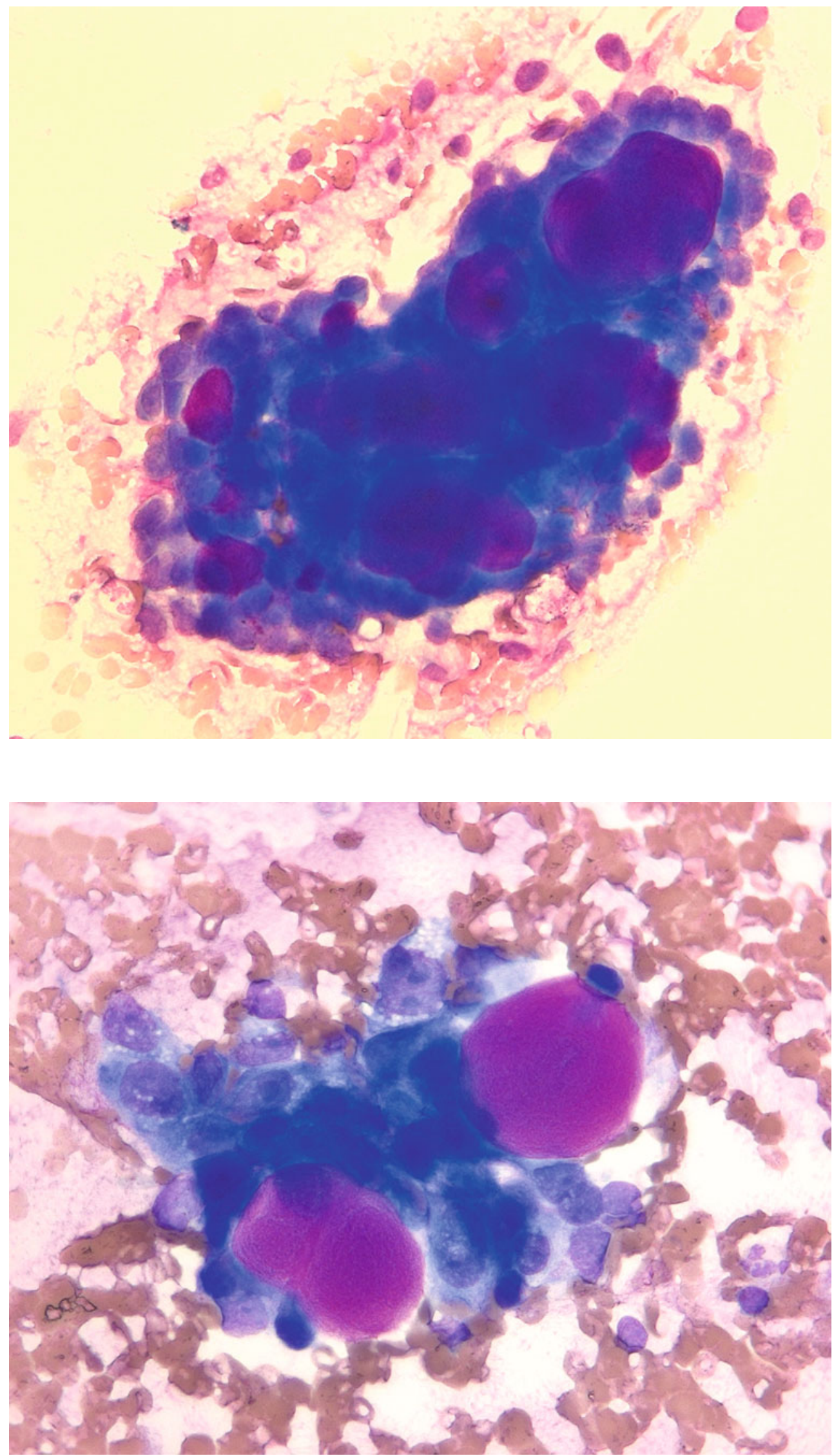
Primary benign clear cell tumors of the lung are rare. They belong to the PEComa group of tumors thought to arise from a specialized perivascular cell with contractile/chemoreceptor properties. They share positivity for HMB45 with the other tumors in this family, and therefore on FNA, immunohistochemistry may aid diagnosis. They used to be called sugar tumors because their cytoplasm is filled with glycogen and virtually no fat. Cytologically they present as large polygonal cells with round or oval nuclei and fine chromatin, but they may be spindled. The differential diagnosis is predictably with metastatic renal cell carcinoma or primary clear cell carcinoma of the lung. Immunohistochemistry can be valuable to distinguish between these conditions, utilizing HMB45, TTF1, and RCC.

Sclerosing hemangioma (also known as papillary pneumocytoma) is an uncommon lung tumor which is usually picked up as an incidental finding. In FNA samples, they manifest as bland epithelioid cells with clear or eosinophilic, sometimes granular cytoplasm. The nuclei have smooth contours surrounding granular, fine chromatin. There may be intranuclear inclusions which can cause confusion with bronchioloalveolar carcinomas.

So-called pulmonary hamartomas are now considered to be benign neoplasms that present as incidental peripheral lesions on radiological investigation of individuals in the sixth or seventh decade, men more often than women. With FNA, the tumor often appears biphasic with sheets of bland epithelial cells admixed with macrophages, in a background of myxoid fibrillary matrix and collagen. Cartilage may be apparent. They resemble benign mixed tumors of the salivary gland.

Oncocytomas are characterized by their plentiful granular eosinophilic cytoplasm due to the accumulation of numerous mitochondria. The nuclei are usually regular in outline and contain fine stippled chromatin. This description is similar to that for carcinoid tumors, paraganglioma, and granular cell tumors, and so it is not surprising that these are the main differential diagnoses.

Langerhans cell histiocytosis is a rare condition in young or middle-aged men, usually associated with smoking, which most frequently involves the lung as an isolated process. It can theoretically be diagnosed on BAL, although this is very uncommon. The lesional cells are round to polygonal histiocytic cells with long cytoplasmic processes and poorly defined borders. The nucleus is kidney shaped, but can be quite irregular, and typically has prominent grooves. Eosinophils may accompany the Langerhans cells. As a rule, the diagnosis requires clinical and radiological support and positive immunohistochemistry for S100, CD1a, CD11, CD14, and langerin. Electron microscopy shows the characteristic Birbeck granules.

Carcinoid tumors can be very difficult to differentiate cytologically (and histologically for that matter) from paraganglioma (chemodectoma). The diagnosis can be suspected on FNA or wash/brush samples when there are monomorphic round/oval or polygonal cells lying singly or in groups. Typical salt-and-pepper nuclear chromatin will be present without obvious nucleoli. Biopsy is usually required for confirmation, and even then diagnostic confidence may be limited.

\section{Lymphoproliferative Disorders}

Systemic lymphoproliferative diseases can involve the lung, and lymphomatous involvement of the lung may be obvious cytologically, but there are several conditions that can affect the lung primarily. These include reactive processes such as follicular bronchitis or bronchiolitis which may occur in patients with juvenile rheumatoid arthritis (RA), immunodeficiency, or chronic infections. Lymphocytic interstitial pneumonia (LIP) is associated with autoimmune disorders, drugs, Sjogren's syndrome, immunodeficiency, and HIV. A limited range of primary lymphomas occur including angioimmunoblastic lymphoma, marginal zone lymphoma (so-called BALTomas), large cell angiocentric lymphoma (lymphomatoid granulomatosis), and posttransplant lymphoproliferative disease (PTLD). Rarely Hodgkin's disease, myeloma, mycosis fungoides, and primary effusion-related lymphoma can be found in the lung and/or pleura. The lymphoid cells often present as a population of cells in streaks on the slide with the relevant morphology (Fig. 3.65). These streaks may mimic small cell carcinoma, but there is generally no engulfment or apoptosis, typical of the latter. High-grade tumors may be suspected from the morphological appearance, but the distinction between reactive conditions and low-grade tumors will require biopsy for confirmation. Immunocytochemistry and flow cytometry may help. There are clearly limitations in the diagnosis of lymphoproliferative disease based on cytology samples, but it may be possible at times to suspect the diagnosis on sputum, brushings, washings, BAL, or FNA samples, at least to encourage the correct subsequent management.

\section{Molecular Analyses}

In this current age of personalized or targeted treatment of various cancers, especially lung cancer, several molecular tests are now regularly used on pathological tissue. These include epidermal growth factor receptor mutational analysis on non-squamous non-small cell cancers, EML4-ALK assessment of adenocarcinoma and other trial molecules such as ERCC1 testing in non-small cell carcinomas. In general, the techniques will benefit from a sizeable sample 
Fig. 3.65 Hodgkin's disease may be suspected in this bronchial wash specimen

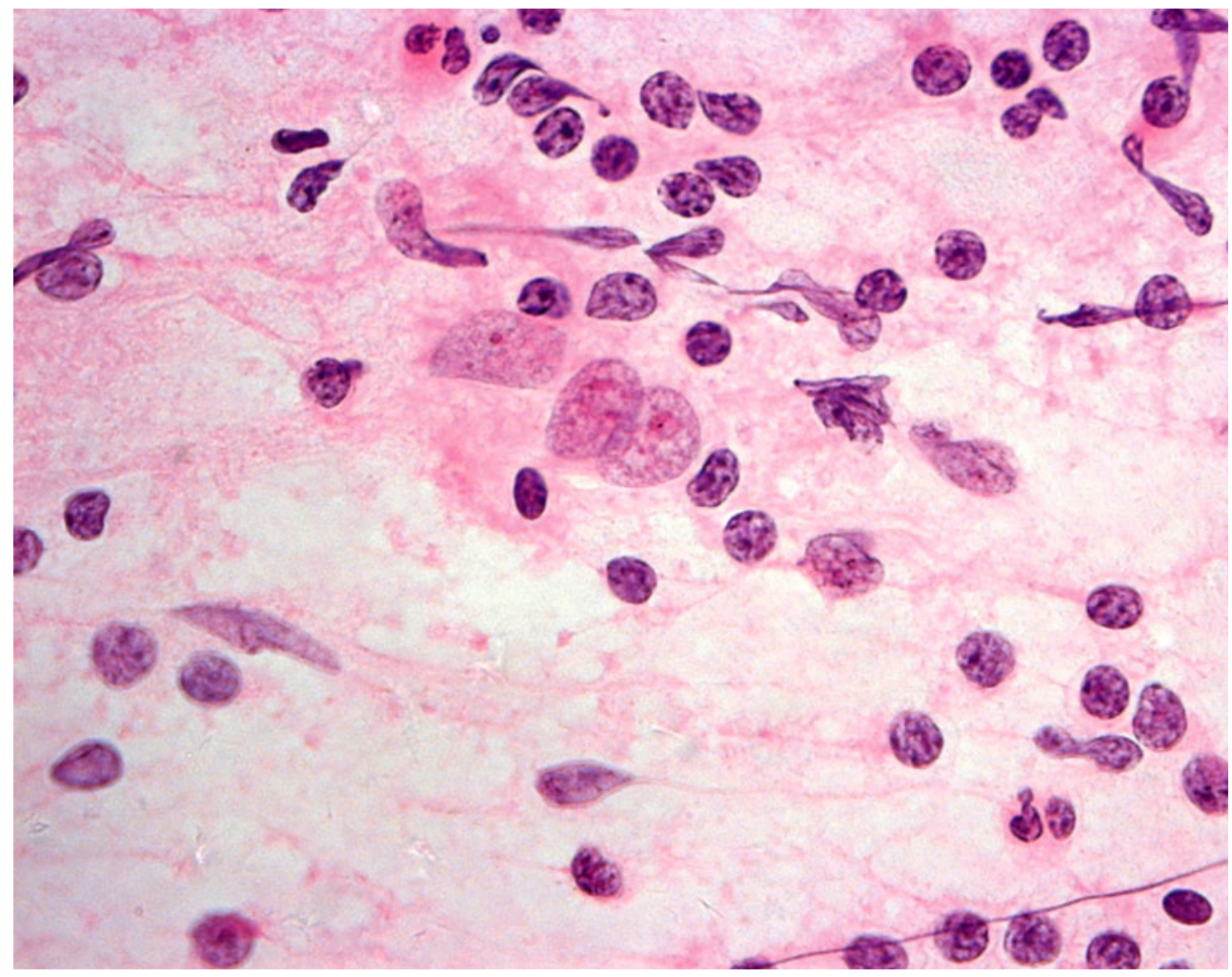

which usually means utilizing tissue from a biopsy. However, with some cytology samples, most notably EBUS material, there may be enough for satisfactory analysis.

\section{Mediastinal Lesions}

A variety of congenital, inflammatory, and neoplastic lesions can arise within the mediastinum or spread to the mediastinum. Diagnostic clues come from the age of the patient and location of the abnormality (Table 3.3). Aspiration may be considered and often provides useful information without the need for more intrusive surgical sampling prior to definitive surgery, or it may avoid the need for surgery altogether. Once again, clinical and radiological correlation is crucial for correct diagnosis.

\section{Thymoma}

This can be a tricky cytological diagnosis because spindleshaped and/or epithelial and lymphoid cells are all likely to be present, and differentiation from sarcoma, carcinoma, and lymphoma is problematic. Thymomas are an interesting group of tumors that often present with associated autoimmune diseases and behave in an unusual and not entirely predictable manner. There have been several classifications over the years with the WHO system currently accepted by many
Table 3.3 Site of mediastinal lesions may aid diagnosis

\begin{tabular}{|c|c|c|}
\hline $\begin{array}{l}\text { Anterior/superior } \\
\text { mediastinum }\end{array}$ & Central mediastinum & Posterior mediastinum \\
\hline Tuberculosis & Pericardial cyst & $\begin{array}{l}\text { Nerve sheath tumors } \\
\text { - benign and malignant }\end{array}$ \\
\hline Sarcoidosis & Bronchial cyst & Paraganglioma \\
\hline Lymphoma & Lymphoma & Neuroblastoma \\
\hline \multirow{2}{*}{$\begin{array}{l}\text { Thymoma/thymic } \\
\text { carcinoma }\end{array}$} & & Ganglioneuroma \\
\hline & & Ganglioneuroblastoma \\
\hline Thymic cyst & & Gastroenteric cyst \\
\hline \multicolumn{3}{|l|}{$\begin{array}{l}\text { Metastatic tumors } \\
\text { especially } \\
\text { carcinomas }\end{array}$} \\
\hline \multicolumn{3}{|l|}{ Germ cell tumors } \\
\hline \multicolumn{3}{|l|}{ Hemangioma } \\
\hline \multicolumn{3}{|l|}{ Lipoma } \\
\hline \multicolumn{3}{|l|}{ Thyroid lesions } \\
\hline Parathyroid lesions & & \\
\hline
\end{tabular}

(WHO classification of lung and thymic tumors). This distinguishes between type $\mathrm{A}, \mathrm{AB}, \mathrm{B}$, and $\mathrm{C}$ thymomas with $\mathrm{B}$ separated into 1,2 , and 3 and $C$ representing thymic carcinoma. This classification offers some indication as to the likely biological behavior and therefore appropriate management. It should be remembered that all thymomas are potentially lethal tumors, and many believe they should be classified in a similar manner to neuroendocrine tumors with type A tumors analogous to carcinoid tumors representing the 
Fig. 3.66 Mediastinal mass aspirate. This is clearly a carcinoma, but it may be a primary thymic carcinoma or metastatic carcinoma

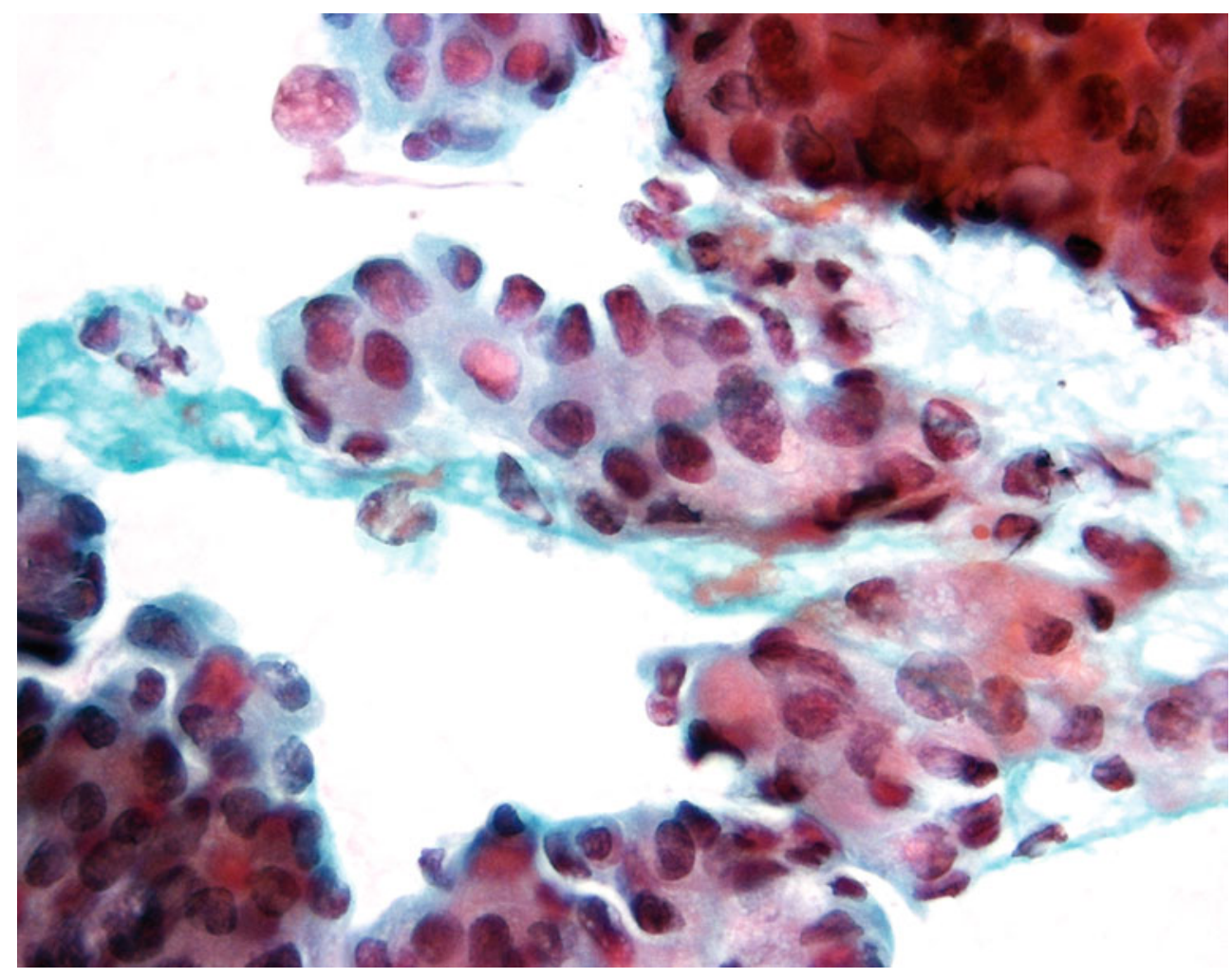

well-differentiated end of the spectrum and type $\mathrm{C}$ thymomas representing high-grade carcinomas. Some have suggested that those tumors with "medullary" epithelial cell predominance behave in an indolent manner and those with a predominance of cortical epithelial cells are more likely to invade and metastasize. Staging is generally more useful for prognostication and is based on the Masaoka system although a TNM system is currently being piloted. These are based partly on histology but principally on surgical findings and radiology as it relies on the presence or absence of capsular invasion, local structure invasion, and metastases.

Although these are rare tumors, small case series suggest that diagnostic accuracy and differentiation from other mediastinal tumors is reasonably robust on FNA samples. It is proposed that FNA is underutilized in this area of diagnostic pathology. Bland spindle-shaped epithelial cells admixed with variable numbers of lymphocytes form the benign end of the spectrum. Thymic carcinomas show more obvious malignant cytological features and may show squamous differentiation. However, the more atypical the aspirated cells, the more difficult it is to appreciate the diagnosis specifically.

Aspirates from thymomas are composed of regular epithelial cells with bland nuclei and pale cytoplasm. There are often admixed small lymphocytes. Mixed and cortical tumors show more obvious nuclear atypia with nuclear enlargement with vesicular chromatin and prominent nucleoli. There may be some difficulty in distinguishing medullary tumors from other spindle cell lesions and cortical tumors from other epithelial neoplasms, especially metastatic carcinomas (Fig. 3.66). Differentiation may be aided by the use of cell blocks although there is no substitute for clinical and radiological input. Occasionally thymoma metastasizes or presents in unusual locations such as the pleura, and it is quite unreasonable for the diagnosis to be made confidently in these situations without advising the pathologist of the possibility.

Lymphomas may be reasonably diagnosed on FNA material, and as with most cytological samples of lymphoma, one can have a good idea about the diagnosis (Figs. 3.67, 3.68, and 3.69), but unless ancillary techniques are used, there is usually a need for a biopsy for tissue diagnosis and classification prior to treatment.

Neuroendocrine and stromal tumors of the thymus such as lipomas may be suspected by the cytological appearance, but histology will generally be required.

Germ cell tumors are less common in the mediastinum than the testis or ovary, but they can be recognized on FNA. These will have the same features as the tumors involving the gonads with teratomas identified by cohesive sheets of squamous epithelial cells and embryonal carcinomas associated with undifferentiated epithelial cells or stromal elements. Seminomas are composed of dissociated nuclei with irregular multiple nucleoli. Yolk sac tumors may show the usual clear cells and possibly even Schiller-Duval bodies. The team will usually need clinical corroboration with serum markers and also immunocytochemistry to nail the diagnosis. 
Fig.3.67 Mixed lymphoid cells, larger binucleate forms, and eosinophils raise the suspicion of Hodgkin's disease (FNA mediastinum MGG)

Fig. 3.68 Mononuclear Hodgkin's cells in an aspirate from a mediastinal mass
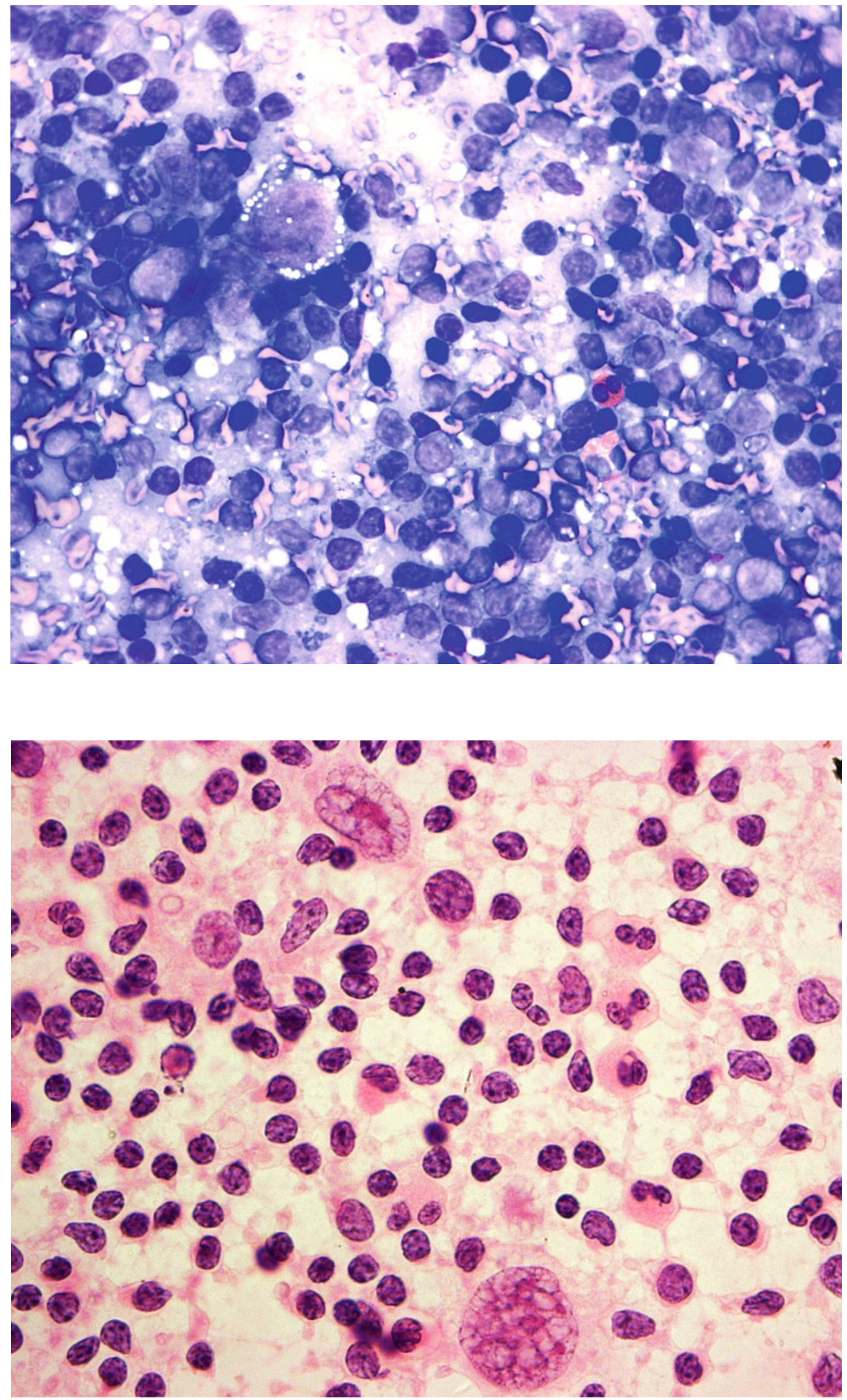
Fig. 3.69 Another case of Hodgkin's disease (mediastinal aspirate)

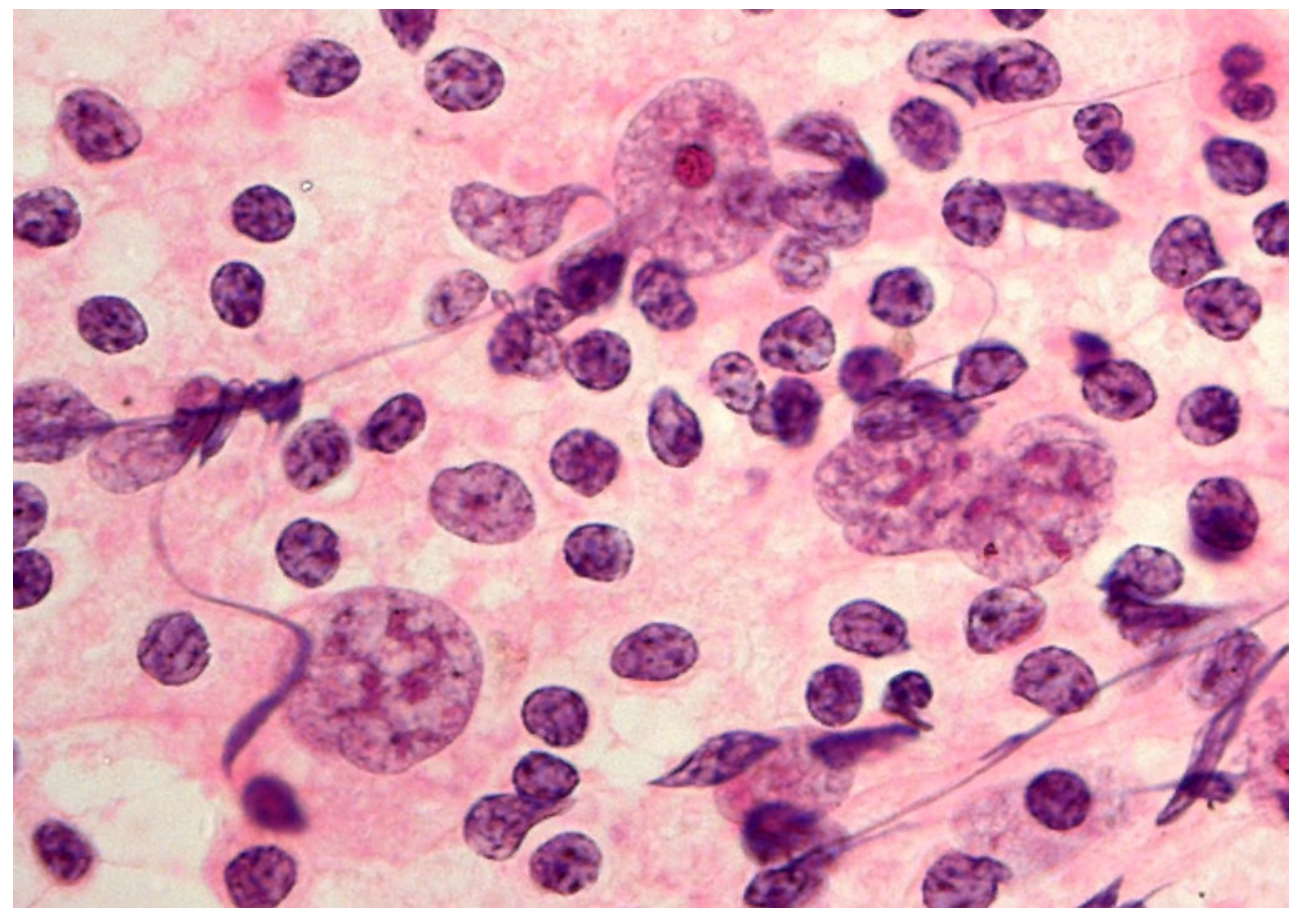

Tumors with more obvious pleomorphism may be confused with metastatic or thymic carcinoma.

Neurogenic and nerve sheath tumors typically arise in the posterior mediastinum. These are composed of oval or wavy nuclei within spindle-shaped cells. Ganglion cells may be present, recognized by their large size, eccentric nucleus, and prominent nucleolus. Neuroblastomas are likely to include significant numbers of small dark cells, devoid of cytoplasm, and the usual differential diagnosis needs to be considered with the appropriate range of antibodies.

Soft tissue tumors of all kinds may arise in the mediastinum on occasion. They are described fully in Chap. 12 and will not be repeated here.

Of course, not all masses in the mediastinum are neoplastic, and tuberculosis and sarcoid often produce radiological abnormalities in this area. The typical features of granulomatous inflammation may be recognized, with or without associated necrosis. Special stains may help as will microbiological investigation.

\section{Useful Resources and Suggested Reading}

American thoracic society (ATS) website - www.thoracic.org. ATS guidelines on the pretreatment evaluation of non-small cell lung cancer (with the European Respiratory Society). Am J Respir Crit Care Med. 1997;156:320-32.

European Respiratory Society website - www.ersnet.org (this provides many guidelines for the investigation of thoracic disease).

Kini S. Color atlas of pulmonary cytopathology. New York: Springer Verlag; 2002.

NICE guidelines for management of lung cancer reference CG121 www.nice.org.uk.

The British Thoracic Society bronchoscopy guideline committee: a sub-Committee of the Standards of Care Committee of the British Thoracic Society. Thorax. 2001;56(Suppl I):i1-21.

The BSCC codes of practice - exfoliative cytopathology (excluding gynaecological cytopathology) and fine needle aspiration cytology. Cytopathology. 2009;20:211-23 and 283-96.

Tissue pathways for exfoliative and fine needle aspiration cytology; www.rcpath.org.

Travis WD, Brambilla E, Muller-Hermelink HK, Harris CC, editors. Pathology and genetics of tumours of the lung, pleura, thymus and heart. Lyon: IARC Press; 2004.

www.clinicalcytology.co.uk/resources/fna.aspuidelines. 